\title{
Cytosolic Diffusion and Peptide-assisted Nuclear Shuttling of Peptide-substituted circa 102 Gold Atom Nanoclusters in Living Cells
}

Dominique Desplancq,' Nadja Groysbeck,' Manuela Chiper,' Etienne Weiss,' Benoit Frisch,'

Jean-Marc Strub, ${ }^{3}$ Sarah Cianferani, ${ }^{3}$ Spyridon Zafeiratos, ${ }^{4}$ Eric Moeglin, ${ }^{\prime}$ Xavier Holy, ${ }^{\circ}$ Anne Laure Favier, ${ }^{6}$ Sacha De Carlo,? Patrick Schultz,,5anièle Spehner, ${ }^{, 5}$ Guy Zuber ${ }^{\prime *}$

1. Université de Strasbourg - CNRS, UMR 7242, Boulevard Sebastien Brant, F-67400 Illkirch, France

2. Université de Strasbourg - CNRS, UMR 7199, Faculté de Pharmacie, F-67400 Illkirch, France 3. Laboratoire de Spectrométrie de Masse BioOrganique, Université de Strasbourg, CNRS, IPHC UMR 7178, F-67000 Strasbourg, France

4. Institut de chimie et procédés pour l'énergie, l'environnement et la santé (ICPEES), ECPM,

UMR 7515 CNRS - Université de Strasbourg, 25 rue Becquerel, F-67087 Strasbourg Cedex, France

5. Centre for Integrative Biology (CBI), Department of Integrated Structural Biology, Institut de Génétique et de Biologie Moléculaire et Cellulaire (IGBMC), 1 rue Laurent Fries, BP10142, F67404 Illkirch Cedex, France

6. Institut de Recherche Biomédicale des Armées (IRBA), 1 Place Valérie André, BP 73, F91223 BrétignysurOrge, France

7. Thermo Fisher Scientific, Achtseweg Noord 5, 5651 GG Eindhoven, the Netherlands.

KEYWORDS: gold particle, electron microscopy, bioconjugate, intracellular delivery, Nuclear Localization Signal, Nuclear Export Signal. 
To cite : Desplancq, D.; Groysbeck, N.; Chiper, M.; Weiss, E.; Frisch, B.; Strub, J.-M.; Cianferani, S.; Zafeiratos, S.;

Moeglin, E.; Holy, X.; et al. Cytosolic Diffusion and Peptide-Assisted Nuclear Shuttling of Peptide-Substituted Circa 102 Gold Atom Nanoclusters in Living Cells. ACS Applied Nano Materials 2018, 1, 4236-4246. Doi :

10.1021/acsanm.8b00988

Abstract. For biological and medical application, a definable nanomaterial and knowledge on its fate after administration are highly recommended if not mandatory. Here, we synthesized a water-soluble gold nanocluster by sodium borohydride reduction of chloroauric acid in presence of 5,5'-dithio-bis(2-nitrobenzoic acid). The resulting gold nanocluster displayed the physical characteristics of a cluster containing an inner core of about 100 gold atoms that was surrounded by an organic monolayer made of about 30 thioaminobenzoic acids (TAB) and 14 anionic thionitrobenzoic acids (TNB). The mixed TAB-,TNB-protected gold nanocluster reacted well in water with thiolated peptides containing a Nuclear Localization Signal (NLS) or a Nuclear Export Signal (NES) mainly by exchange of the TNB, providing gold nanoclusters equipped with 8-9 intracellular active peptides and a remaining ligand coverage consisting mostly of the zwitterion TAB. The behavior of these peptide-gold nanoclusters inside the cytosol and nucleus of cells was then assayed using an electroporation procedure allowing transient plasma membrane permeability. Light and electron microscopy observations demonstrated a consistent inflow and diffusion of the gold nanoclusters into the cytosol. Inside the living cells, the distribution of the gold nanoparticles was specifically driven by the appended signal peptides in a manner similar to the distribution of NLS and NES-bearing proteins, demonstrating diffusion ability, stability and usage of these definable ligand-substituted gold nanoclusters for intracellular applications. 
To cite : Desplancq, D.; Groysbeck, N.; Chiper, M.; Weiss, E.; Frisch, B.; Strub, J.-M.; Cianferani, S.; Zafeiratos, S.;

Moeglin, E.; Holy, X.; et al. Cytosolic Diffusion and Peptide-Assisted Nuclear Shuttling of Peptide-Substituted Circa 102 Gold Atom Nanoclusters in Living Cells. ACS Applied Nano Materials 2018, 1, 4236-4246. Doi :

10.1021/acsanm.8b00988

Gold nanoclusters are attracting materials for biological applications because they can be tailored for photoluminescence, for protein inhibition ${ }^{2}$ glutathione detection ${ }^{3}$ or even sensitizing cancer cells to external radiation sources. ${ }^{46}$ The anionic mercaptobenzoic acid (MBA) has been used for producing water-soluble thiolate monolayer protected nanoclusters (AuNCs) of small sizes and even "magic" clusters with precise formula and structures.-9 The gold cluster stabilized by an MBA-monolayer (AuMBA) could furthermore be conjugated to biological molecules, either by modifying the organic shell ${ }^{10-12}$ or by exchange/substitution of the gold-conjugated mercaptobenzoate with an incoming thiolated macromolecule. ${ }^{13}$ Bioconjugates derived from AuMBA have already proven useful for structural analysis of supramolecular assemblies in aqueous solution using cryo-Electron Microscopy (EM) techniques..$^{10-12}$ They hold promise as a biomolecule-anchoring platform or as an imaging probe within living cells ${ }^{14}$ because the small and defined size of AuMBA should facilitate material characterization and diffusion in dense tissues $^{15}$ and inside cells. ${ }^{16}$ To fulfill these intracellular application promises, passage across the plasma membrane and knowledge on the chemical and physical behavior of any nanomaterial inside the cytosol or nucleus are major challenging issues that still need to be resolved. First, the nanomaterial needs to be delivered into the cytosol, across the cell plasma membrane without impacting cell viability. ${ }^{17,18}$ In the majority of cases, the exogenous nanomaterial is tailored to bind to the cell surface for entrapment inside intracellular vesicles. When it contains as well elements able to lyse membranes, some leakage into the cytosol may occur but at an extremely poor efficiency. ${ }^{1922}$ Second, the chemical and physical behavior of the nanomaterial inside the cell should be compatible with the desired objectives. For performing these investigations, large entrapment of materials within intracellular vesicles severely hampers interpretation and data analysis. Use of an effective delivery method, which bypasses vesicular entrapment for action, should hence bring a substantial benefit in term of data analyses. 
To cite : Desplancq, D.; Groysbeck, N.; Chiper, M.; Weiss, E.; Frisch, B.; Strub, J.-M.; Cianferani, S.; Zafeiratos, S.;

Moeglin, E.; Holy, X.; et al. Cytosolic Diffusion and Peptide-Assisted Nuclear Shuttling of Peptide-Substituted Circa 102 Gold Atom Nanoclusters in Living Cells. ACS Applied Nano Materials 2018, 1, 4236-4246. Doi :

10.1021/acsanm.8b00988

Regarding the thiolate monolayer protected AuNCs, the intra-cytosol and intra-nucleus stability of the Au-S bond remains to be clarified. The Au-S bond has not been reported to be enzymatically cleaved but the cytosol contains thiols and particularly reduced glutathione (GSH) in a $\mathrm{mM}$ concentration range. ${ }^{23}$ Since AuNCs can easily exchange thiolate ligands in solution, ${ }^{8,2}$ it is hence conceivable that the AuNC coupled thiolated ligand (i.e. the attached functional molecule) can suffer exchange with GSH inside living cells. Unstable Au-S bonds were observed for particles that were tailored to get majorly trapped in the intracellular lysosomal vesicles..$^{3 ., 2425}$ However, to our knowledge, no data were reported to clearly demonstrate whether the Au-S bond of thiolate-protected AuNCs inside the cytosol or inside the cell nucleus breaks up or remains steady.

In this report, we develop a novel gold nanocluster allowing synthesis of definable peptide AuNC conjugates and then use an electroporation procedure to investigate the fate and behavior of bioactive peptide-AuNC conjugates inside living cells. First, we synthesized and characterized a new gold nanocluster (AuZ) in which the shell was mostly made of a zwitterionic thioaminobenzoic acid (TAB) because this ligand could stabilize the Au-S bond via a electrondonating substitution, ${ }^{26}$ and because neutrally charged molecules can shield against unspecific interactions..$^{2728}$ Second, to probe the ability of peptide-grafted AuNCs to diffuse within the cell and the stability of the Au-S bond inside the cell, we selected peptide domains that selectively assist nuclear import or export of macromolecules through the nuclear pores. The AuZ was reacted with thiolated peptides containing the SV40 Nuclear Localization Signal (NLS), a mutated NLS defective for nuclear shuttling, or the Nuclear Export Signal (NES) of the protein kinase A inhibitor. The intracellular distribution of these peptide-grafted AuNCs was investigated after electroporation-mediated delivery. Light Microscopy and Transmission Electron Microscopy (TEM) imaging showed that the subcellular localization of the gold particles was specifically driven by the bioactive peptide's coverage, demonstrating that these gold particles can diffuse into the cytosol following electroporation to reach a concentration of 
To cite : Desplancq, D.; Groysbeck, N.; Chiper, M.; Weiss, E.; Frisch, B.; Strub, J.-M.; Cianferani, S.; Zafeiratos, S.;

Moeglin, E.; Holy, X.; et al. Cytosolic Diffusion and Peptide-Assisted Nuclear Shuttling of Peptide-Substituted Circa

102 Gold Atom Nanoclusters in Living Cells. ACS Applied Nano Materials 2018, 1, 4236-4246. Doi :

10.1021/acsanm.8b00988

more than 4,000 molecules/cell and that the thiolated peptides remain stably coordinated to AuNCs for at least $24 \mathrm{~h}$ in living HeLa cells.

\section{Results}

To obtain gold nanoclusters with zwitterionic ligands at a $\mathrm{pH}$ found inside cells, we tried a direct $\mathrm{NaBH}_{4}$ reduction of $\mathrm{HAuCl}_{4}$ in presence of 2,2'-dinitro-5,5'-dithiobenzoic acid (the Ellman's reagent DTNB $^{29}$ ) (Figure 1A), hoping that the anionic thionitrobenzoic acid (TNB) would be reduced to the zwitterionic TAB during the synthesis.$^{30}$ The protocol described by LeviKalisman and colleagues ${ }^{31}$ was slightly modified and cleanly led to a gold nanocluster (named $\mathrm{AuZ}$ ) with a narrow mobility when analyzed by polyacrylamide gel electrophoresis (Figure 1B, inset image). The UV/visible absorbance of a 2.6 $\mu \mathrm{M}$ AuZ solution in 0.1 M HEPES, pH 7.4 gradually decreased with an increase in wavelength (Figure 1B). The spectrum did not contain any absorption band at $409 \mathrm{~nm}$ characteristic of TNB and did not contain a surface plasmon resonance band at wavelengths above $520 \mathrm{~nm}$. This UV/vis spectrum indicated formation of gold nanoclusters containing less than 140 gold atoms because $\mathrm{Au}_{14} \mathrm{MBA}_{60}$ and $\mathrm{AuNCs}$ of higher molecular masses possess a surface plasmon resonance band at $510-530 \mathrm{~nm} .{ }^{2,32}$ A routine $\mathrm{H}$ Nuclear Magnetic Resonance (NMR) spectrum of the $\mathrm{AuZ}$ in $\mathrm{D}_{2} \mathrm{O}$ was apparently featureless (Figure 1C). The aromatic peaks of the thiobenzoic acids, normally between 6-8 ppm, were too broad to be visible. The broadening of the signal was attributed to intimate ligand immobilization on the gold particle's surface that decreases the motion and the spin relaxation time of the analyzed atoms. It might also arise from the fact that Au-coordinated ligands have different chemical environment and hence different NMR signals..$^{33.34}$ 
To cite : Desplancq, D.; Groysbeck, N.; Chiper, M.; Weiss, E.; Frisch, B.; Strub, J.-M.; Cianferani, S.; Zafeiratos, S.; Moeglin, E.; Holy, X.; et al. Cytosolic Diffusion and Peptide-Assisted Nuclear Shuttling of Peptide-Substituted Circa 102 Gold Atom Nanoclusters in Living Cells. ACS Applied Nano Materials 2018, 1, 4236-4246. Doi :

10.1021/acsanm.8b00988

A. Synthesis of gold cluster

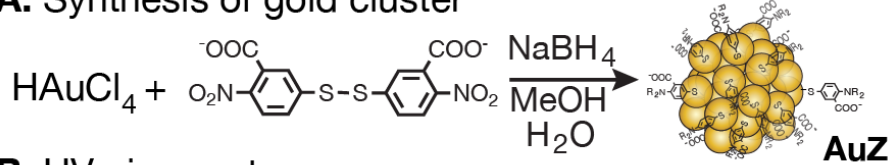

B. UV-vis spectrum

AuZ

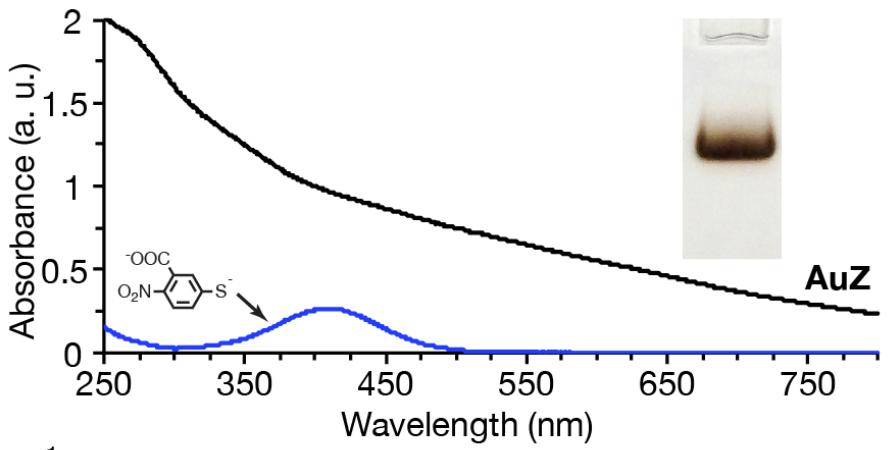

C. ${ }^{1} \mathrm{H}$ NMR spectrum

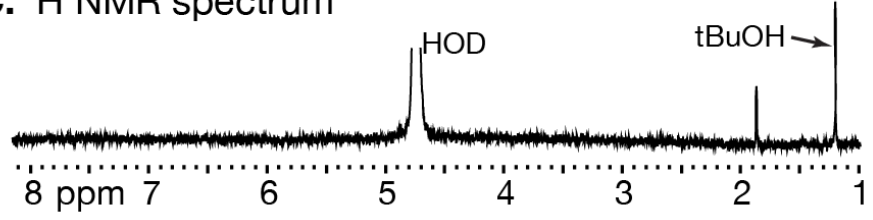

D. Cryo-EM
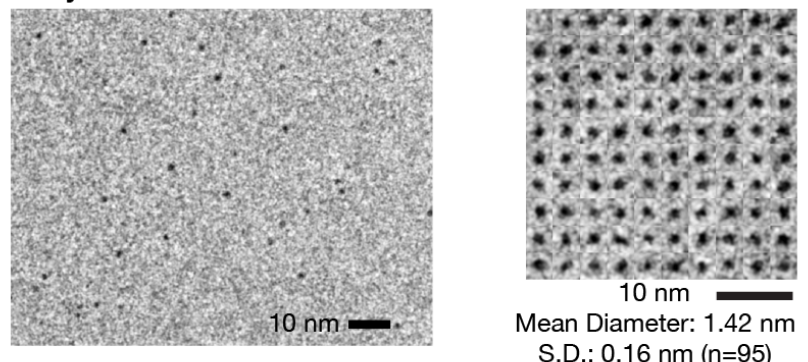

E. Mass spectrum

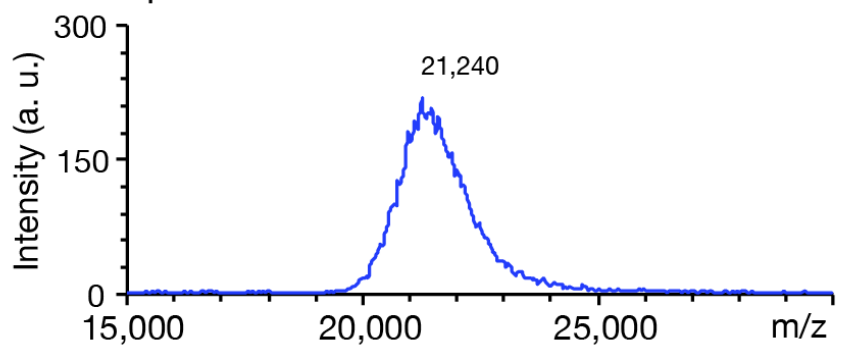

Figure 1. Synthesis and analysis of the AuZ nanoclusters. A. Synthesis protocol. B. UV-vis spectrum of the gold nanocluster AuZ $(2.6 \mu \mathrm{M}$, black line) or thionitrobenzoic acid $(18 \mu \mathrm{M}$, blue line $)$ in $0.1 \mathrm{M}$ HEPES-Na, $\mathrm{pH}$ 7.4. The inset image is a polyacrylamide gel electrophoresis analysis of the AuZ. C. 'H NMR spectrum of $55 \mu \mathrm{M}$ AuZ in $\mathrm{D}_{2} \mathrm{O}$. The large peak at 4.7 is the signal of the $\mathrm{D}_{2} \mathrm{O}$ and was trimmed. Tertio-butanol (100 $\mu \mathrm{M}$ final concentration) was used as an internal standard. D. Cryo-electron microscopy images of AuNCs in a frozen non-crystalline aqueous solution (96 $000 \mathrm{x})$. The right panel shows a gallery of 99 particles that were cropped from the left image. Statistical analysis on 95 particles gave a mean diameter of $1.42 \mathrm{~nm}$ and a standard deviation of $0.16 \mathrm{~nm}$. E. MALDI-TOF mass spectrum of the gold cluster. 
To cite : Desplancq, D.; Groysbeck, N.; Chiper, M.; Weiss, E.; Frisch, B.; Strub, J.-M.; Cianferani, S.; Zafeiratos, S.; Moeglin, E.; Holy, X.; et al. Cytosolic Diffusion and Peptide-Assisted Nuclear Shuttling of Peptide-Substituted Circa 102 Gold Atom Nanoclusters in Living Cells. ACS Applied Nano Materials 2018, 1, 4236-4246. Doi :

10.1021/acsanm.8b00988

To analyze if the AuZ was fully dispersed in water, an AuZ solution was frozen for cryo-EM observation. Images showed mostly a population of individual particles of uniform spherical shape and size (Figure 1D).35 Assuming a spherical morphology for all particles, statistical analysis on 95 particles gave a mean diameter of $1.42 \mathrm{~nm}$ with a standard deviation (S.D.) of $0.16 \mathrm{~nm}$. This diameter corresponds to a metallic cluster of 88 gold atoms using the volumetric mass density of $\mathrm{Au}\left(19.3 \mathrm{~g} . \mathrm{cm}^{3}\right)$. The real diameter of the particle is likely slightly above this mean value because of the applied defocus and delocalized scattering electrons. The MALDITOF mass spectrum (MS) of AuZ displayed a population of molecular masses centered at 21,240 $\mathrm{Da}$ (Figure 1E). This pattern was strikingly similar to the one published for $\mathrm{Au}_{102} \mathrm{MBA}_{44}$ (calculated molecular mass of $26.83 \mathrm{kDa}$ ) where a broad distribution of masses centered at 21 $\mathrm{kDa}$ was obtained, suggesting that the laser-induced desorption and ionization condition promoted in both cases similar sample degradation. ${ }^{31}$

The AuZ was next analyzed by X-ray Photoelectron Spectroscopy (XPS) (Figure 2A). The XPS survey spectrum showed the characteristic peaks of $\mathrm{Au} 4 \mathrm{f}, \mathrm{Si} 2 \mathrm{~s}, \mathrm{~S} 2 \mathrm{p}, \mathrm{C}$ 1s, N 1s and O 1s. The Si 2s peak (around $150 \mathrm{eV}$ ) originates from the Si wafer substrate and no other elements are detected. High-resolution analysis of $S 2 p$, and $C$ 1s peaks confirmed that all the aromatic thiolates were fully coordinated to the gold surface (Supporting Information, Figure S1). The N 1s region (inset of Figure 2A) reveals three distinct nitrogen species with peaks at $399.1 \mathrm{eV}, 401$ $\mathrm{eV}$ and $405.9 \mathrm{eV}$. The peaks at 399.1 and $401 \mathrm{eV}$ can be assigned to an aromatic amine (the $\mathrm{TAB}$ ) and an ammonium (likely residual ammonium counterions), respectively. ${ }^{36}$ The $\mathrm{N} 1 \mathrm{~s}$ peak at $405.8 \mathrm{eV}$ was ascribed to $\mathrm{NO}_{2}$-groups ${ }^{37}$ and originated from the TNB. Integration of the $\mathrm{N} 1 \mathrm{~s}$ peaks led to a TAB/TNB ratio of 2.12 , suggesting that $68 \%$ of the nitro groups were reduced to amines during the nanocluster synthesis. The $\mathrm{Au} 4 \mathrm{f}_{7 / 2}$ photoelectron peak of the AuZ was shifted by $0.46 \mathrm{eV}$ to higher binding energies relative to the polycrystalline $\mathrm{Au}(0)$ (Figure $2 \mathrm{~B})$. 
To cite : Desplancq, D.; Groysbeck, N.; Chiper, M.; Weiss, E.; Frisch, B.; Strub, J.-M.; Cianferani, S.; Zafeiratos, S.; Moeglin, E.; Holy, X.; et al. Cytosolic Diffusion and Peptide-Assisted Nuclear Shuttling of Peptide-Substituted Circa 102 Gold Atom Nanoclusters in Living Cells. ACS Applied Nano Materials 2018, 1, 4236-4246. Doi :
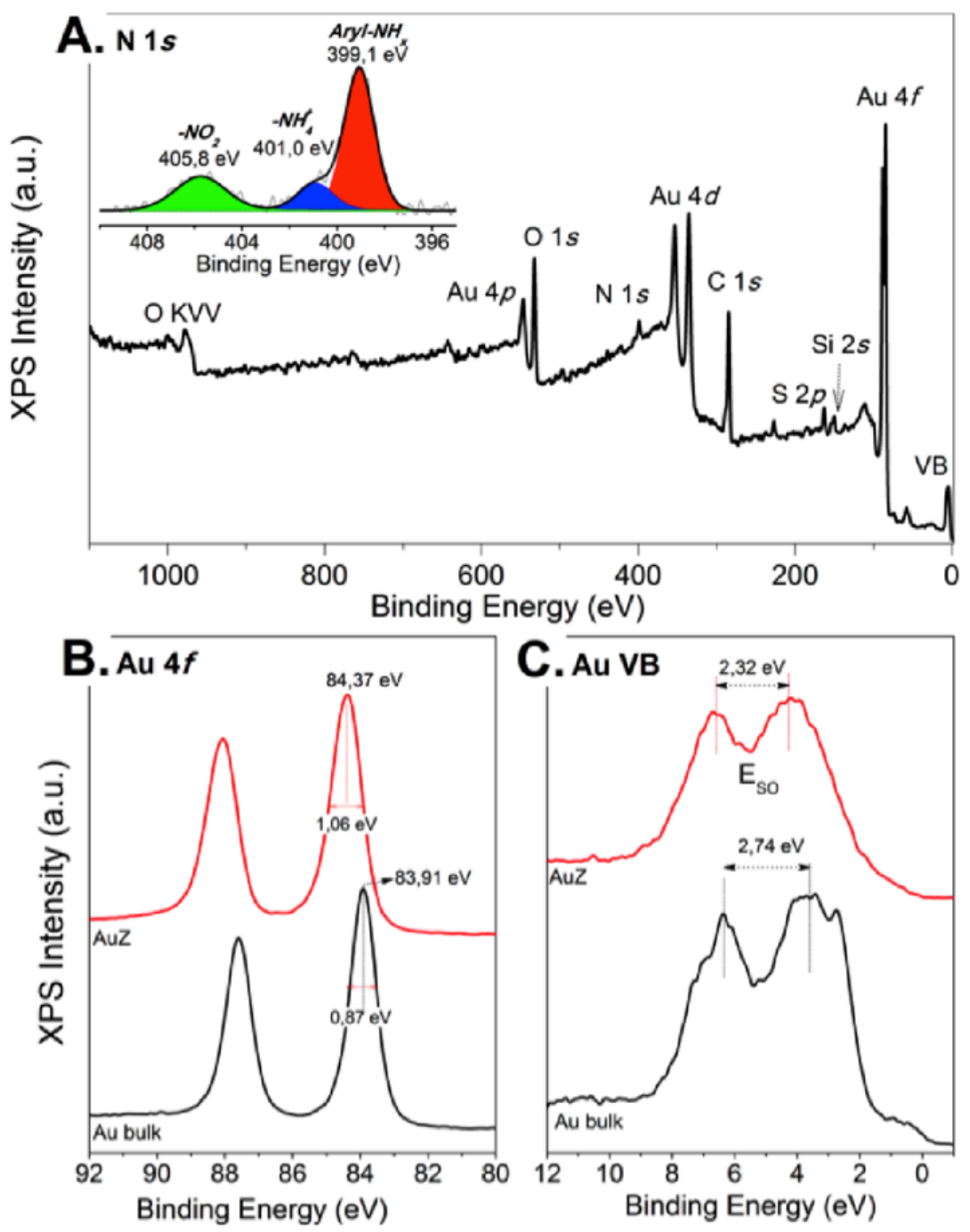

Figure 2. XPS spectra of AuZ particles A. survey spectrum with high resolution $\mathrm{N}$ 1s core level spectrum included in the inset. B. Au $4 \mathrm{f}$ core level peak and $\mathrm{C}$. valence band. The $\mathrm{Au} 4 \mathrm{f}$ and valence band spectra of metallic $\mathrm{Au}(0)$ sample are shown for comparison.

In the same time, the spin-orbit splitting $\mathrm{E}_{\mathrm{so}}$ of $\mathrm{AuZ}(2.32 \mathrm{eV})$ was reduced relative to the $\mathrm{E}_{\mathrm{so}}$ of polycrystalline $\mathrm{Au}(0)(2.74 \mathrm{eV})$ (Figure $2 \mathrm{C})$. Using the published relationship between the gold particle size and these values, the AuZ cluster contains on average $103 \pm 32$ Au atoms. ${ }^{38}$ The XPS analysis suggested that $\mathrm{AuZ}$ is reminiscent of a 102 gold atom cluster, which corresponds to a stable nanocluster according to the closed geometric shell theory. If AuZ is a 102 gold atom 
To cite : Desplancq, D.; Groysbeck, N.; Chiper, M.; Weiss, E.; Frisch, B.; Strub, J.-M.; Cianferani, S.; Zafeiratos, S.; Moeglin, E.; Holy, X.; et al. Cytosolic Diffusion and Peptide-Assisted Nuclear Shuttling of Peptide-Substituted Circa 102 Gold Atom Nanoclusters in Living Cells. ACS Applied Nano Materials 2018, 1, 4236-4246. Doi :

10.1021/acsanm.8b00988

"magic" cluster, it is surrounded by 44 ligands, here 30 TAB and 14 TNB using the XPS integration ratio, leading to a hypothetical formula of $\mathrm{Au}_{102} \mathrm{TAB}_{30} \mathrm{TNB}_{14}$.

\section{A. Ligand exchange reaction}

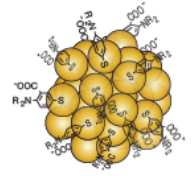

AuZ

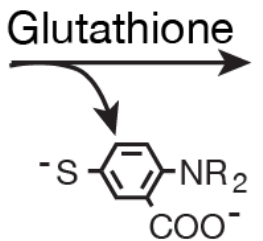

$\mathrm{R}=\mathrm{O}$ or $\mathrm{N}$

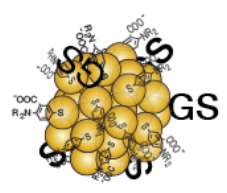

AuGS

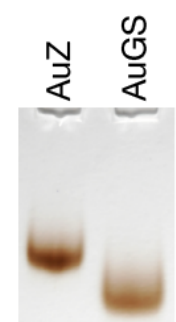

\section{B. Survey using NMR spectroscopy}

\section{AuZ + Glutathione : crude mixture}

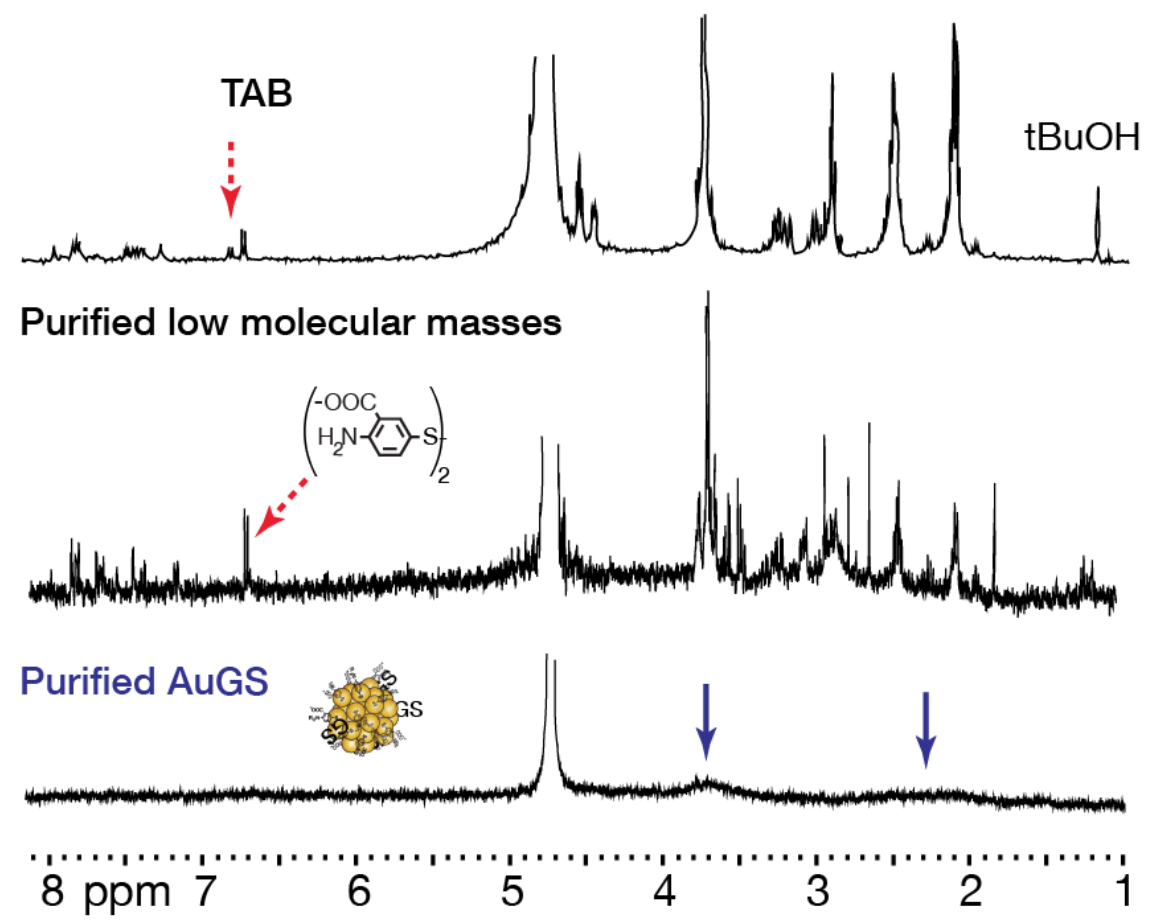

Figure 3. Survey on the ligand exchange ability of the AuZ gold nanocluster using reduced glutathione (GSH). A. Schematic view of the reaction. The inset image is a PAGE analysis of the AuZ and GSgrafted AuZ (AuGS). B. H NMR spectra of the crude reaction mixture, purified solution containing $<10$ $\mathrm{kDa}$ components and purified resulting gold nanocluster (AuGS). The large peak at $4.7 \mathrm{ppm}$ is $\mathrm{D}_{2} \mathrm{O}$ and was trimmed. The peaks between 2-4.7 ppm are assigned to GSH and the ones between 6.5-8.0 ppm correspond to released thionitrobenzoic acid (TNB), thioaminobenzoic acid (TAB) or mixed TNB-, TABdisulfides. The AuZ $(150 \mu \mathrm{M})$ and $\mathrm{GSH}(6000 \mu \mathrm{M})$ in $\mathrm{D}_{2} \mathrm{O}$ containing tert-butanol $(100 \mu \mathrm{M})$ as an internal standard were incubated for $20 \mathrm{~h}$ at $20^{\circ} \mathrm{C}$. The crude reaction was purified using a dialysis methodology with a $10 \mathrm{kDa}$ cut-off membrane. 
To cite : Desplancq, D.; Groysbeck, N.; Chiper, M.; Weiss, E.; Frisch, B.; Strub, J.-M.; Cianferani, S.; Zafeiratos, S.; Moeglin, E.; Holy, X.; et al. Cytosolic Diffusion and Peptide-Assisted Nuclear Shuttling of Peptide-Substituted Circa 102 Gold Atom Nanoclusters in Living Cells. ACS Applied Nano Materials 2018, 1, 4236-4246. Doi :

10.1021/acsanm.8b00988

A thermogravimetric analysis (TGA) was also performed to determine the percentage of organic materials covering gold clusters since this organic layer decomposes and becomes volatile upon heating at a temperature below the metallic gold (Supporting Information, Figure S2). ${ }^{.31}$ A total weight loss of $25.5 \%$ was obtained and the TGA showed a biphasic profile with a first $6.8 \%$ weight loss occurring at $212^{\circ} \mathrm{C}$ and a second $14.8 \%$ weight loss occurring at $420^{\circ} \mathrm{C}$. A small discrepancy is observed between the observed $25.5 \%$ total weight loss and the calculated $29.2 \%$ one for $\mathrm{Au}_{102} \mathrm{TAB}_{30} \mathrm{TNB}_{14}$ but appears within the accuracy range of this method. ${ }^{31} \mathrm{We}$ suggest that the minor $6.8 \%$ weight lost originates from thermal decarboxylation of the 44 ligands (calculated value of $6.9 \%$ ). ${ }^{39}$ The ability of the ligands covering the AuZ to be exchanged with incoming water-soluble thiols in aqueous solution was then assayed using reduced glutathione (GSH) (Figure 3A). When the AuZ $(150 \mu \mathrm{M})$ was reacted with 40 molar equivalents of GSH, a Glutathione-modified AuZ (AuGS) with an increased electrophoretic mobility in comparison to AuZ was obtained (Figure 3A, Inset image). To further analyze the thiolate ligand-exchange reaction, we performed an experiment using NMR spectrometry because the signal of the Au-bound ligands of the AuZ were hardly detectable using routine NMR settings that are used to analyze small organic molecules (see Figure 1B). If exchange occurs, the aromatic ligands should be released in solution and their NMR signals be hence detected. The AuZ $(150 \mu \mathrm{M})$ was reacted with 40 molar equivalents of GSH in $\mathrm{D}_{2} \mathrm{O}$ and a NMR spectrum of the crude mixture was taken after $20 \mathrm{~h}$ incubation at $20^{\circ} \mathrm{C}$ (Figure 3B). The spectrum exhibited peaks between 6.5-8.0 ppm, which were unseen in the AuZ spectrum. The aromatic NMR signals are attributed to hydrogens of TNB, TAB and mixed disulfides with GSH, suggesting indeed ligand release from the AuZ surface. Integration of the NMR signals indicated that TNB and $\mathrm{TAB}$ were released in equal amounts. Using tertio-butanol as an internal standard, the concentration of released ligands was estimated at roughly $1700 \mu \mathrm{M}$ or 11.3 ligands/particle with a $\mathrm{TNB} / \mathrm{TAB}$ ratio of 1 . This ratio is higher than the initial TNB/TAB ratio of 0.46 present at the AuZ surface and confirms that ligand exchange can be favored by para-withdrawing groups on 
To cite : Desplancq, D.; Groysbeck, N.; Chiper, M.; Weiss, E.; Frisch, B.; Strub, J.-M.; Cianferani, S.; Zafeiratos, S.;

Moeglin, E.; Holy, X.; et al. Cytosolic Diffusion and Peptide-Assisted Nuclear Shuttling of Peptide-Substituted Circa 102 Gold Atom Nanoclusters in Living Cells. ACS Applied Nano Materials 2018, 1, 4236-4246. Doi :

10.1021/acsanm.8b00988

the ligand aromatic ring..$^{826} \mathrm{~A}$ dialysis fractionation device with a $10 \mathrm{kDa}$ cut-off was then used to afford solutions containing either the high molecular mass AuGS or $<10 \mathrm{kDa}$ species. Both solutions were lyophilized and the residues were analyzed again. The solution containing $<10$ $\mathrm{kDa}$ species presented a slightly different NMR profile in the $6.5-8 \mathrm{ppm}$ range in comparison to the crude solution. This is likely due to slight acidity variation and to complete air-mediated oxidation of thiols to disulfides. The narrow signals $(1.8,2.7,2.8$ and $2.9 \mathrm{ppm})$ could not be attributed. They likely came from soluble stabilizers present in the dialysis fractionation device. An MS analysis of this solution confirmed disulfide formation and TAB release because an $\mathrm{MH}^{+}$ of 475.06 corresponding to the $\mathrm{MH}^{+}$of GSH-TAB disulfide was detected (Supporting Information, Figure S3). The NMR spectrum of purified AuGS was featureless above $4.7 \mathrm{ppm}$ but displayed broad peaks at 2.2 and $3.7 \mathrm{ppm}$, attributable to Au-bound glutathiones that have different local chemical environment and restricted mobility in a similar manner than aromatic ligands behaved when they are bound to the AuZ's surface (Figure 1C). ${ }^{\star 0}$

\section{Synthesis of peptide-substituted gold nanoclusters}

The AuZ was reacted in HEPES buffer $\mathrm{pH} 7.4$ with increasing amounts of the thiolated peptide HS-NLS which contains an N-terminal Cysteine, followed by the ALNNG sequence that was shown to prevent the metallic gold core from aggregation" and then the SV40 NLS sequence (Figure 4).2 The reaction products were analyzed by polyacrylamide gel electrophoresis (SDSPAGE) and Coomassie blue staining to reveal as well the peptide (Figure 4B). In the reaction mixture at HS-NLS/AuZ ratio of 24, excess peptide (fast moving blue band) was observed, indicating saturation of the substitution sites on the AuZ surface. When the HS-NLS/AuZ ratio was gradually increased from 1 to 24,8 different bands with gradual retardation were observed. By correlating the HS-NLS/AuZ ratios and the bands, we presumed that NLS peptide-AuNC conjugate at saturation level is surface-grafted with about 9 peptides. 
A. Reactivity with thiolated peptides

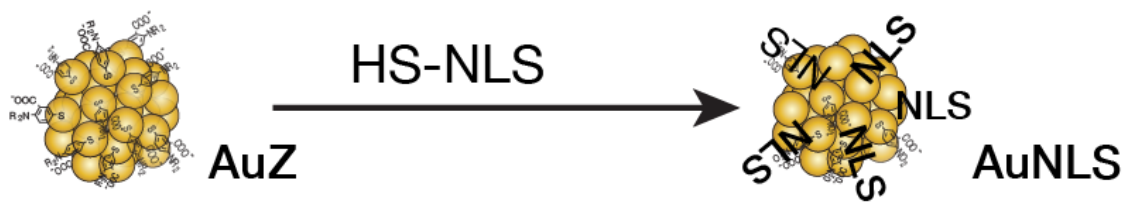

HS-NLS: CALNNGAGPKKKRKVED

NLS: Nuclear Localization Signal

B. Ligands to peptides substitution assay HS-NLS peptide/AuZ ratio

$\begin{array}{lllllllll}0 & 1 & 2 & 4 & 8 & 12 & 16 & 24\end{array} * \begin{array}{r}\mathrm{MW} \\ \mathrm{kDa}\end{array}$
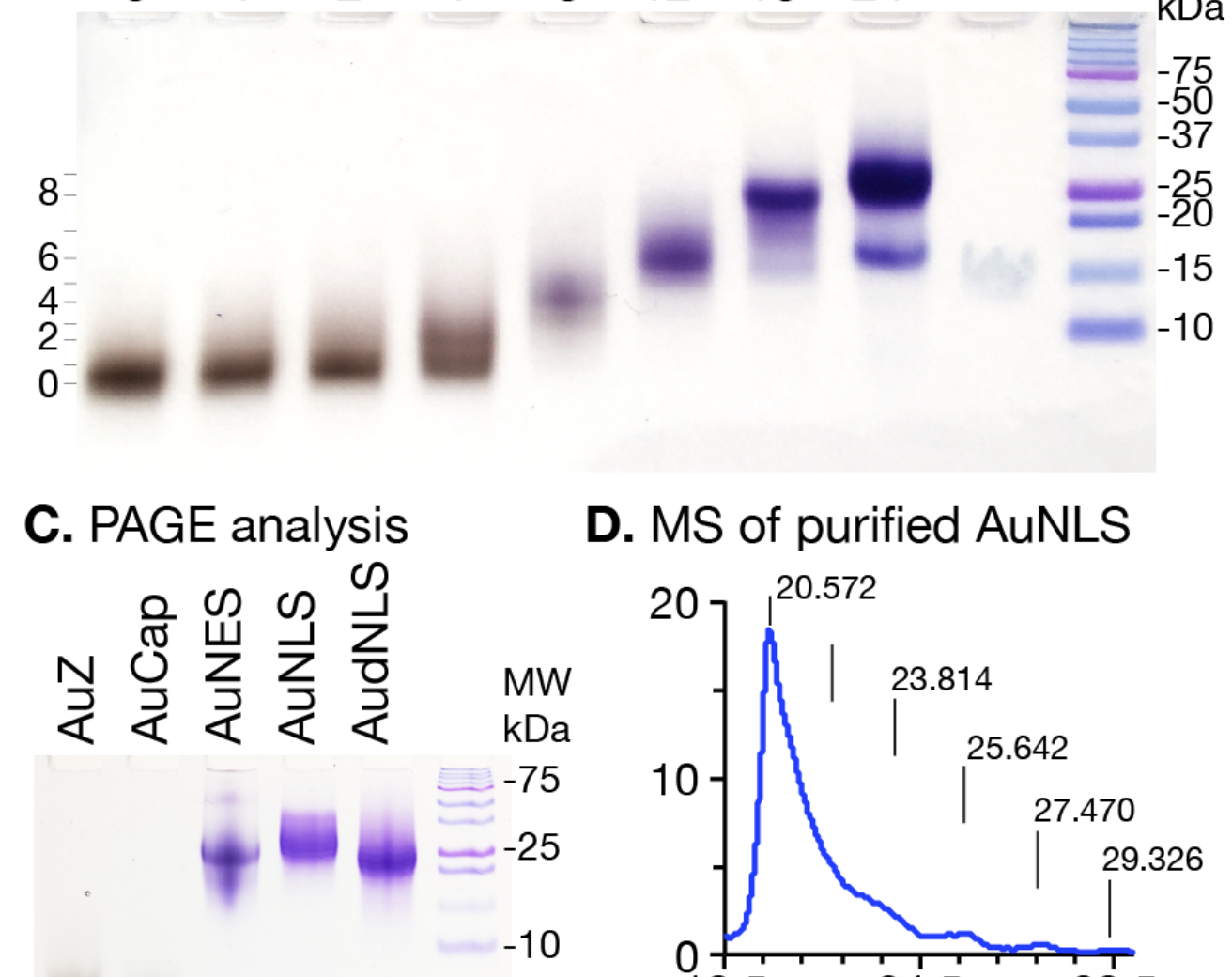

D. MS of purified AuNLS

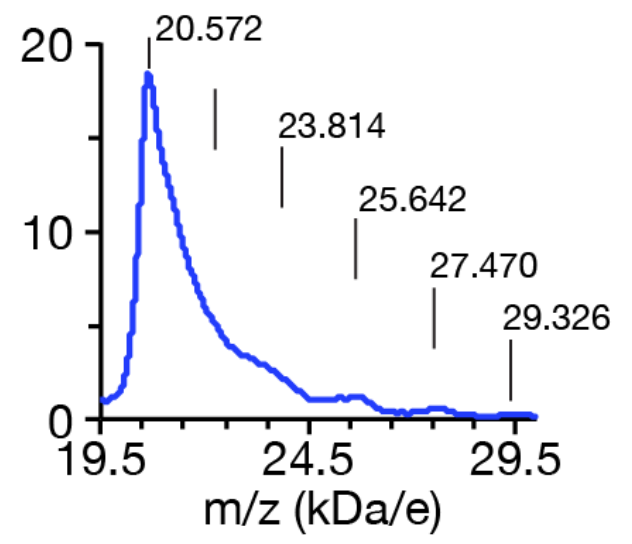

Figure 4. Reactivity of the AuZ with thiolated peptides. A. Schematic view. B. PAGE analysis of the reaction between AuZ and thiolated Nuclear Localization Signal Peptide (HS-NLS) at increasing molar ratios. *: HS-NLS alone. Last right lane: protein standards. Left numbers point to new gold clusters with different electrophoretic mobilities. C. PAGE analysis of AuZ and purified peptide-substituted gold nanoclusters made at a peptide/AuZ input molar ratio of 32. Cap: CALLNG, NES (Nuclear Export Signal peptide): CALNNGLALKLAGLDINKT ${ }_{\text {amise }}$, NLS (Nuclear Localization Signal): CALNNGAGPKKKRKVED, dNLS (defective NLS): CALNNGAGPKTKRKVED. Gels were stained with Coomassie blue. D. MALDI-TOF spectrum of purified AuNLS made at peptide/AuZ ratio of 32. 
To cite : Desplancq, D.; Groysbeck, N.; Chiper, M.; Weiss, E.; Frisch, B.; Strub, J.-M.; Cianferani, S.; Zafeiratos, S.;

Moeglin, E.; Holy, X.; et al. Cytosolic Diffusion and Peptide-Assisted Nuclear Shuttling of Peptide-Substituted Circa 102 Gold Atom Nanoclusters in Living Cells. ACS Applied Nano Materials 2018, 1, 4236-4246. Doi :

10.1021/acsanm.8b00988

Several peptide-gold nanocluster conjugates were similarly prepared by incubating AuZ with respectively the CALLNG peptide alone (Cap), the Cap linked to the protein kinase A inhibitor Nuclear Export Signal peptide (NES), ${ }^{43}$ the HS-NLS and a defective NLS peptide (dNLS) in which one lysine was replaced by a threonine..$^{42}$ To ensure full substitution, the peptide/AuZ feed ratio was set at 32 . The peptide-substituted AuNCs were then purified from the excess of free peptides and released ligands by dialysis. PAGE analysis showed that the Cap-substituted AuNC (AuCap) migrated as a single band with electrophoretic mobility similar to the starting AuZ as expected by the size and net charge of the Cap peptide that matches that of TNB (Figure 4C). The NES- and dNLS-substituted AuNCs (respectively AuNES and AudNLS) were significantly retarded and had an electrophoretic mobility close to NLS-substituted AuNC (AuNLS), suggesting that each gold nanocluster was also covered with 8-9 peptides. The AuNLS displayed a MALDI-TOF mass spectrum containing one major population (maximum at $20.6 \mathrm{kDa}$ ) and minor humps at higher molecular weights (Figure 4D). As previously found for AuZ (Figure 1E), the major population can be assigned to an AuNC species devoid of the organic coverage which was presumably fragmented by the laser-induced desorption and ionization. ${ }^{31}$ The novel humps were remarkably equidistant by a value $(1.8 \mathrm{kDa})$ corresponding to the molecular mass of the HS-NLS peptide, suggesting that AuNCs equipped with 1 to 5 NLS peptides partially sustained degradation imposed by the analytical process. The MS of AuCap, AudNLS and AuNES (Supporting Information, Figure S4) exhibited similar molecular weight patterns. The peptidesubstituted AuNCs were finally analyzed by electron microscopy (Figure 5). The AuNCs differently stuck to the Carbon film but were homogenous in diameter (average apparent diameters of $1.4 \mathrm{~nm}$ ) suggesting that these ligand exchange conditions were producing little etching of the gold metallic core. ${ }^{21}$ 
To cite : Desplancq, D.; Groysbeck, N.; Chiper, M.; Weiss, E.; Frisch, B.; Strub, J.-M.; Cianferani, S.; Zafeiratos, S.; Moeglin, E.; Holy, X.; et al. Cytosolic Diffusion and Peptide-Assisted Nuclear Shuttling of Peptide-Substituted Circa 102 Gold Atom Nanoclusters in Living Cells. ACS Applied Nano Materials 2018, 1, 4236-4246. Doi :

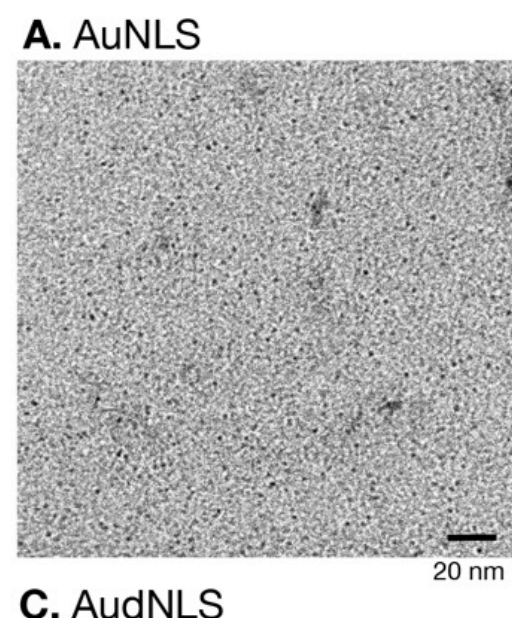

\section{B. AudNLS}
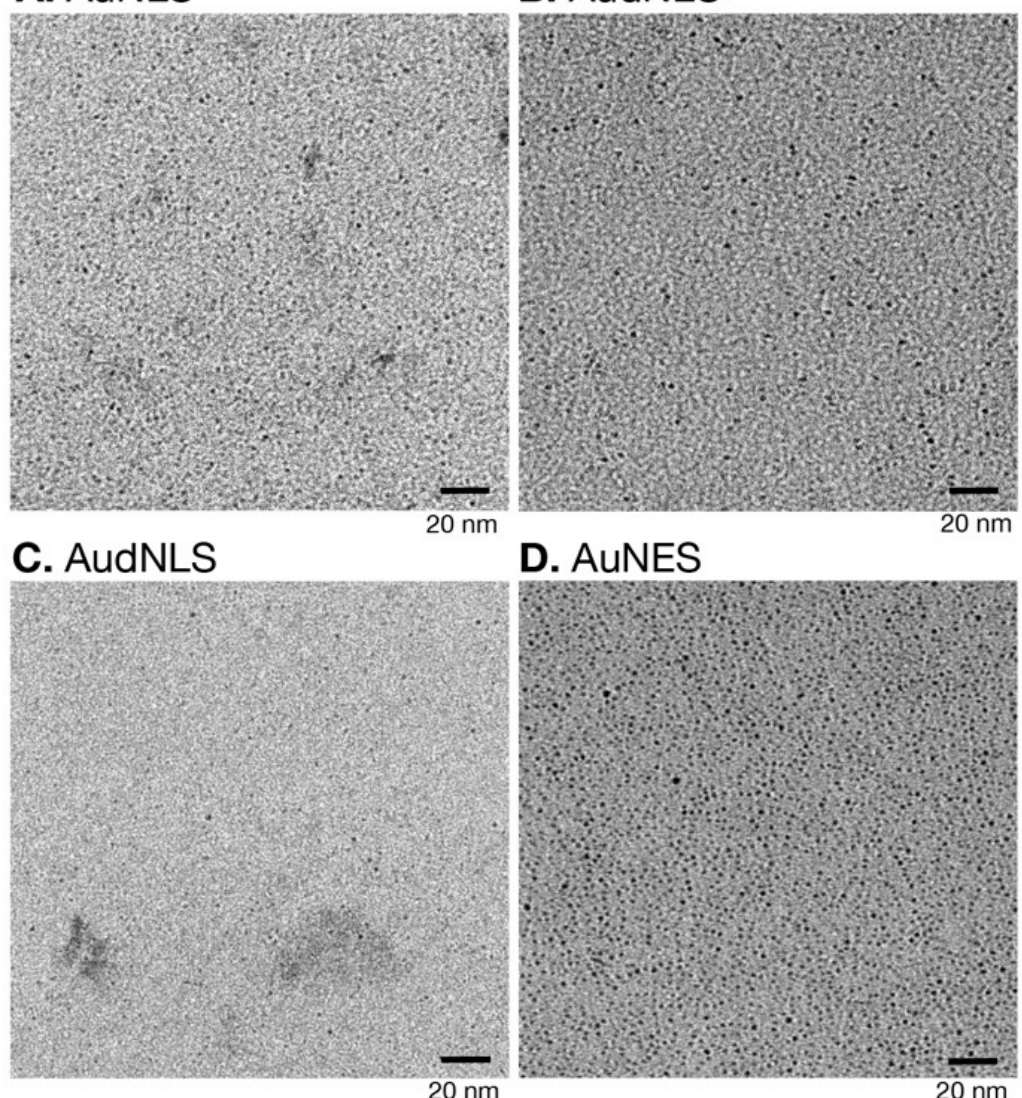

D. AUNES

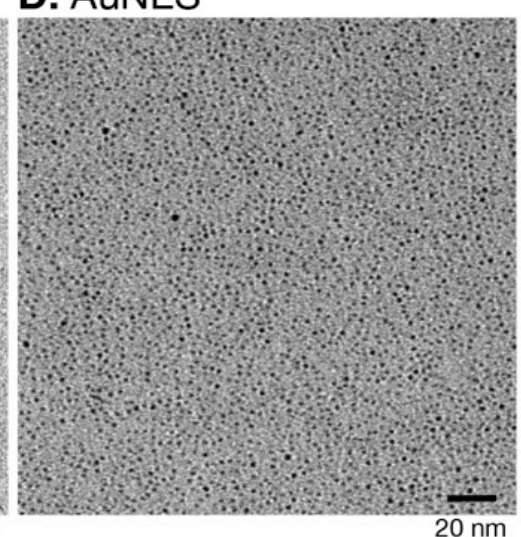

Figure 5. Transmission Electron Microscopy images of the peptide-modified gold nanoclusters. A. AuNLS. B. AudNLS. C. AudNLS. D. AuNES.

\section{Fate of AuNCs following cytosolic delivery inside living HeLa cells}

An electroporation protocol creating transient holes in the plasma membrane to direct influx of proteins inside the cytosol without inducing cellular lethality was described. ${ }^{4 t}$ The similarity in terms of size between AuNCs and proteins suggests that this electroporation procedure might also promote a direct influx of gold nanoparticles into the cytosol of living cells. This delivery method, which does not rely on any particular design of the particles or passage through vesicular compartments, creates an opportunity to precisely analyze the intracellular behavior of peptide-modified gold nanoclusters and whether they can diffuse and remain stable within the cell cytosol and nucleus. 
To cite : Desplancq, D.; Groysbeck, N.; Chiper, M.; Weiss, E.; Frisch, B.; Strub, J.-M.; Cianferani, S.; Zafeiratos, S.; Moeglin, E.; Holy, X.; et al. Cytosolic Diffusion and Peptide-Assisted Nuclear Shuttling of Peptide-Substituted Circa 102 Gold Atom Nanoclusters in Living Cells. ACS Applied Nano Materials 2018, 1, 4236-4246. Doi :

10.1021/acsanm.8b00988

The effect of the peptide-substituted AuNCs on the viability of native HeLa cells and transiently permeabilized HeLa cells (done using an electroporation device) was explored using a MTT assay (Figure 6). ${ }_{45}$ The experimental conditions were the ones that were optimized for the effective antibody transduction with minimal cell toxicity. ${ }^{44}$ The cell viability was measured $24 \mathrm{~h}$ after addition of the AuNCs and application of the electric pulses. Addition of AuNCs to HeLa cells with unimpaired cell plasma membrane (no electric pulses; blue bars) did not promote acute cytotoxicity (viability measured at above $75 \%$ for all AuNCs). Apparent cytotoxicity was also not observed when the plasma membrane was transiently permeabilized using electric pulses, regardless of the peptide-substituted AuNCs (yellow bars). A similar low cytotoxicity profile was also observed using the non-cancerous human fibroblast HFF-1 cell line (Supporting Information, Figure S5).

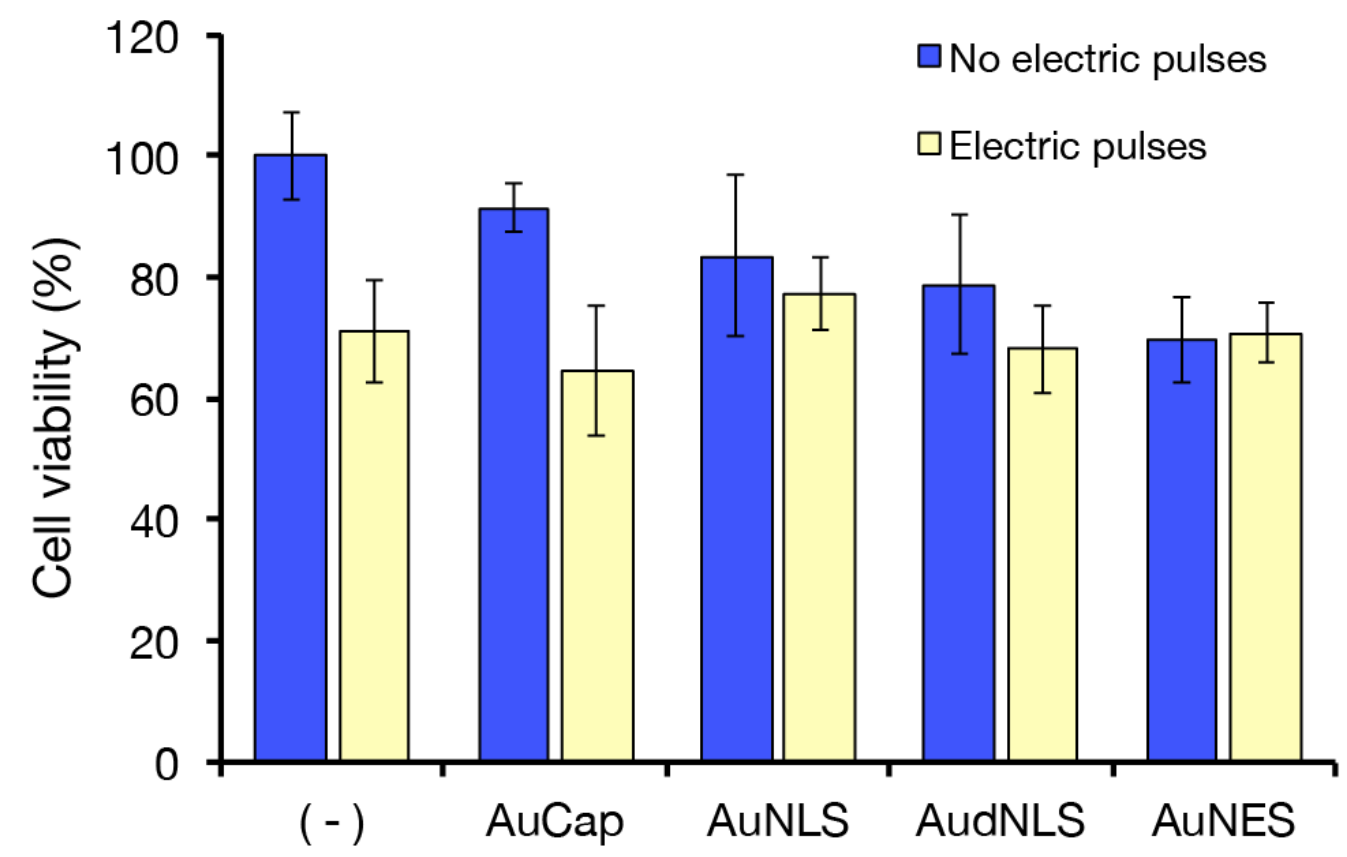

Figure 6. Evaluation of the HeLa cell line viability in presence of the peptide-substituted AuNCs (blue bars) and with electric pulses allowing transient permeabilization of the plasma membrane (yellow bars). Viability was measured $24 \mathrm{~h}$ after addition of the AuNCs. Values are averages and standard deviation of hexaplicates. Final AuNC concentration: 114 nM. 
To cite : Desplancq, D.; Groysbeck, N.; Chiper, M.; Weiss, E.; Frisch, B.; Strub, J.-M.; Cianferani, S.; Zafeiratos, S.;

Moeglin, E.; Holy, X.; et al. Cytosolic Diffusion and Peptide-Assisted Nuclear Shuttling of Peptide-Substituted Circa 102 Gold Atom Nanoclusters in Living Cells. ACS Applied Nano Materials 2018, 1, 4236-4246. Doi :

10.1021/acsanm.8b00988

Next, the AuCap, AuNLS and AudNLS were incubated with freshly trypsinized HeLa cells for 30 min without or with an electroporation treatment and the cells were left to adhere and grow for $24 \mathrm{~h}$ onto glass lamella. After cell-fixation, the gold particles were revealed using a silver staining procedure (Figure 7). For AuNCs that were incubated with the cells in the absence of the electric-induced membrane-permeability (Figure 7A), gold nanoclusters were mostly observed at distinguishable perinuclear compartments resembling lysosomes. This perinuclear accumulation was not unexpected since any binding to the cell outer-membrane surface can trigger a dynamic entry into intracellular vesicles and sequestration into lysosomes. ${ }^{46,47}$ When the same AuCap, AuNLS, AudNLS nanoclusters were mixed with HeLa cells and then subjected to electric pulses for transient plasma membrane permeabilization(Figures $7 \mathrm{~B}),{ }^{44}$ the intracellular silver staining was greatly enhanced as compared to non-electric pulsed-cells, indicating that the gold nanoclusters penetrated into cells through the plasma membranes upon the transient electric pulse-induced pores. The AuCaps were dispersed throughout the cytoplasm and the nucleus indicating that they can freely diffuse throughout the cell. The AuNLS strongly accumulated in the cell nuclei. In contrast, the mutated AudNLS carrying a defective NLS was spread throughout the entire cell. Important to mention, most adherent cells containing the different AuNCs had an adherent morphology similar to untreated cells, confirming the MTT assay ant that electroporation and cytosolic-delivered nanoclusters do not dramatically interfere with the cellular physiology of this cancer cell line. Observation of a sequence-specific nuclear import of the gold nanocluster clearly demonstrated that the gold-coupled NLS peptides remain coordinated to the gold nanocluster inside the HeLa cells. 
To cite : Desplancq, D.; Groysbeck, N.; Chiper, M.; Weiss, E.; Frisch, B.; Strub, J.-M.; Cianferani, S.; Zafeiratos, S.; Moeglin, E.; Holy, X.; et al. Cytosolic Diffusion and Peptide-Assisted Nuclear Shuttling of Peptide-Substituted Circa 102 Gold Atom Nanoclusters in Living Cells. ACS Applied Nano Materials 2018, 1, 4236-4246. Doi :

10.1021/acsanm.8b00988

A. Incubation of gold nanoclusters with HeLa cells
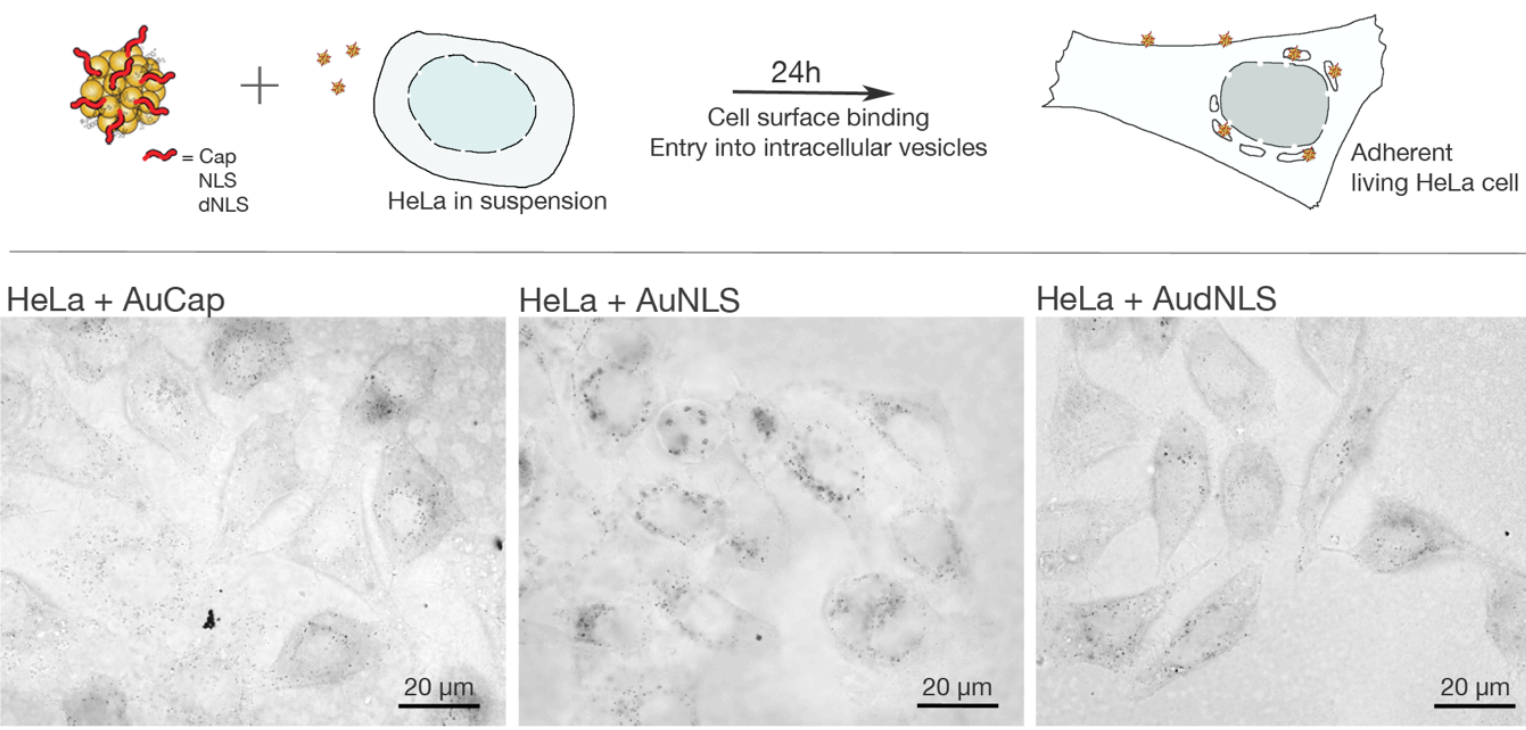

$\mathrm{HeLa}+$ AuNLS

HeLa + AudNLS

B. Incubation of gold nanoclusters with membrane-permeabilized HeLa cells
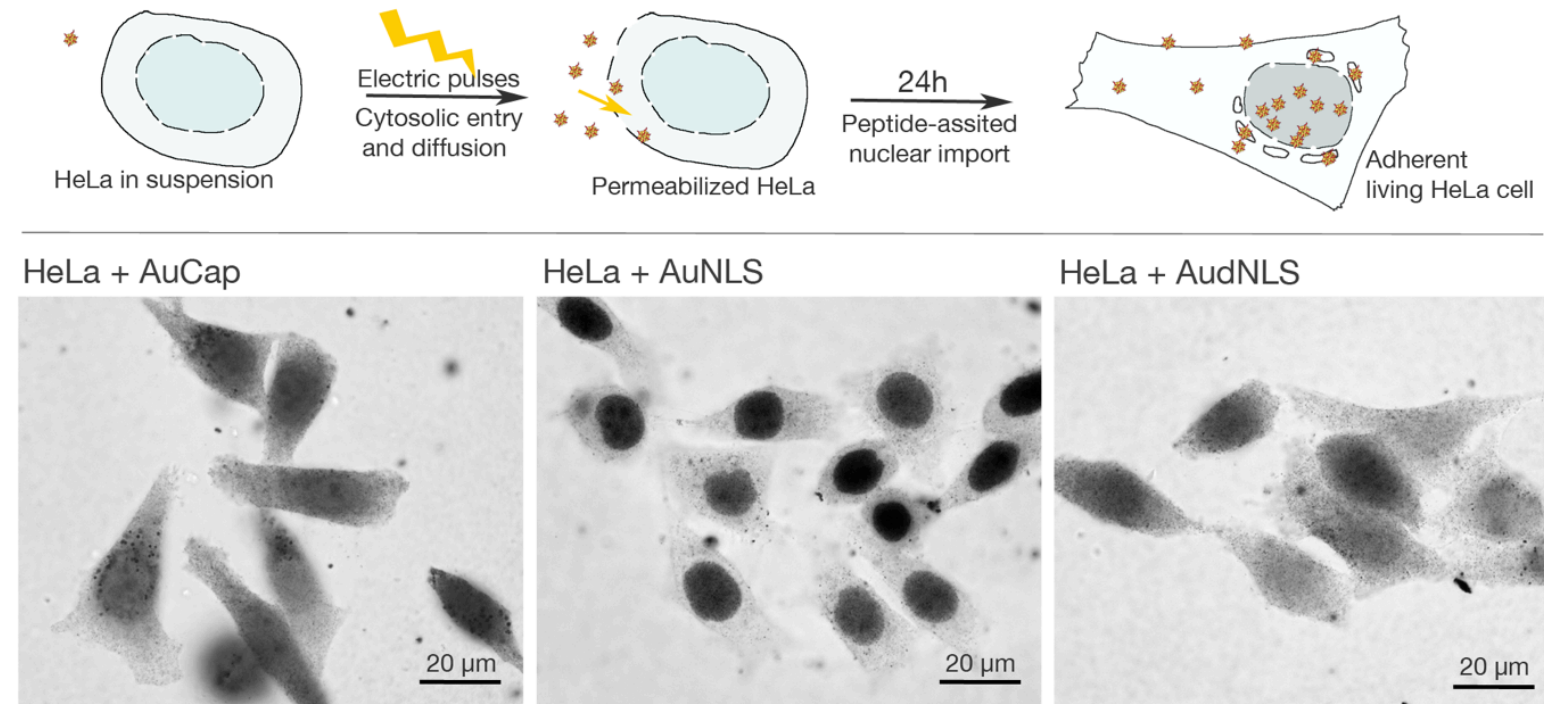

HeLa + AudNLS

Figure 7. Illustration of each experimental procedure and optical micrographs of Hela cells incubated for $24 \mathrm{~h}$ with the indicated peptide-substituted gold nanoclusters (AuNCs). A. The various peptide-AuNCs were added to HeLa cells in suspension. The cells were then added into wells for cell adhesion and monolayer formation. B. The various peptide-AuNCs were added to HeLa cells in suspension and the mixture treated with electric pulses for transient membrane permeabilization. The cells were then added into wells for cell adhesion and monolayer formation. Following the $24 \mathrm{~h}$ incubation period at $37^{\circ} \mathrm{C}$, the cells were fixed with glutaraldehyde $(2.5 \% \mathrm{w} / \mathrm{v})$ and subjected to silver staining for AuNC detection.

To further evaluate the diffusion ability of the AuNC and the stability of the Au-S bond in the nucleus, we evaluated as well a peptide signal-assisted nuclear export using the nuclear export signal peptide-grafted gold nanocluster (AuNES) (Figure 8). 


\section{A. AuNES with HeLa cells} HeLa
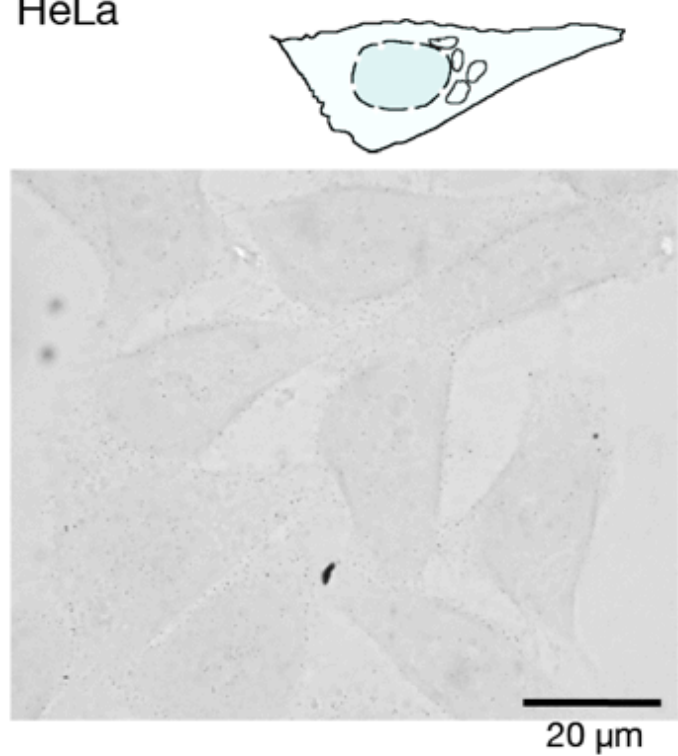

HeLa + AuNES
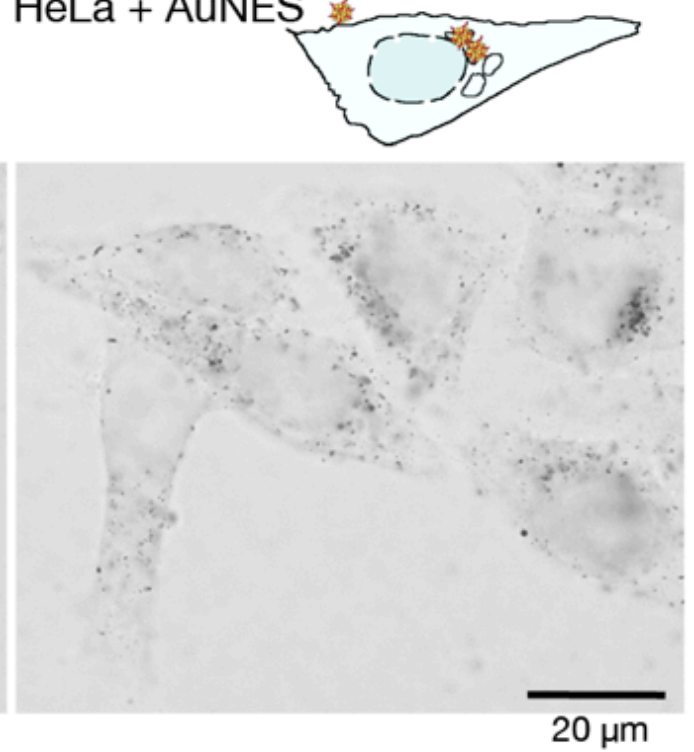

\section{B. AuNES with membrane-permeabilized HeLa cells}
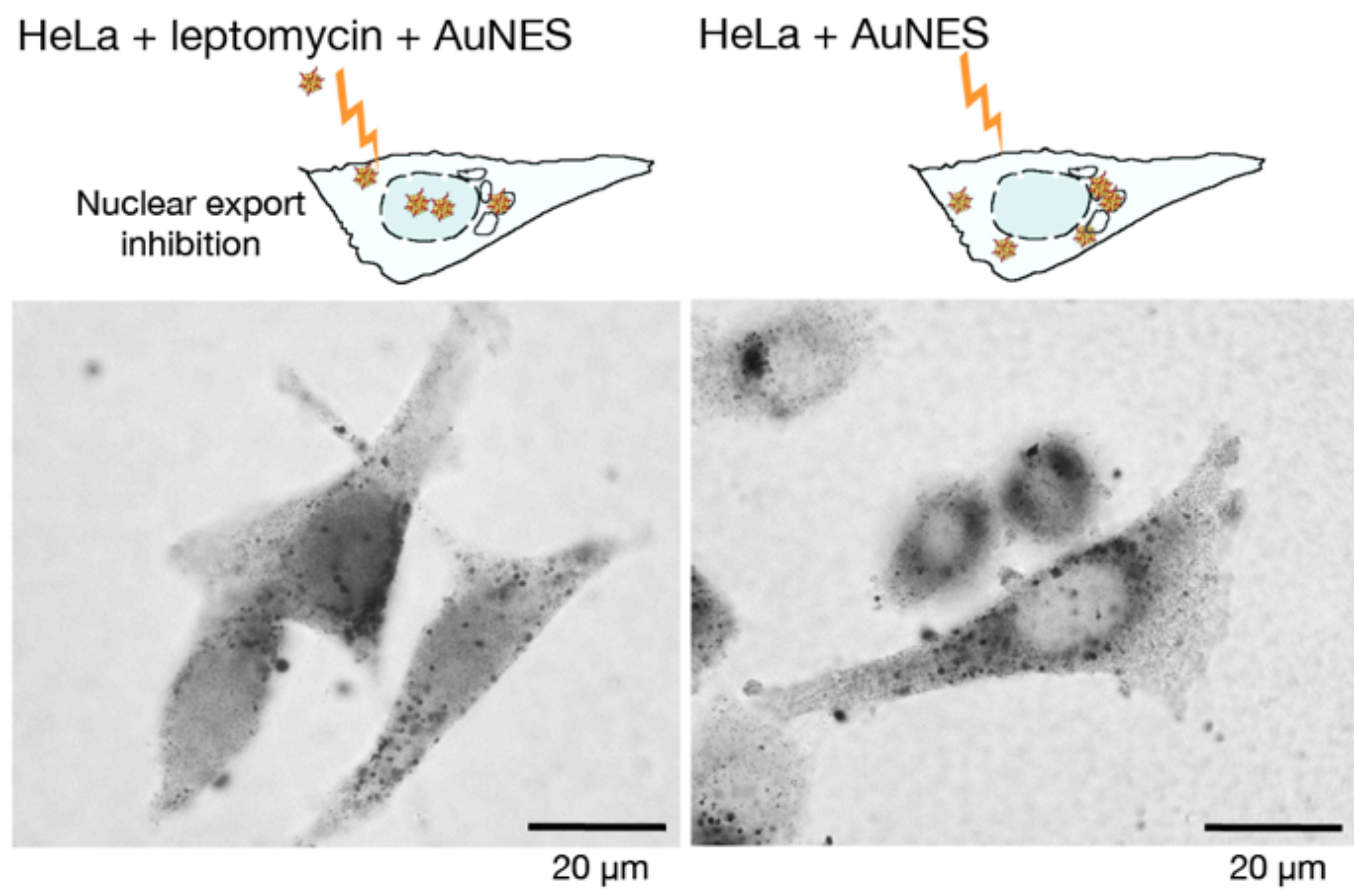

Figure 8. Optical micrographs of Hela cells incubated for 24h with the AuNES. A. Addition of AuNES to non-permeabilized HeLa cells. B. AuNES and HeLa cells were subjected to electroporation with or without leptomycin, an inhibitor of the NES-dependent nuclear export machinery. Following the $24 \mathrm{~h}$ incubation period at $37^{\circ} \mathrm{C}$, the cells were fixed with glutaraldehyde $(2.5 \% \mathrm{w} / \mathrm{v})$ and subjected to silver staining for AuNC detection. 
To cite : Desplancq, D.; Groysbeck, N.; Chiper, M.; Weiss, E.; Frisch, B.; Strub, J.-M.; Cianferani, S.; Zafeiratos, S.;

Moeglin, E.; Holy, X.; et al. Cytosolic Diffusion and Peptide-Assisted Nuclear Shuttling of Peptide-Substituted Circa 102 Gold Atom Nanoclusters in Living Cells. ACS Applied Nano Materials 2018, 1, 4236-4246. Doi :

10.1021/acsanm.8b00988

Addition of the AuNES to native non-permeabilized HeLa cells led to nanocluster accumulation in perinuclear compartments (Figure 8A) in an analogous manner than AuCap, AuNLS and AudNLS did. When the AuNES and the HeLa cells were subjected to electroporation and when the NES-dependent nuclear export was inhibited by leptomycin, ${ }^{48}$ the intracellular AuNES was homogeneously dispersed inside the entire cell, including the nucleus (Figure 8B, left image). In the absence of leptomycin, the nuclear export machinery was fully functional. In this condition, hardly any AuNES was detected in the nuclei (Figure 8B, right image) but rather appeared to localize and aggregate in subcellular organelles. Such redistribution is analogous of that observed with NES-grafted fluorescent proteins." Similar specific peptide-mediated nuclear in/out shuttling of AuNCs were obtained using the U2OS cell line and the non-cancerous human fibroblast HFF-1 cell line (Supporting Information, Figures S6 and S7), indicating that the observation was not HeLa-specific and can be extended to another cell lines.

The intracellular distribution of AuCap, AuNLS and AuNES within HeLa cells was further investigated by Transmission Electron Microscopy (TEM) 24h after the electroporation treatment (Figure 9). The gold nanoclusters were grown to $8-13 \mathrm{~nm}$ diameter particles by silverenhancement of specimens before resin-embedding in conditions that do not produce autonucleated silver particles (Supporting Information, Figure S8). ${ }^{14}$ The electroporation treatment and the presence of gold particles did not lead to any visible histological modification of the HeLa cells and the images showed similar gold nanocluster distribution patterns to those observed in light microcopy. The AuCaps were detected as single particles or in groups, both in the cytoplasm and in the nucleus in a roughly equivalent proportion (Figure 9, left image). The AuNLS were mostly detected as individual dots in the nucleus at areas with low heavy-metal contrast, corresponding probably to areas of the nuclei devoid of condensed chromatin (Figure 9, middle image). In a representative cell section 100 silver-amplified particles were counted in the nucleus (nuclear particle density of $13 \mathrm{AuNLS} / \mu \mathrm{m}^{3}$ ) and only 14 particles were spotted in the 
To cite : Desplancq, D.; Groysbeck, N.; Chiper, M.; Weiss, E.; Frisch, B.; Strub, J.-M.; Cianferani, S.; Zafeiratos, S.; Moeglin, E.; Holy, X.; et al. Cytosolic Diffusion and Peptide-Assisted Nuclear Shuttling of Peptide-Substituted Circa 102 Gold Atom Nanoclusters in Living Cells. ACS Applied Nano Materials 2018, 1, 4236-4246. Doi :

10.1021/acsanm.8b00988

cytoplasm, including 3 particles that were clearly entrapped inside vesicular bodies. Knowing the volume of the HeLa cell nucleus $\left(374 \mu \mathrm{m}^{3}\right){ }^{49}$ we calculated that the entire nucleus contains about 4,860 AuNLS. The AuNES were barely detected inside the nucleus and were seen to congregate in cytosolic areas (Figure 9, right image).

\section{A. TEM images}
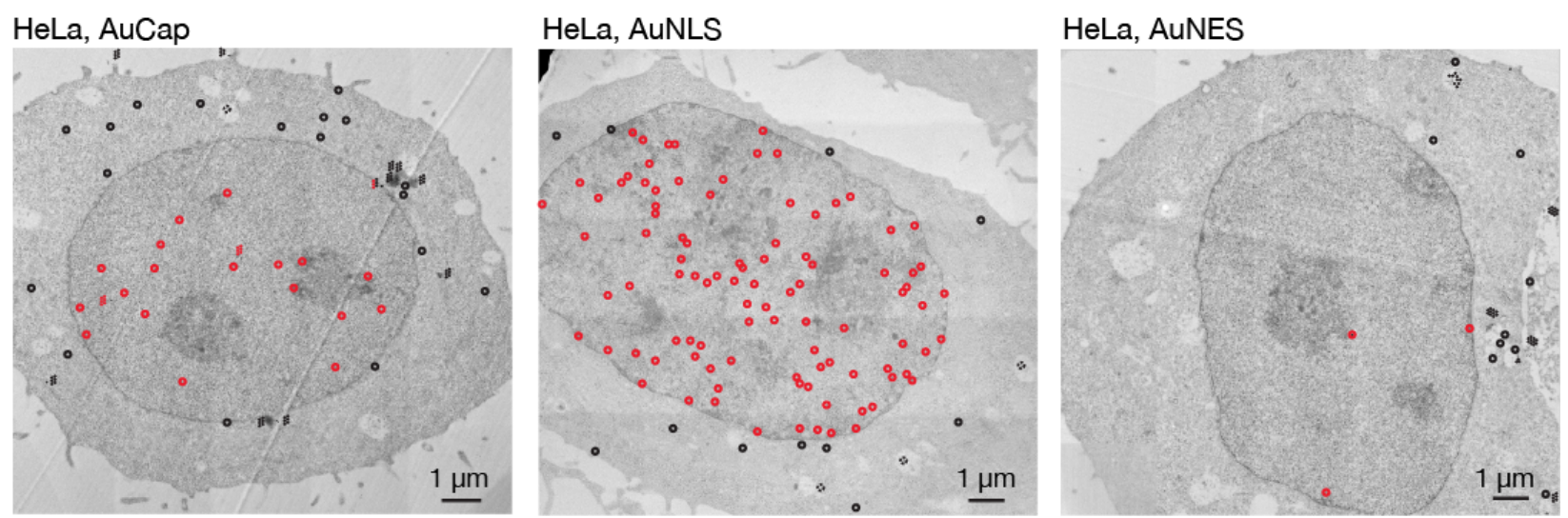

\section{B. Illustration of the TEM images}
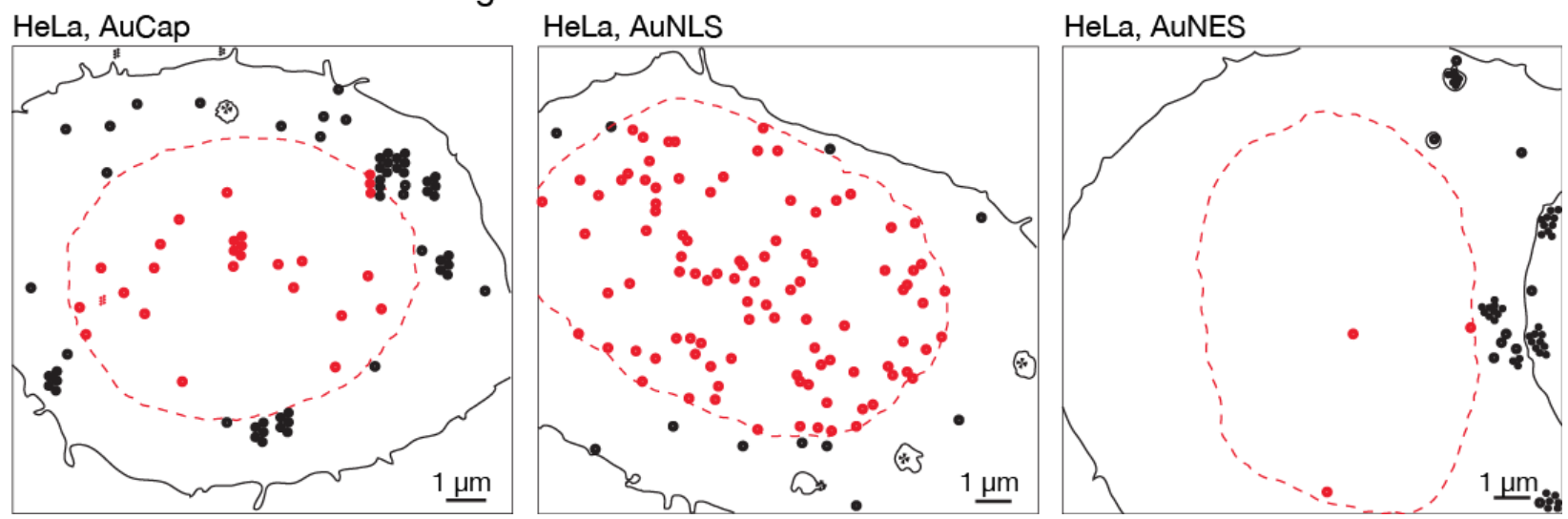

Figure 9. Transmission electron microscopy images of Hela cells after cytosolic delivery of peptidesubstituted gold nanoclusters as indicated. A. TEM images. Individual 8-13 nm diameter dark dots, corresponding to amplified AuNCs, were visualized on the micrographs at high magnification then highlighted in circles; aggregates of AuNCs were featured as columns; cytoplasmic and nuclear localizations were colored in black and red, respectively. B. Illustration of the imaged cells along with the position of AuNCs. The different peptide-AuNCs were delivered by electroporation into the cytosol of $\mathrm{HeLa}$ cells. The living cells were incubated for $24 \mathrm{~h}$ at $37^{\circ} \mathrm{C}$ and then processed for electron microscopy observation. The AuNCs were mildly silver-enhanced to ensure AuNC detection and ultrastructure preservation of specimen. 
To cite : Desplancq, D.; Groysbeck, N.; Chiper, M.; Weiss, E.; Frisch, B.; Strub, J.-M.; Cianferani, S.; Zafeiratos, S.;

Moeglin, E.; Holy, X.; et al. Cytosolic Diffusion and Peptide-Assisted Nuclear Shuttling of Peptide-Substituted Circa 102 Gold Atom Nanoclusters in Living Cells. ACS Applied Nano Materials 2018, 1, 4236-4246. Doi :

10.1021/acsanm.8b00988

\section{Discussion}

Availability of definable nanomaterials for any applications is really helpful and promises reliability. First we demonstrated the feasibility of preparing highly homogeneous gold nanoclusters, which can be further grafted with several thiolate-containing active peptides. A new type of gold nanoclusters of uniform size was synthesized from chloroauric acid and the Ellman's reagent upon reduction with sodium borohydride. Seventy percent of the TNB was reduced to the zwitterionic $\mathrm{TAB}$ during the nanocluster formation and was likely assisted by the presence of gold atoms. ${ }^{30}$ The UV/vis spectrum, cryo-EM image of AuZ in a vitrified aqueous solution, MALDI-TOF MS, XPS, TGA and theoretical calculation on cluster stability ${ }^{\text {so }}$ support the formation of gold clusters nearing the $\mathrm{Au}_{102}(\mathrm{TAB})_{30}(\mathrm{TNB})_{14}$ formula. Although not exclusive, the TNB ligand exchanged more readily than the TAB when reacted with external thiolated molecules, leaving a surrounding shell consisting of grafted peptides and mainly of the zwitterionic TAB ligand. The properties of AuZ and peptide-substituted AuZs to migrate as discrete bands in polyacrylamide gels are highly valuable for materials characterization. PAGE analysis is for instance not suited for characterization of less definable citrate-stabilized $4.5 \mathrm{~nm}$ gold nanoparticles (Figure S9). In our hands, AuZ was also substantially easier to produce as a single particle population than the AuMBA as judged by PAGE analysis (Figure S10).

Second, we evaluated the diffusion abilities and the fate of bioactive peptides-substituted AuZs when added to living cells for which the plasma membrane was transiently impaired by electric pulses. The remaining live cells adhering to lamella were seen to contain diffusible AuNCs and peptide-AuNC conjugates that shuttle across the nuclear envelop in a peptide-dependent manner. Altogether, our aggregated data clearly demonstrated that peptides remained grafted onto the gold nanoclusters (i.e.: the $\mathrm{Au}-\mathrm{S}$ is stable) for at least $24 \mathrm{~h}$ inside the cytosol and nucleus of cells. These AuNCs were also small enough to pass through electric pulses-mediated holes in the plasma membrane and mobile inside the cytosol and in the nucleus. This observation was in sharp contrast to a similar experiment in where $4.5 \mathrm{~nm}$ diameter gold nanoparticles did not homogenously spread inside the cells (Figure S11). Other data on the intracellular fate/behavior 
To cite : Desplancq, D.; Groysbeck, N.; Chiper, M.; Weiss, E.; Frisch, B.; Strub, J.-M.; Cianferani, S.; Zafeiratos, S.;

Moeglin, E.; Holy, X.; et al. Cytosolic Diffusion and Peptide-Assisted Nuclear Shuttling of Peptide-Substituted Circa 102 Gold Atom Nanoclusters in Living Cells. ACS Applied Nano Materials 2018, 1, 4236-4246. Doi :

10.1021/acsanm.8b00988

of other types of gold particles and cytosolic/nuclear localization can be found in the literature.

For example, PEGylated $2.4 \mathrm{~nm}$ gold particles ${ }^{16}$ or tiopronin-protected ca. $3 \mathrm{~nm}$ particles,,$^{51}$ when equipped with Cell Penetrating Peptides (CPP) having an adventitious NLS, were detected in the nucleus 1 to $3 \mathrm{~h}$ after addition to living cells but the efficiency of the process was unfortunately not quantified. Gold particles larger than $5.5 \mathrm{~nm}$ in diameter were also similarly equipped with CPP but their intracellular distribution appeared heterogeneous and experiment-dependent, ranging from exclusive entrapping onto the cell surface and in cellular vesicles ${ }^{1,52}$ or alternatively penetration into the nucleus. ${ }^{1952.54}$ Gold particles in the nucleus were in some cases accompanied by a dramatic modification of cell morphology, ${ }^{52}$ indicating that these materials interfered with an important cellular mechanism, leading to cell death. In other cases, the nuclear distribution of gold particles ${ }^{53}$ and of photoluminescent $2 \mathrm{~nm}$ gold nanoclusters ${ }^{4.5}$ was heterogeneous, suggesting strong non-specific interactions with nuclear components and/or impaired diffusion. Additional insight into the ability of gold nanoparticles to traffic to the cell nuclei were obtained by grafting different and independent bioactive organic species to gold particles of about $15 \mathrm{~nm}$ in diameter. ${ }^{1954}$ However, when quantitative analysis was done, only a small portion and number $(<10)$ of the multifunctionalized particles were detected in the cell nuclei, questioning their nuclear targeting abilities in regard to statistical significance.

In here, the electroporation protocol provided a significant improvement in cytosolic delivery of small and diffusible gold nanoclusters over previously reported methods undergoing a passage into intracellular vesicles. Almost $100 \%$ cells contained AuNCs inside the cytosol or into the nucleus and the materials within intracellular vesicles did not overwhelm the ones inside the cytosol (Figures 7 and 8; Supporting Information, Figures S6-7). The delivery efficiency in term of quantity (for instance, $>4,000$ nuclear particles per cell using the AuNLS) was also appreciated and considerably facilitated data analysis. In our investigation, the electroporation protocol helped demonstrating that peptide-conjugated AnNCs (either the AuNLS or the AuNES), made from the AuZ, can be shuttled across the nuclear pores using cellular machineries 
To cite : Desplancq, D.; Groysbeck, N.; Chiper, M.; Weiss, E.; Frisch, B.; Strub, J.-M.; Cianferani, S.; Zafeiratos, S.;

Moeglin, E.; Holy, X.; et al. Cytosolic Diffusion and Peptide-Assisted Nuclear Shuttling of Peptide-Substituted Circa 102 Gold Atom Nanoclusters in Living Cells. ACS Applied Nano Materials 2018, 1, 4236-4246. Doi :

10.1021/acsanm.8b00988

in a protein-like manner. This finding clearly implies a stable Au-S bond between the AuZ and the thiolated active peptide for at least $24 \mathrm{~h}$. It opens some intracellular usages of the definable AuZ gold nanoclusters which are amenable to facile derivatization with bioactive peptides or organic ligands and have mobility into the densely packed intracellular environment. The AuMBA has similar properties than the AuZ (Supporting Information, Figure S10). An NLSgrafted AuMBA also accumulated in the cell nuclei using the electroporation treatment suggesting that the intracellular stability of $\mathrm{Au}-\mathrm{S}$ coordination bond is insensitive to neighboring ligands. Nuclear accumulation of the NLS-grafted AuMBA in the non-cancerous HFF-1 cells appeared nonetheless less intense than that of the NLS-grafted AuZ (Figure S10D), suggesting in fine that the nanocluster-bound zwitterionic TABs might diminish undesired association to the HFF-1 cytoskeleton and represent an improved coverage in comparison to the anionic MBAs.

\section{Conclusion}

We have synthesized a novel monolayer organothiolate-protected gold nanoparticle by $\mathrm{NaBH}_{4}$ reduction of a mixture containing chloroauric acid and the Ellman's reagent. The procedure essentially yielded a uniform gold nanocluster, which is easily isolated by precipitation with excess methanol. Analytical data of this gold nanocluster characterized it as close to a superatom cluster containing 102 gold atoms, which are surrounded by an organic monolayer made of about 30 thioaminobenzoic acids and 14 thionitrobenzoic acids. These ligands, preferentially the thionitrobenzoic acids, are readily exchanged with thiolated peptides in aqueous solutions, providing gold nanoclusters that are grafted with ca. 8-9 peptides and mainly coated with remaining zwitterionic $\mathrm{TAB}$ ligands. The peptide-gold nanocluster conjugates can furthermore be delivered via an electroporation treatment into the cytosol of living cells wherein the Au-S coordination bond between thiolated peptide $\mathrm{an} \approx \mathrm{d} \mathrm{Au}(\mathrm{I})$ at the surface of the $\mathrm{Au}_{102}$ nanocluster was stable for at least $24 \mathrm{~h}$. Altogether, we have synthesized new definable gold nanoclusters and peptide-AuNC conjugates. We have also demonstrated the usefulness of electroporation for nanocluster cytosolic delivery with low to moderate vesicular entrapment and a $24 \mathrm{~h}$-stability of 
To cite : Desplancq, D.; Groysbeck, N.; Chiper, M.; Weiss, E.; Frisch, B.; Strub, J.-M.; Cianferani, S.; Zafeiratos, S.;

Moeglin, E.; Holy, X.; et al. Cytosolic Diffusion and Peptide-Assisted Nuclear Shuttling of Peptide-Substituted Circa 102 Gold Atom Nanoclusters in Living Cells. ACS Applied Nano Materials 2018, 1, 4236-4246. Doi :

10.1021/acsanm.8b00988

surface-modified gold AuNCs inside the cytosol and cell nucleus in where they can diffuse and specifically associate to molecular transport machineries. These data opened the usage of precise peptide-functionalized gold nanoclusters for intracellular investigation and application. These AuNCs might be particularly useful for building novel EM probes for high-resolution immunolabeling inside living cells.

\section{Experimental section}

General. Materials and additional protocols are described in the supporting information.

Gold nanocluster synthesis. The synthesis was done following a described procedure." Hydrogen tetrachloroaurate(III) trihydrate (14.2 mg, $36 \mu \mathrm{mol})$, DTNB (24.4 mg, $54 \mu \mathrm{mol})$, $\mathrm{NaOH}(13 \mathrm{mg}, 324 \mu \mathrm{mol})$ and $\mathrm{NaBH}_{4}(4 \mathrm{mg}, 108 \mu \mathrm{mol})$ were mixed in a methanol/water solution and the mixture was shaken overnight. The gold clusters were then precipitated by addition of a $2 \mathrm{M} \mathrm{AcONH}_{4}$ solution $(2 \mathrm{~mL})$ and methanol $(34 \mathrm{~mL})$. The black pellet (gold nanoparticle) was resuspended in water and desalted by a size exclusion chromatography (Sephadex G50). The black fraction was lyophilized resulting in AuZ (4.2 mg, $152 \mathrm{nmol})$ as a black powder.

Ligand exchange reaction with an increasing ratio of thiolated peptide to gold nanocluster. The thiolated NLS peptide was freshly diluted in water to 1 and $4 \mathrm{mM}$ concentrations. Aliquots $(0.8$ and $1.6 \mu \mathrm{L}$ of the $1 \mathrm{mM}$ NLS peptide solution and $0.8,1.6,2.4,3.2$ and 4.8 of the $4 \mathrm{mM}$ NLS peptide solution) were carefully dispensed at the bottom of different $0.5 \mathrm{~mL}$ tubes. The AuZ (10 $\mu \mathrm{L}$ of an $80 \mu \mathrm{M}$ solution in $100 \mathrm{mM}$ HEPES $\mathrm{pH} 7.4,0.8 \mathrm{nmol}$ ) was then rapidly added to each tube containing the peptide $(0.8,1.6,3.2,6.4,9.6,12.8$ and $19.2 \mathrm{nmol})$. The mixtures were then incubated for $18 \mathrm{~h}$ and reaction products were analyzed by electrophoresis on a $10 \%$ polyacrylamide gel.

Peptide-coated gold nanoclusters. A solution of $80 \mu \mathrm{M}$ AuZ $(80 \mu \mathrm{L}$ in $100 \mathrm{mM}$ HEPES pH 7.4, $6.4 \mathrm{nmol})$ was rapidly added to a solution containing $10 \mathrm{mM}$ thiolated peptide $(20.5 \mu \mathrm{L}, 205$ nmol) and $50 \mathrm{mM}$ TCEP, $\mathrm{pH} 7.4(4.3 \mu \mathrm{L}, 215 \mathrm{nmol})$ which was previously dispensed into a 0.5 $\mathrm{mL}$ polypropylene tube. The mixture was incubated at room temperature for $24 \mathrm{~h}$. Each crude 
To cite : Desplancq, D.; Groysbeck, N.; Chiper, M.; Weiss, E.; Frisch, B.; Strub, J.-M.; Cianferani, S.; Zafeiratos, S.; Moeglin, E.; Holy, X.; et al. Cytosolic Diffusion and Peptide-Assisted Nuclear Shuttling of Peptide-Substituted Circa 102 Gold Atom Nanoclusters in Living Cells. ACS Applied Nano Materials 2018, 1, 4236-4246. Doi :

10.1021/acsanm.8b00988

mixture was then diluted with water to $0.5 \mathrm{~mL}$ and the gold nanoparticles were purified from low molecular weight components using $0.5 \mathrm{~mL}$ Microcon ${ }^{\circledR} 30 \mathrm{kDa}$ centrifugal filter device (Merck, Molsheim) and 7 centrifugation cycles $\left(2 \times\right.$ water, $2 \times 0.4 \mathrm{M} \mathrm{NH}_{4} \mathrm{HCO}_{3}$ and $3 \times$ water). The concentration of the nanocluster was determined by measuring absorbance at $520 \mathrm{~nm}$ and a $\mathrm{e}_{520}$ of $2.7 \times 10^{s} \mathrm{~mol}^{-1} \times \mathrm{L} \mathrm{x} \mathrm{cm}^{-1}$. Final concentrations were adjusted to $80 \mu \mathrm{M}$ in AuNC with water. About 70 to $80 \%$ of the gold nanoparticles were recovered. The gold nanoparticles were analyzed using PAGE.

Ligand exchange measured by NMR spectroscopy. The gold nanocluster (3.2 mg, $120 \mathrm{nmol})$ was dissolved in $\mathrm{D}_{2} \mathrm{O}(0.5 \mathrm{~mL})$. The concentration was determined by measuring absorbance at $520 \mathrm{~nm}$. The cluster was then diluted in $\mathrm{D}_{2} \mathrm{O}$ to a final concentration of $150 \mu \mathrm{M}$. A $0.6 \mathrm{~mL}$ volume was withdrawn and taken for 'H NMR analysis at $293{ }^{\circ} \mathrm{K}$. Tertio-butanol (final concentration of $0.1 \mathrm{mM}$ ) was used as an internal standard. A 0.3 M glutathione, pD 7.4 was freshly prepared in $\mathrm{D}_{2} \mathrm{O}$. An aliquot $(12 \mu \mathrm{L}, 3600 \mathrm{nmol})$ was added to the $150 \mu \mathrm{M}$ AuNCs $(600$ $\mu \mathrm{L}, 90 \mathrm{nmol})$. The $\mathrm{H}$ NMR spectra were then collected 2 and $6 \mathrm{~h}$ later. The crude solution was then purified using a $0.5 \mathrm{~mL}$ Microcon ${ }^{\circledR} 10 \mathrm{kDa}$ centrifugal filter device (5 times water). The flow-through containing the species with molecular masses $<10 \mathrm{kDa}$ and the AuNC solutions were lyophilized, dissolved in $\mathrm{D}_{2} \mathrm{O}(0.6 \mathrm{~mL})$ and the ${ }^{\mathrm{H}} \mathrm{NMR}$ spectrum was recorded again.

XPS analyses. A $10 \mu \mathrm{M}$ nanoparticle solution in water/methanol (9/1)(20 $\mu \mathrm{L})$ was deposited onto a silicon wafer support. The water/methanol was left to evaporate in air under a fume hood and the sample was dried under high vacuum. The XPS measurements were performed in a UHV setup equipped with a monochromatic $\mathrm{Al} \mathrm{K} \alpha \mathrm{X}$-ray source and a VSW Class WA hemispherical electron analyzer..$^{55}$ The binding energy scale of the spectrometer was calibrated prior to the measurements and since samples did not have electrostatic charging, the binding energies are presented without any correction. The Shirley method was employed for background subtraction, prior to the fitting procedure. The elemental atomic ratio was calculated by the integrated XPS peak areas of high resolution spectra normalized to the atomic sensitivity factors and by assuming a homogeneous distribution arrangement model..$^{56}$ 
To cite : Desplancq, D.; Groysbeck, N.; Chiper, M.; Weiss, E.; Frisch, B.; Strub, J.-M.; Cianferani, S.; Zafeiratos, S.; Moeglin, E.; Holy, X.; et al. Cytosolic Diffusion and Peptide-Assisted Nuclear Shuttling of Peptide-Substituted Circa 102 Gold Atom Nanoclusters in Living Cells. ACS Applied Nano Materials 2018, 1, 4236-4246. Doi :

10.1021/acsanm.8b00988

Electroporation Protocol. Transduction experiments were conducted as previously described using the Neon ${ }^{\mathrm{R}}$ transfection system and three $10 \mathrm{~ms}$ pulses at $1550 \mathrm{~V} \cdot{ }^{4}$ For light microscopy imaging, HeLa cells (10; cells in $12 \mu \mathrm{L}$ of the Neon Buffer R) were mixed with each AuNC (80 pmol, $1 \mu \mathrm{L}$ of a $80 \mu \mathrm{M}$ solution). For TEM imaging, the electroporation was scaled up 6 fold (6 X $10^{s}$ cells in $110 \mu \mathrm{L}$ Neon Buffer R, $6 \mu \mathrm{L}$ AuNCs). After the electric pulses, the cells were diluted into prewarmed cell culture medium without antibiotics $(1 \mathrm{~mL})$. The cells were recovered by gentle centrifugation, suspended into the warmed complete cell culture medium without antibiotics and added into wells of 24-wells plates for cell adherence and cell growth into a cell culture incubator.

Cell viability assay. The assay was done according to a published procedure. the cells mixtures were treated as described in the electroporation protocol and then diluted for culture in 96-wells plate. Assay was performed $24 \mathrm{~h}$ after addition of the sample.

Cellular Specimen preparation for Light Microscopy. 24h after the electroporation treatment, the cell monolayers were washed with warmed $\left(37^{\circ} \mathrm{C}\right)$ Sorenson's buffer $(3 \times 1 \mathrm{~mL})$. The cells were then fixed with $2.5 \%$ glutaraldehyde diluted in $133 \mathrm{mM}$ Sorenson's buffer $(1 \mathrm{~mL})$ for $1 \mathrm{~h}$. Unreacted aldehydes were blocked by incubation with a 100 mM Sorenson's buffer, pH 7.4 containing $50 \mathrm{mM}$ glycine ( $1 \mathrm{~mL}, 20 \mathrm{~min})$. The plasma membrane was permeabilized using $0.1 \mathrm{M}$ Sorenson's buffer $\mathrm{pH} 7.4$ containing $0.05 \%(\mathrm{w} / \mathrm{v})$ saponin $(1 \mathrm{~mL}, 15 \mathrm{~min})$ before proceeding for silver-mediated amplification of the gold particles according to a modified Danscher protocol ${ }^{s s}$ using silver acetate and propyl gallate..$^{99}$ The glass plates were mounted on slides (StarFrost, Knittel Glass, Germany) and samples were observed using a Leica DM5500B microscope equipped with a Leica DFC350FX camera. Image acquisition was made with Leica LAS AF software.

Cellular Specimen preparation for Electron Microscopy. 24h after the electroporation treatment, the adherent cells were washed with warmed $\left(37^{\circ} \mathrm{C}\right)$ Sorenson's buffer $(3$ times 2 $\mathrm{mL})$. The cells were then fixed with $2.5 \%$ glutaraldehyde $(1 \mathrm{~mL})$ for at least 4 hours. The cells 
To cite : Desplancq, D.; Groysbeck, N.; Chiper, M.; Weiss, E.; Frisch, B.; Strub, J.-M.; Cianferani, S.; Zafeiratos, S.;

Moeglin, E.; Holy, X.; et al. Cytosolic Diffusion and Peptide-Assisted Nuclear Shuttling of Peptide-Substituted Circa 102 Gold Atom Nanoclusters in Living Cells. ACS Applied Nano Materials 2018, 1, 4236-4246. Doi :

10.1021/acsanm.8b00988

were then washed with TEM storage solution $(5 \mathrm{x}, 1 \mathrm{~mL})$. Enhancement of sizes of the gold particles with silver was performed using the SE-EM kit (Aurion, the Netherlands) and according to the manufacturer's protocol. The cells were then contrasted with $0.5 \%$ osmium for 20 min followed by $2 \%$ uranyl acetate both diluted in water. The specimens were then dehydrated in a solution containing increasing concentrations of ethanol and flat embedded in epon (Ladd Research Industries, Williston, Vermont, USA). The resin-embedded specimens were sectioned into $100 \mathrm{~nm}$ thick slices that were deposited on a 200 mesh electron microscopy grid.

\section{ASSOCIATED CONTENT}

The supporting file (pdf) is available free of charge The document contains additional experimental procedures; a table summarizing the peptide sequences; XPS spectra and thermogravimetric analysis of AuZ; UV/vis spectra of AuZ after reaction with glutathione; TEM and Mass spectra of peptide-AuNC conjugates; distribution analysis of AuNCs in U2OS and HFF-1 cells; TEM of untreated silver-stained cells; reactivity and delivery assay of peptideAuMBA conjugates; synthesis and cytosolic delivery of $4.5 \mathrm{~nm}$ nanoparticles; fluorescence emission spectra of AuZ and AuGS; HPLC profile and MS of peptides; FT-IR spectra of the AuNCs;; synthesis and cytosolic delivery of Alexa488-labeled AuNLS; and color images of cytosolic delivery of AuNCs in HeLa cells.

\section{AUTHOR INFORMATION}

\section{Corresponding Author}

*zuber@unistra.fr

\section{ACKNOWLEDGMENT}

We are grateful to Jean Daraspe for providing the Montage Software, Estefania Oliva for Mass Spectrum analysis of exchanged ligands and Robert Drillien for style-editing the manuscript. This research was supported by the ANR-10-LABX-0026_CSC, the French Infrastructure for 
To cite : Desplancq, D.; Groysbeck, N.; Chiper, M.; Weiss, E.; Frisch, B.; Strub, J.-M.; Cianferani, S.; Zafeiratos, S.; Moeglin, E.; Holy, X.; et al. Cytosolic Diffusion and Peptide-Assisted Nuclear Shuttling of Peptide-Substituted Circa 102 Gold Atom Nanoclusters in Living Cells. ACS Applied Nano Materials 2018, 1, 4236-4246. Doi :

10.1021/acsanm.8b00988

Integrated Structural Biology (FRISBI ANR-10-INBS-05). NG received a Ph. D. fellowship

from the IdEX Unistra (Université de Strasbourg and Investissements d'Avenir).

\section{REFERENCES}

(1) Luo, Z.; Yuan, X.; Yu, Y.; Zhang, Q.; Leong, D. T.; Lee, J. Y.; Xie, J. From Aggregation-Induced Emission of $\mathrm{Au}(\mathrm{I})-$ Thiolate Complexes to Ultrabright $\mathrm{Au}(0) @ \mathrm{Au}(\mathrm{I})-\mathrm{Thiolate}$ Core-Shell Nanoclusters. J. Am. Chem. Soc. 2012, 134 (40), 16662-16670.

(2) An, D.; Su, J.; Weber, J. K.; Gao, X.; Zhou, R.; Li, J. A Peptide-Coated Gold Nanocluster Exhibits Unique Behavior in Protein Activity Inhibition. J. Am. Chem. Soc. 2015, 137 (26), 8412-8418.

(3) Zhang, X.; Wu, F.-G.; Liu, P.; Gu, N.; Chen, Z. Enhanced Fluorescence of Gold Nanoclusters Composed of $\mathrm{HAuCl}$ 4and Histidine by Glutathione: Glutathione Detection and Selective Cancer Cell Imaging. Small 2014, 10 (24), 5170-5177.

(4) Wang, Y.; Chen, J.; Irudayaraj, J. Nuclear Targeting Dynamics of Gold Nanoclusters for Enhanced Therapy of HER2 +Breast Cancer. ACS Nano 2011, 5 (12), 9718-9725. Vankayala, R.; Kuo, C.-L.; Nuthalapati, K.; Chiang, C.-S.; Hwang, K. C. NucleusTargeting Gold Nanoclusters for Simultaneous in Vivo Fluorescence Imaging, Gene Delivery, and NIR-Light Activated Photodynamic Therapy. Adv. Funct. Mater. 2015, 25 (37), 5934-5945.

(6) Zhang, X.; Chen, X.; Jiang, Y.-W.; Ma, N.; Xia, L.-Y.; Cheng, X.; Jia, H.-R.; Liu, P.; Gu, N.; Chen, Z.; Wu, F.-G. Glutathione-Depleting Gold Nanoclusters for Enhanced Cancer Radiotherapy Through Synergistic External and Internal Regulations. ACS Appl. Mater. Interfaces 2018, 10 (13), 10601-10606.

(7) Jadzinsky, P. D.; Calero, G.; Ackerson, C. J.; Bushnell, D. A.; Kornberg, R. D. Structure of a Thiol Monolayer-Protected Gold Nanoparticle at 1.1 a Resolution. Science 2007, 318 (5849), 430-433.

(8) Donkers, R. L.; Song, Y.; Murray, R. W. Substituent Effects on the Exchange Dynamics of Ligands on 1.6 Nm Diameter Gold Nanoparticles. Langmuir 2004, 20 (11), 47034707.

(9) Azubel, M.; Koivisto, J.; Malola, S.; Bushnell, D.; Hura, G. L.; Koh, A. L.; Tsunoyama, H.; Tsukuda, T.; Pettersson, M.; Häkkinen, H.; Kornberg, R. D. Electron Microscopy of Gold Nanoparticles at Atomic Resolution. Science 2014, 345 (6199), 909-912.

(10) Marjomaki, V.; Lahtinen, T.; Martikainen, M.; Koivisto, J.; Malola, S.; Salorinne, K.; Pettersson, M.; Häkkinen, H. Site-Specific Targeting of Enterovirus Capsid by Functionalized Monodisperse Gold Nanoclusters. Proc. Natl. Acad. Sci. U.S.A. 2014, 111 (4), 1277-1281.

(11) Martikainen, M.; Salorinne, K.; Lahtinen, T.; Malola, S.; Permi, P.; Häkkinen, H.; Marjomäki, V. Hydrophobic Pocket Targeting Probes for Enteroviruses. Nanoscale 2015, 7 (41), 17457-17467.

(12) Postupalenko, V.; Desplancq, D.; Orlov, I.; Arntz, Y.; Spehner, D.; Mely, Y.; Klaholz, B. P.; Schultz, P.; Weiss, E.; Zuber, G. Protein Delivery System Containing a NickelImmobilized Polymer for Multimerization of Affinity-Purified His-Tagged Proteins Enhances Cytosolic Transfer. Angew. Chem. Int. Ed. Engl. 2015, 54 (36), 10583-10586. 
To cite : Desplancq, D.; Groysbeck, N.; Chiper, M.; Weiss, E.; Frisch, B.; Strub, J.-M.; Cianferani, S.; Zafeiratos, S.; Moeglin, E.; Holy, X.; et al. Cytosolic Diffusion and Peptide-Assisted Nuclear Shuttling of Peptide-Substituted Circa 102 Gold Atom Nanoclusters in Living Cells. ACS Applied Nano Materials 2018, 1, 4236-4246. Doi :

10.1021/acsanm.8b00988

(13) Sexton, J. Z.; Ackerson, C. J. Determination of Rigidity of Protein Bound $\mathrm{Au}_{144}$ Clusters by Electron Cryomicroscopy. J. Phys. Chem. C 2010, 114 (38), 16037-16042.

(14) Orlov, I.; Schertel, A.; Zuber, G.; Klaholz, B.; Drillien, R.; Weiss, E.; Schultz, P.; Spehner, D. Live Cell Immunogold Labelling of RNA Polymerase II. Sci Rep 2015, 5, 8324.

(15) Huang, K.; Ma, H.; Liu, J.; Huo, S.; Kumar, A.; Wei, T.; Zhang, X.; Jin, S.; Gan, Y.; Wang, P. C.; He, S.; Zhang, X.; Liang, X.-J. Size-Dependent Localization and Penetration of Ultrasmall Gold Nanoparticles in Cancer Cells, Multicellular Spheroids, and Tumors in Vivo. ACS Nano 2012, 6 (5), 4483-4493.

(16) Oh, E.; Delehanty, J. B.; Sapsford, K. E.; Susumu, K.; Goswami, R.; Blanco-Canosa, J. B.; Dawson, P. E.; Granek, J.; Shoff, M.; Zhang, Q.; Goering, P. L.; Huston, A.; Medintz, I. L. Cellular Uptake and Fate of PEGylated Gold Nanoparticles Is Dependent on Both Cell-Penetration Peptides and Particle Size. ACS Nano 2011, 5 (8), 6434-6448. Chiper, M.; Niederreither, K.; Zuber, G. Transduction Methods for Cytosolic Delivery of Proteins and Bioconjugates Into Living Cells. Adv. Healthcare Mater. 2018, 7 (6), e1701040.

(18) Lévy, R.; Shaheen, U.; Cesbron, Y.; Sée, V. Gold Nanoparticles Delivery in Mammalian Live Cells: a Critical Review. Nano Reviews 2010, 1 (1), 4889.

(19) Nativo, P.; Prior, I. A.; Brust, M. Uptake and Intracellular Fate of Surface-Modified Gold Nanoparticles. ACS Nano 2008, 2 (8), 1639-1644.

(20) Pinel, S.; Aman, E.; Erblang, F.; Dietrich, J.; Frisch, B.; Sirman, J.; Kichler, A.; Sibler, A.-P.; Dontenwill, M.; Schaffner, F.; Zuber, G. Quantitative Measurement of Delivery and Gene Silencing Activities of siRNA Polyplexes Containing Pyridylthiourea-Grafted Polyethylenimines. J Control Release 2014, 182, 1-12.

(21) Sousa, A. A.; Morgan, J. T.; Brown, P. H.; Adams, A.; Jayasekara, M. P. S.; Zhang, G.; Ackerson, C. J.; Kruhlak, M. J.; Leapman, R. D. Synthesis, Characterization, and Direct Intracellular Imaging of Ultrasmall and Uniform Glutathione-Coated Gold

Nanoparticles. Small 2012, 8 (14), 2277-2286.

(22) Zuber, G.; Dontenwill, M.; Behr, J.-P. Synthetic Viruslike Particles for Targeted Gene Delivery to Alphavbeta3 Integrin-Presenting Endothelial Cells. Mol. Pharm. 2009, 6 (5), 1544-1552.

(23) Smith, C. V.; Jones, D. P.; Guenthner, T. M.; Lash, L. H.; Lauterburg, B. H. Compartmentation of Glutathione: Implications for the Study of Toxicity and Disease. Toxicol. Appl. Pharmacol. 1996, 140 (1), 1-12.

(24) Hong, R.; Han, G.; Fernández, J. M.; Kim, B.-J.; Forbes, N. S.; Rotello, V . M. Glutathione-Mediated Delivery and Release Using Monolayer Protected Nanoparticle Carriers. J. Am. Chem. Soc. 2006, 128 (4), 1078-1079.

(25) Zhu, Z.-J.; Tang, R.; Yeh, Y.-C.; Miranda, O. R.; Rotello, V. M.; Vachet, R. W. Determination of the Intracellular Stability of Gold Nanoparticle Monolayers Using Mass Spectrometry. Anal. Chem. 2012, 84 (10), 4321-4326.

(26) Gao, Y. Ligand Effects of Thiolate-Protected Au 102Nanoclusters. J. Phys. Chem.C 2013, 117 (17), 8983-8988.

(27) Zhan, N.; Palui, G.; Safi, M.; Ji, X.; Mattoussi, H. Multidentate Zwitterionic Ligands Provide Compact and Highly Biocompatible Quantum Dots. J. Am. Chem. Soc. 2013, 135 (37), 13786-13795.

(28) Huo, S.; Jiang, Y.; Jiang, Z.; Landis, R. F.; Liang, X.-J.; Rotello, V. M. Stable and 
To cite : Desplancq, D.; Groysbeck, N.; Chiper, M.; Weiss, E.; Frisch, B.; Strub, J.-M.; Cianferani, S.; Zafeiratos, S.; Moeglin, E.; Holy, X.; et al. Cytosolic Diffusion and Peptide-Assisted Nuclear Shuttling of Peptide-Substituted Circa 102 Gold Atom Nanoclusters in Living Cells. ACS Applied Nano Materials 2018, 1, 4236-4246. Doi :

10.1021/acsanm.8b00988

Oxidant Responsive Zwitterionic Nanoclusters. Nanoscale 2018, 10 (16), 7382-7386.

(29) Ellman, G. L. Tissue Sulfhydryl Groups. Arch. Biochem. Biophys . 1959, 82 (1), 70-77.

(30) Shivhare, A.; Ambrose, S. J.; Zhang, H.; Purves, R. W.; Scott, R. W. J. Stable and Recyclable Au 25clusters for the Reduction of 4-Nitrophenol. Chem. Commun. 2013, 49 (3), 276-278.

(31) Levi-Kalisman, Y.; Jadzinsky, P. D.; Kalisman, N.; Tsunoyama, H.; Tsukuda, T.; Bushnell, D. A.; Kornberg, R. D. Synthesis and Characterization of $\mathrm{Au}_{102}(P-\mathrm{Mba})_{44}$ Nanoparticles. J. Am. Chem. Soc. 2011, 133 (9), 2976-2982. Lahtinen, T.; Hulkko, E.; Solkolowska, K.; Tero, T.-R.; Saarnio, V.; Lindgren, J.; Pettersson, M.; Häkkinen, H.; Lehtovaara, L. Covalently Linked Multimers of Gold

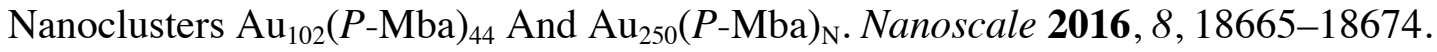

(33) Castner, D. G.; Hinds, K.; Grainger, D. W. X-Ray Photoelectron Spectroscopy Sulfur 2p Study of Organic Thiol and Disulfide Binding Interactions with Gold Surfaces. Langmuir 1996, 12 (21), 5083-5086.

(34) Salorinne, K.; Malola, S.; Wong, O. A.; Rithner, C. D.; Chen, X.; Ackerson, C. J.; Häkkinen, H. Conformation and Dynamics of the Ligand Shell of a Water-Soluble Au. Nat. Commun 2016, 7, 1-8.

(35) Dubochet, J.; Adrian, M.; Chang, J. J.; Homo, J. C.; Lepault, J.; McDowall, A. W.; Schultz, P. Cryo-Electron Microscopy of Vitrified Specimens. Q. Rev. Biophys. 1988, 21 (2), 129-228.

(36) Stevens, J. S.; de Luca, A. C.; Pelendritis, M.; Terenghi, G.; Downes, S.; Schroeder, S. L. M. Quantitative Analysis of Complex Amino Acids and RGD Peptides by X-Ray Photoelectron Spectroscopy (XPS). Surf. Interface Anal. 2013, 45 (8), 1238-1246.

(37) Stevens, J. S.; Byard, S. J.; Seaton, C. C.; Sadiq, G.; Davey, R. J.; Schroeder, S. L. M. Proton Transfer and Hydrogen Bonding in the Organic Solid State: a Combined XRD/XPS/ssNMR Study of 17 Organic Acid-Base Complexes. Phys. Chem. Chem. Phys. 2014, 16 (3), 1150-1160.

(38) Visikovskiy, A.; Matsumoto, H.; Mitsuhara, K.; Nakada, T.; Akita, T.; Kido, Y. Electronic D-Band Properties of Gold Nanoclusters Grown on Amorphous Carbon. Phys. Rev. B 2011, 83, 165428.

(39) Manikyam, D. S.; Sundaram, E. V. Thermal Decarboxylation of Nitrobenzoic Acids. I. Bull. Chem. Soc. Jpn. 1970, 43, 3651-3652.

(40) Qian, H.; Zhu, M.; Gayathri, C.; Gil, R. R.; Jin, R. Chirality in Gold Nanoclusters Probed by NMR Spectroscopy. ACS Nano 2011, 5 (11), 8935-8942.

(41) Lévy, R.; Thanh, N. T. K.; Doty, R. C.; Hussain, I.; Nichols, R. J.; Schiffrin, D. J.; Brust, M.; Fernig, D. G. Rational and Combinatorial Design of Peptide Capping Ligands for Gold Nanoparticles. J. Am. Chem. Soc. 2004, 126 (32), 10076-10084.

(42) Kalderon, D.; Roberts, B. L.; Richardson, W. D.; Smith, A. E. A Short Amino-Acid Sequence Able to Specify Nuclear Location. Cell 1984, 39 (3), 499-509.

(43) Wen, W.; Meinkoth, J. L.; Tsien, R. Y.; Taylor, S. S. Identification of a Signal for Rapid Export of Proteins From the Nucleus. Cell 1995, 82 (3), 463-473.

(44) Freund, G.; Sibler, A.-P.; Desplancq, D.; Oulad-Abdelghani, M.; Vigneron, M.; Gannon, J.; Van Regenmortel, M. H.; Weiss, E. Targeting Endogenous Nuclear Antigens by Electrotransfer of Monoclonal Antibodies in Living Cells. mAbs 2014, 5 (4), 518-522. Creusat, G.; Thomann, J.-S.; Maglott, A.; Pons, B.; Dontenwill, M.; Guérin, E.; Frisch, B.; Zuber, G. Pyridylthiourea-Grafted Polyethylenimine Offers an Effective Assistance 
To cite : Desplancq, D.; Groysbeck, N.; Chiper, M.; Weiss, E.; Frisch, B.; Strub, J.-M.; Cianferani, S.; Zafeiratos, S.; Moeglin, E.; Holy, X.; et al. Cytosolic Diffusion and Peptide-Assisted Nuclear Shuttling of Peptide-Substituted Circa 102 Gold Atom Nanoclusters in Living Cells. ACS Applied Nano Materials 2018, 1, 4236-4246. Doi :

10.1021/acsanm.8b00988

to siRNA-Mediated Gene Silencing in Vitro and in Vivo. J Control Release 2012, 157 (3), 418-426.

(46) Fraley, A. W.; Pons, B.; Dalkara, D.; Nullans, G.; Behr, J.-P.; Zuber, G. Cationic Oligonucleotide-Peptide Conjugates with Aggregating Properties Enter Efficiently Into Cells While Maintaining Hybridization Properties and Enzymatic Recognition. J. Am. Chem. Soc. 2006, 128 (33), 10763-10771.

(47) Maity, A. R.; Stepensky, D. Journal of Controlled Release. J Control Release 2017, 257 (C), 32-39.

(48) Kudo, N.; Wolff, B.; Sekimoto, T.; Schreiner, E. P.; Yoneda, Y.; Yanagida, M.; Horinouchi, S.; Yoshida, M. Leptomycin B Inhibition of Signal-Mediated Nuclear Export by Direct Binding to CRM1. Exp. Cell.Res. 1998, 242 (2), 540-547.

(49) Maul, G. G.; Deaven, L. Quantitative Determination of Nuclear Pore Complexes in Cycling Cells with Differing DNA Content. J. Cell Biol. 1977, 73 (3), 748-760.

(50) Walter, M.; Akola, J.; Lopez-Acevedo, O.; Jadzinsky, P. D.; Calero, G.; Ackerson, C. J.; Whetten, R. L.; Grönbeck, H.; Häkkinen, H. A Unified View of Ligand-Protected Gold Clusters as Superatom Complexes. Proc. Natl. Acad. Sci. U.S.A. 2008, 105 (27), 91579162.

(51) la Fuente, de, J. M.; Berry, C. C. Tat Peptide as an Efficient Molecule to Translocate Gold Nanoparticles Into the Cell Nucleus. Bioconjug. Chem. 2005, 16 (5), 1176-1180.

(52) Sun, L.; Liu, D.; Wang, Z. Functional Gold Nanoparticle-Peptide Complexes as CellTargeting Agents. Langmuir 2008, 24 (18), 10293-10297.

(53) Kang, B.; Mackey, M. A.; El-Sayed, M. A. Nuclear Targeting of Gold Nanoparticles in Cancer Cells Induces DNA Damage, Causing Cytokinesis Arrest and Apoptosis. J. Am. Chem. Soc. 2010, 132 (5), 1517-1519.

(54) Yang, C.; Uertz, J.; Yohan, D.; Chithrani, B. D. Peptide Modified Gold Nanoparticles for Improved Cellular Uptake, Nuclear Transport, and Intracellular Retention. Nanoscale 2014, 6, 12026-12033.

(55) Luo, W.; Zafeiratos, S. Tuning Morphology and Redox Properties of Cobalt Particles Supported on Oxides by an in Between Graphene Layer. J. Phys. Chem. C 2016, 120 (26), 14130-14139.

(56) Zafeiratos, S.; Kennou, S. A Study of Gold Ultrathin Film Growth on Yttria-Stabilized $\mathrm{ZrO}_{2}(100)$. Surface Science 1999, 443 (3), 238-244.

(57) Chiper, M.; Tounsi, N.; Kole, R.; Kichler, A.; Zuber, G. Self-Aggregating 1.8kDa Polyethylenimines with Dissolution Switch at Endosomal Acidic pH Are Delivery Carriers for Plasmid DNA, mRNA, siRNA and Exon-Skipping Oligonucleotides. $J$ Control Release 2017, 246, 60-70.

(58) Danscher, G.; Nörgaard, J. O. Light Microscopic Visualization of Colloidal Gold on Resin-Embedded Tissue. J. Histochem. Cytochem. 1983, 31 (12), 1394-1398.

(59) Burry, R. W.; Vandre, D. D.; Hayes, D. M. Silver Enhancement of Gold Antibody Probes in Preembedding Electron-Microscopic Immunocytochemistry. J. Histochem. Cytochem. 1992, 40 (12), 1849-1856. 
To cite : Desplancq, D.; Groysbeck, N.; Chiper, M.; Weiss, E.; Frisch, B.; Strub, J.-M.; Cianferani, S.; Zafeiratos, S.; Moeglin, E.; Holy, X.; et al. Cytosolic Diffusion and Peptide-Assisted Nuclear Shuttling of Peptide-Substituted Circa 102 Gold Atom Nanoclusters in Living Cells. ACS Applied Nano Materials 2018, 1, 4236-4246. Doi :

10.1021/acsanm.8b00988

TOC Graphic

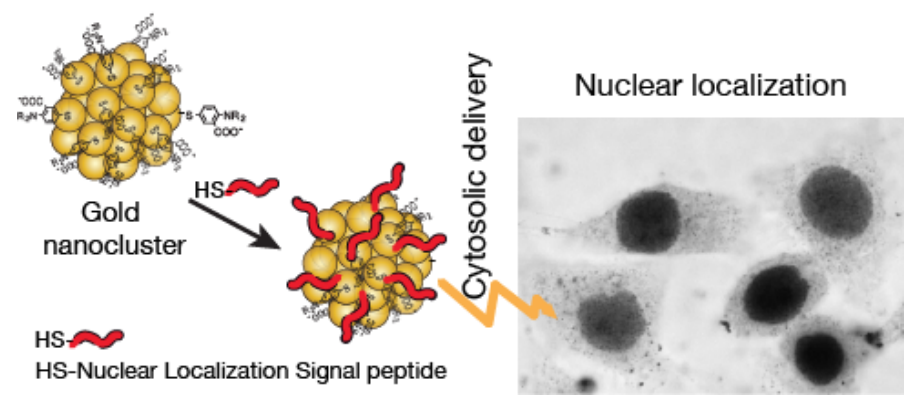




\section{Supporting Information}

\section{Table of content}

Complement to materials and methods

Table S1. Sequence of peptides

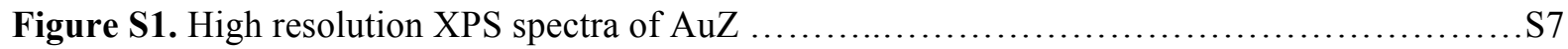

Figure S2. Thermogravimetric curve and derivative weight change curve of the AuZ .............S8

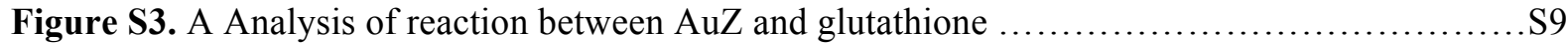

Figure S4. MALDI-TOF Mass spectra of AuGS, AudNLS, AuCap and AuNES ....................S10

Figure S5. MTT Cell viability assay using the HFF-1 normal cell line.......................... 11

Figure S6. Images of U2OS cells incubated for 24h with peptide-substituted AuNCs ..............S12

Figure S7. Images of HFF-1 cells incubated for 24h with peptide-substituted AuNCs..............S13

Figure S8. TEM of untreated HeLa cells..................................................

Figure S9. Synthesis of peptide-grafted gold nanoparticle from citrate-gold nanoparticle ...........S15

Figure S10. Reactivity and delivery of NLS-grafted gold nanoclusters from AuMBA...............S16

Figure S11. Evaluation of the intracellular fate of peptide-subtituted $4.5 \mathrm{~nm}$ nanoparticles ...........S17

Figure S12. Fluorescence emission spectra of the AuZ and AuGS nanoclusters...................S18

Figure S13. HPLC profile and mass spectrometry analysis of the Cap peptide........................ 19

Figure S14. HPLC profile and mass spectrometry analysis of the NLS peptide ....................S20

Figure S15. HPLC profile and mass spectrometry analysis of the dNLS peptide.................S21

Figure S16. HPLC profile and mass spectrometry analysis of the NES peptide....................S22

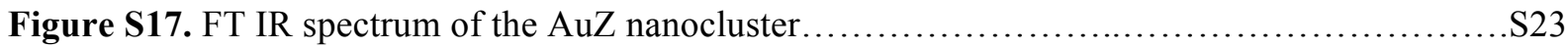


To cite : Desplancq, D.; Groysbeck, N.; Chiper, M.; Weiss, E.; Frisch, B.; Strub, J.-M.; Cianferani, S.; Zafeiratos, S.; Moeglin, E.; Holy, X.; et al. Cytosolic Diffusion and Peptide-Assisted Nuclear Shuttling of Peptide-Substituted Circa 102 Gold Atom Nanoclusters in Living Cells. ACS Applied Nano Materials 2018, 1, 4236-4246. Doi :

10.1021/acsanm.8b00988

Figure S18. FT IR spectrum of the AuGS nanocluster. S24

Figure S19. FT IR spectrum of the AuCap nanocluster. S25

Figure S20. FT IR spectrum of the AuNLS nanocluster. S26

Figure S21. FT IR spectrum of the AudNLS nanocluster. S27

Figure S22. FT IR spectrum of the AuNES nanocluster. . $\mathrm{S} 28$

Figure S23. Synthesis of Alexa488-labeled AuNLS. S29

Figure S24. Characterization of Alexa488-labeled AuNLS S30

Figure S25. Analysis of fate of Alexa488-labeled AuNLS after addition to HFF-1 cells S31

Figure S26. Color images of HeLa cells incubated with AuCap, AuNLS and AudNLS.... . $\mathrm{S} 32$

Figure S27. Color images of HeLa cells incubated with AuNES S33

References .S34 
To cite : Desplancq, D.; Groysbeck, N.; Chiper, M.; Weiss, E.; Frisch, B.; Strub, J.-M.; Cianferani, S.; Zafeiratos, S.; Moeglin, E.; Holy, X.; et al. Cytosolic Diffusion and Peptide-Assisted Nuclear Shuttling of Peptide-Substituted Circa 102 Gold Atom Nanoclusters in Living Cells. ACS Applied Nano Materials 2018, 1, 4236-4246. Doi :

10.1021/acsanm.8b00988

\section{Complement to Materials and Methods}

\section{Chemicals}

5,5'-dithio-bis(2-nitrobenzoic acid)(DTNB) (Sigma-Aldrich D8130)

Hydrogen tetrachloroaurate(III) trihydrate (Sigma-Aldrich 520918-1G)

Sodium borohydride $\left(\mathrm{NaBH}_{4}\right)$ (Aldrich 45,288-2)

Sodium hydroxide (Fluka 71691)

4-(2-Hydroxyethyl)-piperazine-1-ethanesulfonic acid, N-(2-Hydroxyethyl)piperazine-N'-(2ethanesulfonic acid) (HEPES) (Euromedex 10-110)

Trishydroxymethylaminomethane base (Tris) (Euromedex, 26-128-3094B)

Glycine (Gly)(Euromedex 26-128-6405C)

Peptides were purchased from GeneCust (Dudelange, Luxembourg)

Glutathione reduced (GSH) (Sigma G6013-5g)

Methanol (Sigma-Aldrich 179957-5L)

Water Bi-distilled

Tris(2-carboxyethyl)phosphine hydrochloride (Sigma-Aldrich BioUltra 75259)

Ammonium hydroxide 28\% (EMS cat\#10600 EMS group, Hatfield, PA, USA)

Glutaraldehyde 25\% solution EM grade (EMS cat\#16220, EMS group, Hatfield, PA, USA)

HSPEG (Code PEG1169-0005, MW 2015Da, Iris Biotech, Germany)

Materials. The pH-meter was a Hanna HI2210 instrument combined with a HI 1131B electrode. Centrifugation of $50 \mathrm{~mL}$ solutions was performed using an Eppendorf 5810R centrifuge and the rotor A-4-81. Centrifugation of small volumes (0.5 to $2 \mathrm{~mL})$ was performed using a Sigma 1$15 \mathrm{~K}$ Eppendorf centrifuge with a 12132-H rotor. For gold particle formation, agitation was performed on a rocking platform (Heidolph Rotamax 120). The Nuclear Magnetic Resonance (NMR) data were taken with a Bruker DPX $400 \mathrm{MHz}$ spectrometer. The UV-vis absorbance spectra were recorded using a Varian Cary 100Bio spectrometer. Nanoparticles were purified and concentrated using $0.5 \mathrm{~mL}$ Microcon ${ }^{\circledR}$ centrifugal filters (Merck, Molsheim) with cut-off of 10 or $30 \mathrm{kDa}$ according to the manufacturer's specification. The spectrofluorometer was a Xenius Safas (Monaco, France). 
To cite : Desplancq, D.; Groysbeck, N.; Chiper, M.; Weiss, E.; Frisch, B.; Strub, J.-M.; Cianferani, S.; Zafeiratos, S.; Moeglin, E.; Holy, X.; et al. Cytosolic Diffusion and Peptide-Assisted Nuclear Shuttling of Peptide-Substituted Circa 102 Gold Atom Nanoclusters in Living Cells. ACS Applied Nano Materials 2018, 1, 4236-4246. Doi :

10.1021/acsanm.8b00988

\section{Devices}

Small volumes of aqueous solutions were dispensed using pipettes (Gilson Pipetman ${ }^{\circledR}$ classic P10, P100, P1000 models). Large volumes were dispensed using serological pipettes (Falcon® 5 10 or $25 \mathrm{~mL}$ ) and a single channel Omega Pipettor (Argos Technologies Inc, Elgin IL). Reactions were performed unless indicated in polypropylene tubes of different volumes $(50 \mathrm{~mL}$, $15 \mathrm{~mL}, 2.0 \mathrm{~mL}, 1.5 \mathrm{~mL}$ or $0.5 \mathrm{~mL}$ ).

\section{Preparation of aqueous stock solutions}

- Peptides were made at $10 \mathrm{mM}$ concentration in water and stored in aliquots at $-20^{\circ} \mathrm{C}$.

- Tris(2-carboxyethyl)phosphine (TCEP), $0.1 \mathrm{M}$ solution, $\mathrm{pH} 7.4$ was prepared by incremental addition of $2 \mathrm{M} \mathrm{NaOH}$ to a $0.2 \mathrm{M}$ TCEP hydrochloride $\left(286.65 \mathrm{mg}\right.$ in $5 \mathrm{~mL} \mathrm{H}_{2} \mathrm{O}$ ) solution under stirring and by monitoring $\mathrm{pH}$ increase with a $\mathrm{pH}$-meter. When the $\mathrm{pH}$ reached 7.4 , the TCEP solution was set at $0.1 \mathrm{M}$ and stored in aliquots at $-20^{\circ} \mathrm{C}$.

- 4-(2-Hydroxyethyl)-piperazine-1-ethanesulfonic acid, N-(2-Hydroxyethyl)piperazine-N'-(2ethanesulfonic acid) (HEPES) (23.83 g, $0.1 \mathrm{~mol})$ was dissolved in water $(50 \mathrm{~mL})$. The $\mathrm{pH}$ was adjusted to $\mathrm{pH} 7.4$ with incremental addition of $1 \mathrm{M} \mathrm{NaOH}$ and using a $\mathrm{pH}$-meter. The solution was then adjusted to $100 \mathrm{~mL}$ and was filtered for sterilization using a $33 \mathrm{~mm}$ syringe-driven filter unit (0.22 $\mu \mathrm{m}$ Millex-GP, Millipore, Molsheim France). The 1M HEPES-Na solution pH 7.4 was stored at $4-8^{\circ} \mathrm{C}$.

- Hydrogen tetrachloroaurate(III) trihydrate $\left(\mathrm{HAuCl}_{4}-3 \mathrm{H}_{2} \mathrm{O}\right)(1 \mathrm{~g}, 2.539 \mathrm{mmol})$ was dissolved in water $(6.35 \mathrm{~mL})$ to a final concentration of $0.4 \mathrm{M}$ in aurate. This stock solution was stored at 4$6^{\circ} \mathrm{C}$ in a brown vial and can be stored for more than 6 months.

- The $2 \mathrm{M}$ ammonium acetate solution was buffered to $\mathrm{pH} 4.7$ with $2 \mathrm{M}$ acetic acid solution using a $\mathrm{pH}-$ meter.

- 5,5'-dithio-bis(2-nitrobenzoic acid) (DTNB) (198.2 mg, $50 \mu \mathrm{mol}$ ) was dissolved in $0.3 \mathrm{M}$ aqueous $\mathrm{NaOH}$ solution $(10 \mathrm{~mL})$ to a final $50 \mathrm{mM}$ DTNB concentration. The orange solution was used within $48 \mathrm{~h}$ and stored at $4-6^{\circ} \mathrm{C}$ in the dark when not freshly used.

- Glutathione (GST) solutions were freshly prepared in water and buffered to pH 7.0 using 0.3 M $\mathrm{NaOH}$. For the ESI-MS analysis, the glutathione was buffered to $\mathrm{pH} 7.8$ using $\mathrm{NH}_{4} \mathrm{OH}$.

- The $133 \mathrm{mM}$ Sorenson's buffer, $\mathrm{pH} 7.4$ was prepared by combining $133 \mathrm{mM} \mathrm{Na} 2 \mathrm{HPO}_{4}(804$ $\mathrm{mL})$ with $133 \mathrm{mM} \mathrm{KH}{ }_{2} \mathrm{PO}_{4}(196 \mathrm{~mL})$. After verification of the $\mathrm{pH}$ with the $\mathrm{pH}$-meter, the solution was filtered for sterilization using a $33 \mathrm{~mm}$ syringe-driven filter unit $(0.22 \mu \mathrm{m}$ MillexGP, Millipore, Molsheim France).

- The TEM storage solution was a $0.1 \mathrm{M}$ Sodium cacodylate buffer, $\mathrm{pH} 7.2$ containing $2 \%(\mathrm{w} / \mathrm{v})$ sucrose, $1 \mathrm{mM} \mathrm{MgCl} 2$ and $1 \mathrm{mM} \mathrm{CaCl}_{2}$. The solution was filtered for sterilization using a $33 \mathrm{~mm}$ syringe-driven filter unit $\left(0.22 \mu \mathrm{m}\right.$ Millex-GP, Millipore, Molsheim France) and stored at $4-6^{\circ} \mathrm{C}$. 
To cite : Desplancq, D.; Groysbeck, N.; Chiper, M.; Weiss, E.; Frisch, B.; Strub, J.-M.; Cianferani, S.; Zafeiratos, S.; Moeglin, E.; Holy, X.; et al. Cytosolic Diffusion and Peptide-Assisted Nuclear Shuttling of Peptide-Substituted Circa 102 Gold Atom Nanoclusters in Living Cells. ACS Applied Nano Materials 2018, 1, 4236-4246. Doi :

10.1021/acsanm.8b00988

Estimation of the absorption coefficient of the gold nanocluster. The dried AuZ pellet (4.2 $\mathrm{mg})$ was dissolved in water $(350 \mu \mathrm{L})$ and the solution $\mathrm{pH}$ was adjusted to 7.0 by addition of 50 $\mathrm{mM}$ aqueous $\mathrm{NH}_{4} \mathrm{OH}$ to a final concentration of $11.28 \mathrm{~g} \mathrm{x} \mathrm{L}^{-1}$. Aliquots $(1 \mu \mathrm{L}$ volume $)$ were withdrawn and diluted with water (final volume of $700 \mu \mathrm{L}$ ) giving a concentration of 16.114 $\mathrm{mg} / \mathrm{L}$. An optical density (OD) of 0.153 at $520 \mathrm{~nm}$ was measured using a $1 \mathrm{~cm}$-path quartz cuvette. Using the Beer-Lambert equation $(\mathrm{OD}=\varepsilon 1 \mathrm{c})$ and an estimated molecular mass of $28382 \mathrm{Da}\left(\mathrm{Au}_{102} \mathrm{TAB}_{30} \mathrm{TNB}_{14}\right)$, extinction coefficients $\left(\varepsilon_{520}\right)$ of $9.51 \mathrm{~g}^{-1} \mathrm{~L} \mathrm{x} \mathrm{cm}^{-1}$ and $2.7 \times 10^{5}$ $\mathrm{mol}^{-1} \mathrm{x} \mathrm{L} \mathrm{x} \mathrm{cm}^{-1}$ were determined.

Preparation of gold nanoparticles. The citrate-stabilized gold nanoparticles were prepared according to a described procedure. ${ }^{1}$ After preparation, the particles were purified and concentrated using the $0.5 \mathrm{~mL}$ Microcon ${ }^{\circledR}$ centrifugal filters (cut-off: $100 \mathrm{kDa}$ ). Particle concentration was estimated at $116 \mathrm{nM}$ by UV/vis spectrometry using the nanoparticle absorption at $509 \mathrm{~nm}$. Next, the gold particles $(0.2 \mathrm{nmol})$ were reacted with the Cap peptide (32 nmol), HSPEG (32 nmol), Cap/HSNLS (9/1) mixture (32 nmol total) and Cap/HSNLS (9/1) mixture (32 nmol total) in $150 \mathrm{mM} \mathrm{K}_{2} \mathrm{CO}_{3}$ for $24 \mathrm{~h}$ at room temperature. The particles were then purified and concentrated using the $0.5 \mathrm{~mL}$ Microcon ${ }^{\circledR}$ centrifugal filters (cut-off: $100 \mathrm{kDa}$ ). Concentrations of the peptide-grafteraqueous solutions were spectrophotometrically estimated and set at $4 \mu \mathrm{M}$.

PolyAcrylamide Gel Electrophoresis. 10\% Polyacrylamide Gels (1 mm thick) were casted using the BioRad MiniProtean system in $25 \mathrm{mM}$ Tris- $186 \mathrm{mM}$ glycine buffer $\mathrm{pH} 8.3$ containing $0.1 \%(\mathrm{w} / \mathrm{v})$ Sodium Dodecyl Sulfate (SDS). For electrophoresis, the running buffer was $25 \mathrm{mM}$ Tris-186 mM glycine buffer $\mathrm{pH} 8.3$ containing $0.1 \%$ SDS unless indicated otherwise. The polyacrylamide gel was pre-run for $20 \mathrm{~min}$ at $90 \mathrm{~V}$. For loading in the wells, $50 \%(\mathrm{v} / \mathrm{v})$ glycerol in water was diluted to $10 \%$ into samples (5-10 $\mu \mathrm{L}$ volume; $40 \mathrm{nmol}$ in AuNC). The electrophoresis was run at room temperature for 45 minutes at $90 \mathrm{~V}$. The gold nanoclusters were observed as black-brown bands. Peptides were visualized after Coomassie blue staining.

Thermal Gravimetric Analyses. The analysis was performed on a Q 5000IR apparatus (TA Instruments) under a flow of nitrogen on vacuum-dried particles $(0.2990 \mathrm{mg})$ and at a heating rate of $10^{\circ} \mathrm{C} / \mathrm{min}$.

Electron Microscopy. Imaging of cells and peptide-modified AuNCs was performed using a FEI G2 F20 Transmission Electron Microscope operating at $200 \mathrm{kV}$. Image acquisition was performed on a 2048 x 2048 CCD camera (Ultrascan 1000, Gatan Inc., Pleasanton) by collecting 25 adjacent images using the SerialEM software (Boulder, Colorado, USA). The final image was reconstructed by stitching the adjacent images using the Montage plugin package (Jean Daraspe, Université de Lausanne, Switzerland) and the iMod software. ${ }^{2}$

For standard-EM imaging of isolated nanoparticles, $10 \mu \mathrm{L}$ of a $5 \mu \mathrm{M}$ nanocluster solution was 
To cite : Desplancq, D.; Groysbeck, N.; Chiper, M.; Weiss, E.; Frisch, B.; Strub, J.-M.; Cianferani, S.; Zafeiratos, S.; Moeglin, E.; Holy, X.; et al. Cytosolic Diffusion and Peptide-Assisted Nuclear Shuttling of Peptide-Substituted Circa 102 Gold Atom Nanoclusters in Living Cells. ACS Applied Nano Materials 2018, 1, 4236-4246. Doi :

10.1021/acsanm.8b00988

applied onto the ultrathin carbon support film of 100 Mesh EM grids (UMC Utrecht, The Netherlands). After 1 min. adsorption, the excess liquid was removed with a filter paper.

For cryo-EM imaging, samples $(3 \mu \mathrm{L})$ of $10 \mu \mathrm{M}$ AuNC solution in $10 \mathrm{mM}$ HEPES, pH 7.4 were applied to lacey carbon grids, blotted with filter paper from both sides for half a second in the temperature- and humidity-controlled Vitrobot Mark IV apparatus (FEI, Eindhoven, Netherlands, $\mathrm{T}=20^{\circ} \mathrm{C}$, humidity $95 \%$, Blot Force 5 , Blot time $0.5 \mathrm{sec}$ ) and plunge-frozen in liquid ethane precooled by liquid nitrogen to embed the complex in a thin film of vitrified buffer spanning the holes of the carbon film. Images were collected at liquid nitrogen temperature with a FEI Titan Krios EM operating at $300 \mathrm{kV}$ with a dose of 20 electrons per $\AA^{2}$ using a FEI Falcon II Camera with pixel size of $0.8936 \AA$, integration time $1 \mathrm{~s}$, bining 1 and defocus of $-0.5 \mu \mathrm{m}$.

MALDI-TOF mass spectrometry. Mass measurements were carried out on an Autoflex ${ }^{\mathrm{TM}}$ MALDI-TOF mass spectrometer (Bruker Daltonics GmbH, Bremen, Germany). This instrument was used at a maximum accelerating potential of $20 \mathrm{kV}$ in positive mode and was operated in linear mode at $19 \mathrm{kV}$. The delay extraction was fixed at $80 \mathrm{~ns}$ and the frequency of the laser (nitrogen $337 \mathrm{~nm}$ ) was set at $5 \mathrm{~Hz}$. The acquisition mass range was set to $5000-30000 \mathrm{~m} / \mathrm{z}$ with a matrix suppression deflection (cut-off) set to $500 \mathrm{~m} / \mathrm{z}$. The equipment was externally calibrated with a standard protein calibration mixture that contained 5 proteins (Bruker Protein Standard II \#8207234, Bruker Daltonics GmbH, Bremen, Germany) covering the 10,000-70,000 m/z range. Each raw spectrum was opened with flexAnalysis 2.4 build 11 (Bruker Daltonics $\mathrm{GmbH}$, Bremen, Germany) software. Sample preparation was performed with the dried droplet method using a mixture of $0.5 \mu 1$ of sample with $0.5 \mu 1$ of matrix solution dried at room temperature. The matrix solution was prepared from a saturated solution of $\alpha$-cyano-4-hydroxycinnamic acid in water/acetonitrile 50/50 diluted three fold in water/acetonitrile/trifluoroacetic acid 50/49.9/0.1.

Cell culture. The HeLa (ATCC CCL2) and U2OS (ATCC HTB-96) human cancer cell lines and the non-cancer human fibroblast HFF-1 cell line (ATCC SCRC-1041) were maintained in Dulbecco's modified Eagles tissue culture medium (DMEM) supplemented with 10\% heat inactivated FCS (Life Technologies), $2 \mathrm{mM} \mathrm{L-glutamine} \mathrm{and} \mathrm{antibiotics.} \mathrm{Cells} \mathrm{were} \mathrm{grown} \mathrm{in}$ humidified atmosphere at $37^{\circ} \mathrm{C}$ and with $5 \% \mathrm{CO}_{2}$. Cells were maintained in culture for less than 12 passages. 
To cite : Desplancq, D.; Groysbeck, N.; Chiper, M.; Weiss, E.; Frisch, B.; Strub, J.-M.; Cianferani, S.; Zafeiratos, S.; Moeglin, E.; Holy, X.; et al. Cytosolic Diffusion and Peptide-Assisted Nuclear Shuttling of Peptide-Substituted Circa 102 Gold Atom Nanoclusters in Living Cells. ACS Applied Nano Materials 2018, 1, 4236-4246. Doi :

Table S1. Sequence of peptides used for preparing Peptide-grafted AuZ gold clusters

\begin{tabular}{|c|l|l|c|l|}
\hline Abbre & Activity & Sequence (N->C) & $\begin{array}{c}\text { Molecular } \\
\text { mass } \\
\left(\mathrm{g}^{-\mathrm{mol}^{-1}}\right)\end{array}$ & Reference \\
\hline GSH & Passivation & $\gamma$-ECG (Glutathione) & 307.32 & 3,4 \\
\hline Cap & Protection & CALNNG & 590.65 & 5 \\
\hline NLS & Nuclear import & CALNNGAGPKKKRKVED & 1828.13 & 6 \\
\hline dNLS & $\begin{array}{l}\text { Defective } \\
\text { nuclear import }\end{array}$ & CALNNGAGPKTKRKVED & 1801.06 & 6 \\
\hline NES & Nuclear export & CALNNGLALKLAGLDINKT amide & 1941.33 & 7 \\
\hline
\end{tabular}


To cite : Desplancq, D.; Groysbeck, N.; Chiper, M.; Weiss, E.; Frisch, B.; Strub, J.-M.; Cianferani, S.; Zafeiratos, S.; Moeglin, E.; Holy, X.; et al. Cytosolic Diffusion and Peptide-Assisted Nuclear Shuttling of Peptide-Substituted Circa 102 Gold Atom Nanoclusters in Living Cells. ACS Applied Nano Materials 2018, 1, 4236-4246. Doi :
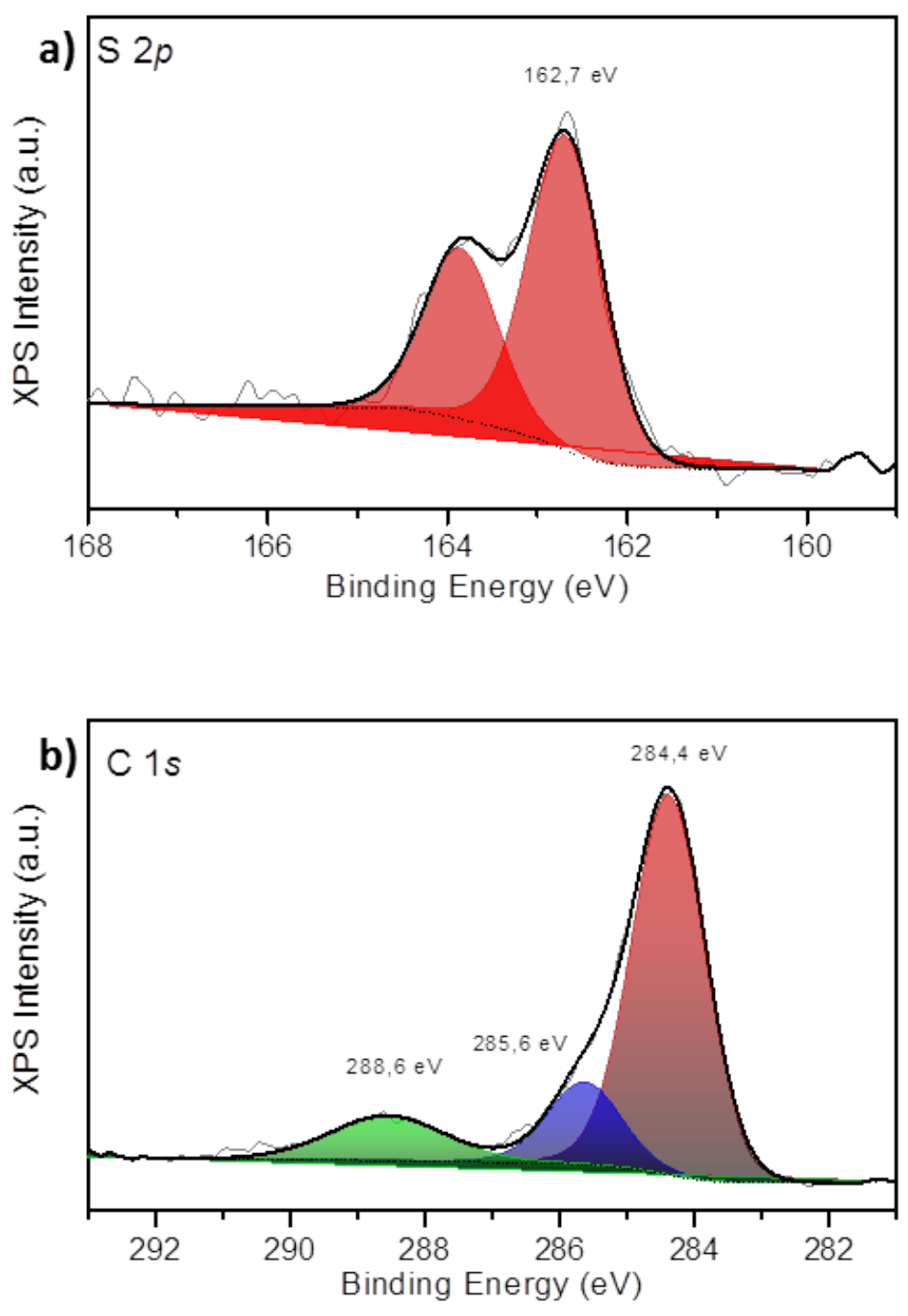

Figure S1. High resolution XPS spectra of AuZ particles a) S $2 p$ and b) C 1s. The S2p3/2 and $\mathrm{S} 2 \mathrm{p} 1 / 2$ peaks are consistent with most sulfur atoms being engaged in a coordination bond with the gold surface atoms ${ }^{8}$ The $\mathrm{C} 1 \mathrm{~s}$ components at $284.4,285.6$ and $288.6 \mathrm{eV}$ are assigned to various carbon species $\mathrm{C}-\mathrm{C}, \mathrm{C}-\mathrm{O}-\mathrm{C}, \mathrm{C}-\mathrm{N}$ and $\mathrm{C}=\mathrm{O}, \mathrm{O}-\mathrm{C}=\mathrm{O}$ respectively, ${ }^{9}$ in good agreement with the expected carbon species in the organic coating. 
To cite : Desplancq, D.; Groysbeck, N.; Chiper, M.; Weiss, E.; Frisch, B.; Strub, J.-M.; Cianferani, S.; Zafeiratos, S.; Moeglin, E.; Holy, X.; et al. Cytosolic Diffusion and Peptide-Assisted Nuclear Shuttling of Peptide-Substituted Circa 102 Gold Atom Nanoclusters in Living Cells. ACS Applied Nano Materials 2018, 1, 4236-4246. Doi :

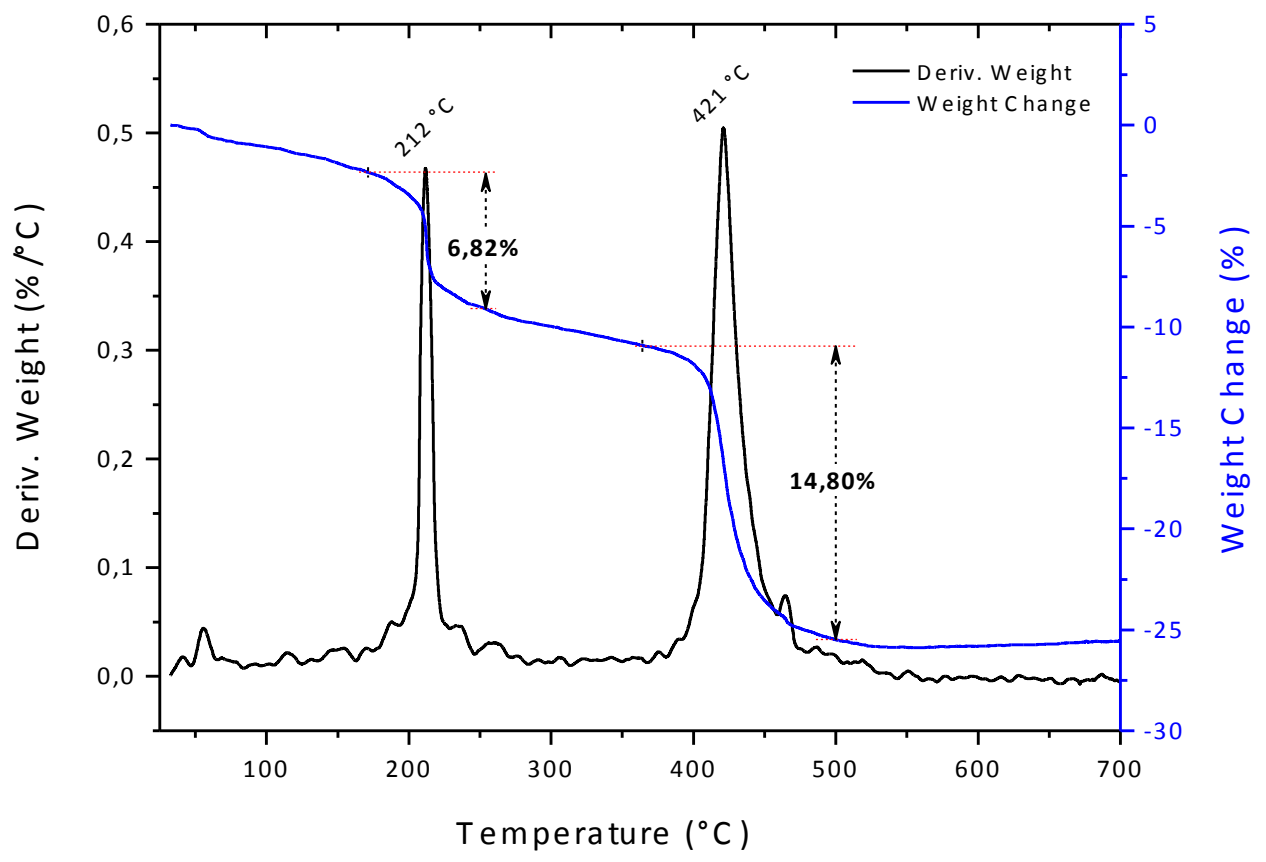

Figure S2. Thermogravimetric curve and derivative weight change curve of the AuZ. 
To cite : Desplancq, D.; Groysbeck, N.; Chiper, M.; Weiss, E.; Frisch, B.; Strub, J.-M.; Cianferani, S.; Zafeiratos, S.; Moeglin, E.; Holy, X.; et al. Cytosolic Diffusion and Peptide-Assisted Nuclear Shuttling of Peptide-Substituted Circa 102 Gold Atom Nanoclusters in Living Cells. ACS Applied Nano Materials 2018, 1, 4236-4246. Doi :

A. Survey of AuZ+GSH reaction using UV/vis absorbance

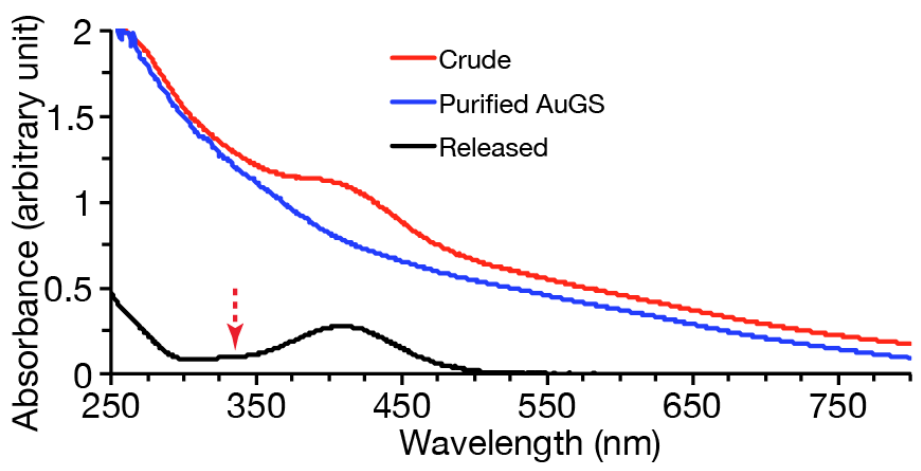

B. MS of $<10 \mathrm{kDa}$ species

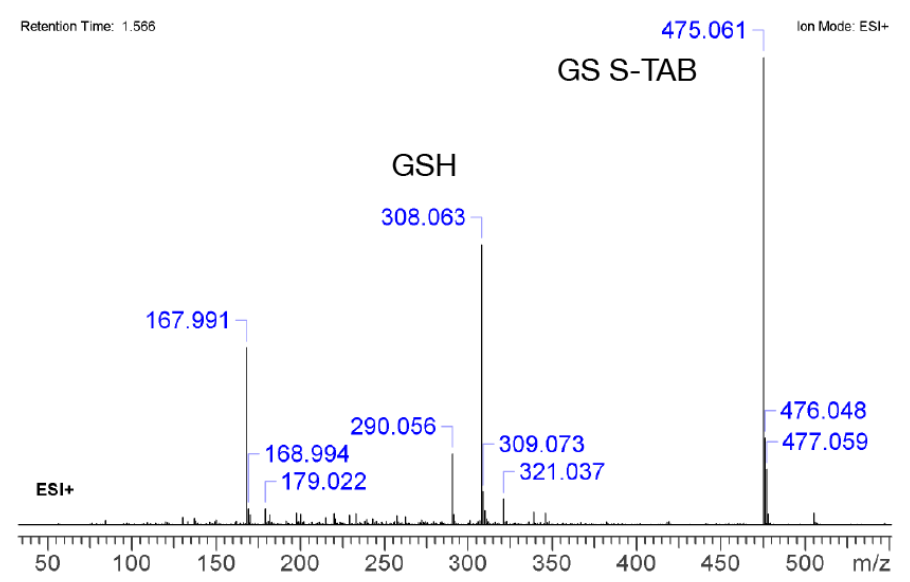

Figure S3. Analysis of reaction between $\mathrm{AuZ}$ and glutathione (GSH). A. UV/vis spectra of the crude reaction (red line), purified GSH-gold nanocluster (AuGS) (blue line) and released low molecular weight components (black line). The red dotted arrow pinpoints a novel absorption band. B. ElectroSpray Mass Spectrum of the released species after a 20h reaction of AuZ (45.6 nmol, $200 \mu \mathrm{L}$ of a $228 \mu \mathrm{M}$ solution) with Glutathione, $\mathrm{pH} 7.8(570 \mathrm{nmol}, 5.7 \mu \mathrm{L}$ of a $0.1 \mathrm{M}$ solution). The glutathione solution was freshly prepared and buffered by addition of $\mathrm{NH}_{4} \mathrm{OH}$. The gold clusters were separated from unreacted glutathione and released species using a $0.5 \mathrm{~mL}$ microcon-10 $\mathrm{kDa}$ centrifugal filter unit. The flow through contained a thionitrobenzoic acid (TNB) concentration of $848 \mu \mathrm{M}$ using the absorption coefficient of $14,150 \mathrm{M}^{-1} . \mathrm{cm}^{-1}$ at $412 \mathrm{~nm}$. The mass spectrum was taken 7 days after the reaction.

Comment. The UV/vis spectra of aliquots from the crude reaction, purified AuGS and released low molecular mass species were taken into the NMR spectroscopy survey (Figure 3B). The crude reaction (red line) exhibited now an UV/vis absorption spectrum corresponding to the sum of UV/vis absorption spectra of purified AuGS (blue line) and to released aqueous-soluble ligands (black line). The spectrum of the released species was analogous to the spectrum of TNB (Figure 1B) with the exception of a light shoulder (red dot arrow), indicating release of another ligand from the AuNCs. This absorption band is likely due to TAB. Using an absorption coefficient of $14150 \mathrm{M}^{-1} . \mathrm{cm}^{-1}$ at $412 \mathrm{~nm}$ for TNB, we estimated the concentration of released 
To cite : Desplancq, D.; Groysbeck, N.; Chiper, M.; Weiss, E.; Frisch, B.; Strub, J.-M.; Cianferani, S.; Zafeiratos, S.; Moeglin, E.; Holy, X.; et al. Cytosolic Diffusion and Peptide-Assisted Nuclear Shuttling of Peptide-Substituted Circa 102 Gold Atom Nanoclusters in Living Cells. ACS Applied Nano Materials 2018, 1, 4236-4246. Doi :

10.1021/acsanm.8b00988

TNB at $335 \mu \mathrm{M}$. This value corresponds to about $50 \%$ of the overall concentration of released ligands estimated by NMR and corresponds to a release of a TNB/TAB molecular ratio of 1 . 
To cite : Desplancq, D.; Groysbeck, N.; Chiper, M.; Weiss, E.; Frisch, B.; Strub, J.-M.; Cianferani, S.; Zafeiratos, S.; Moeglin, E.; Holy, X.; et al. Cytosolic Diffusion and Peptide-Assisted Nuclear Shuttling of Peptide-Substituted Circa 102 Gold Atom Nanoclusters in Living Cells. ACS Applied Nano Materials 2018, 1, 4236-4246. Doi :

10.1021/acsanm.8b00988

A. AuGS

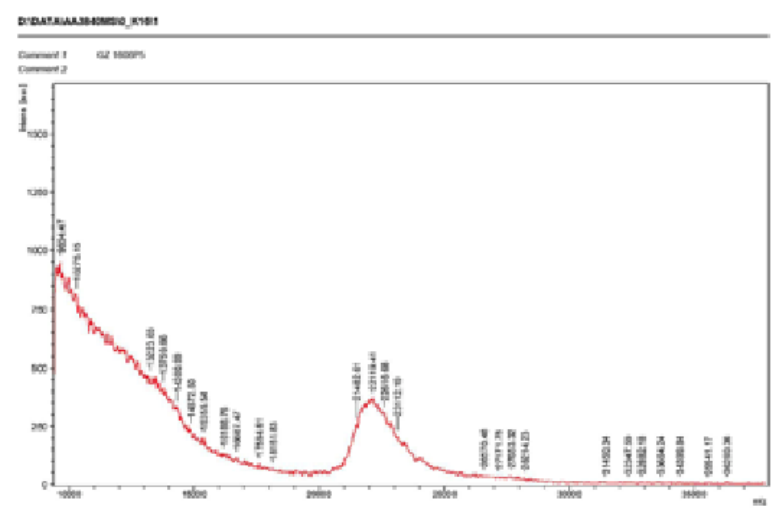

\section{AuCap (CALNNG)}

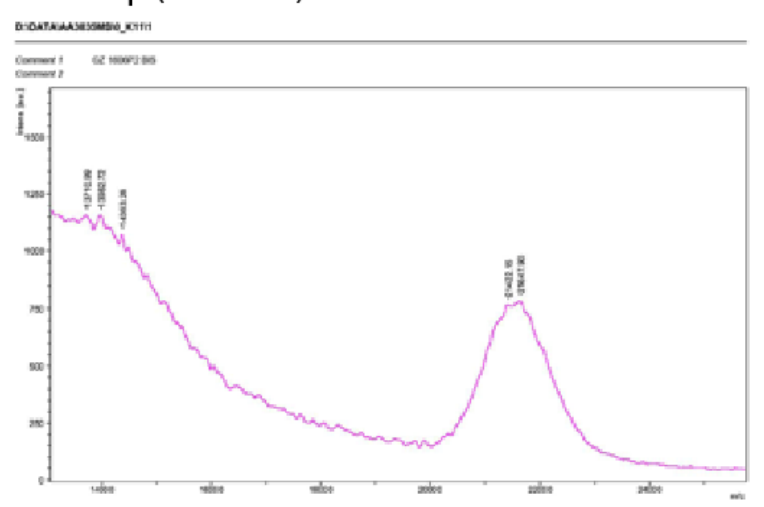

\section{B. AudNLS}

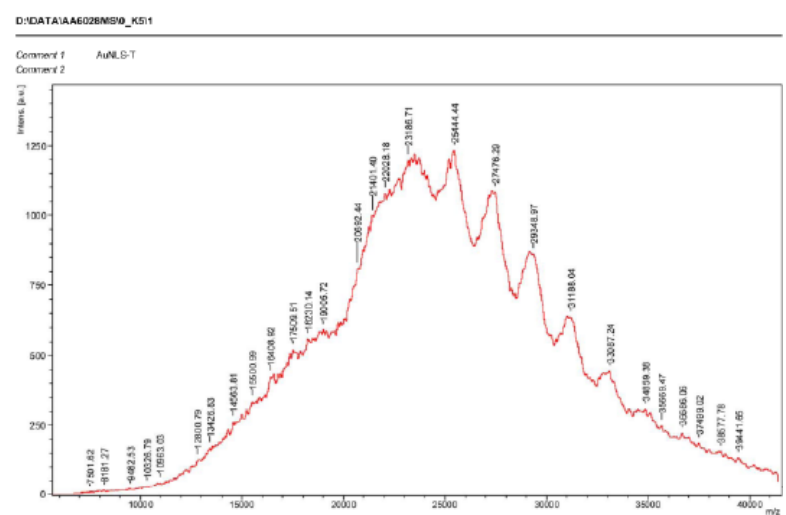

\section{AuNES}

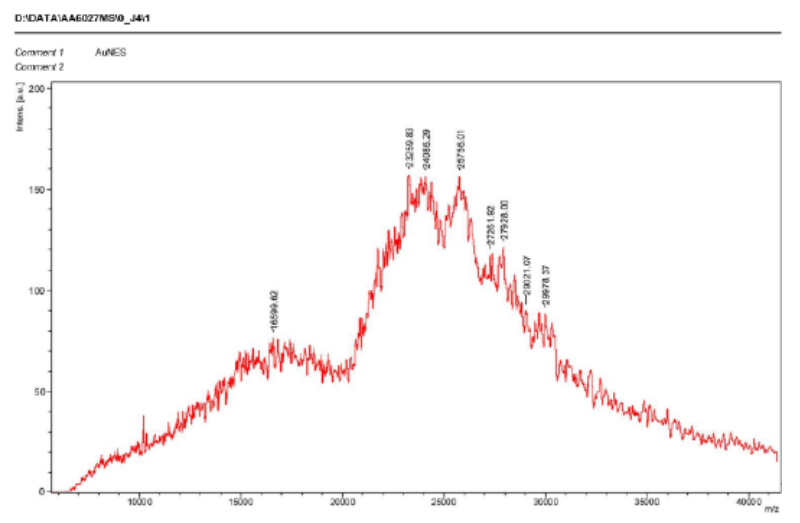

Figure S4. MALDI-TOF Mass spectra of AuGS (A), AudNLS (B), AuCap (C) and AuNES (D). 
To cite : Desplancq, D.; Groysbeck, N.; Chiper, M.; Weiss, E.; Frisch, B.; Strub, J.-M.; Cianferani, S.; Zafeiratos, S.; Moeglin, E.; Holy, X.; et al. Cytosolic Diffusion and Peptide-Assisted Nuclear Shuttling of Peptide-Substituted Circa 102 Gold Atom Nanoclusters in Living Cells. ACS Applied Nano Materials 2018, 1, 4236-4246. Doi :

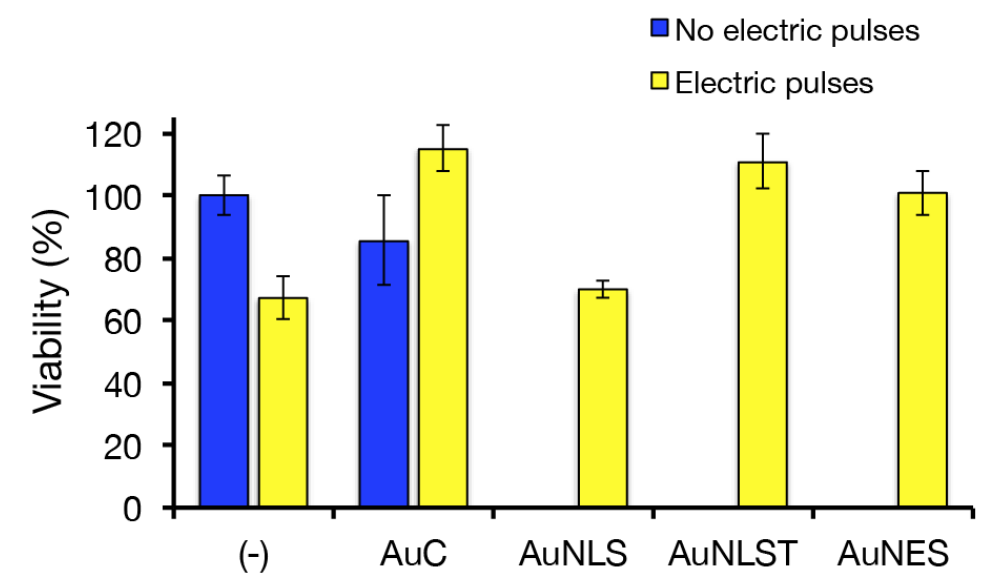

Figure S5. MTT Cell viability assay using the HFF-1 normal cell line. Freshly trypsinized HFF1 cells $(50,000$ cells) in presence of the indicated nanoclusters were added in the Neon transfection device in conditions that were used for electroporation, with the electric pulses (yellow bars) or without electric pulses (blue bars). Cells were then diluted in the cell culture medium and let to growth for $24 \mathrm{~h}$. Values indicated the averages and standard deviations of hexaplicates. 

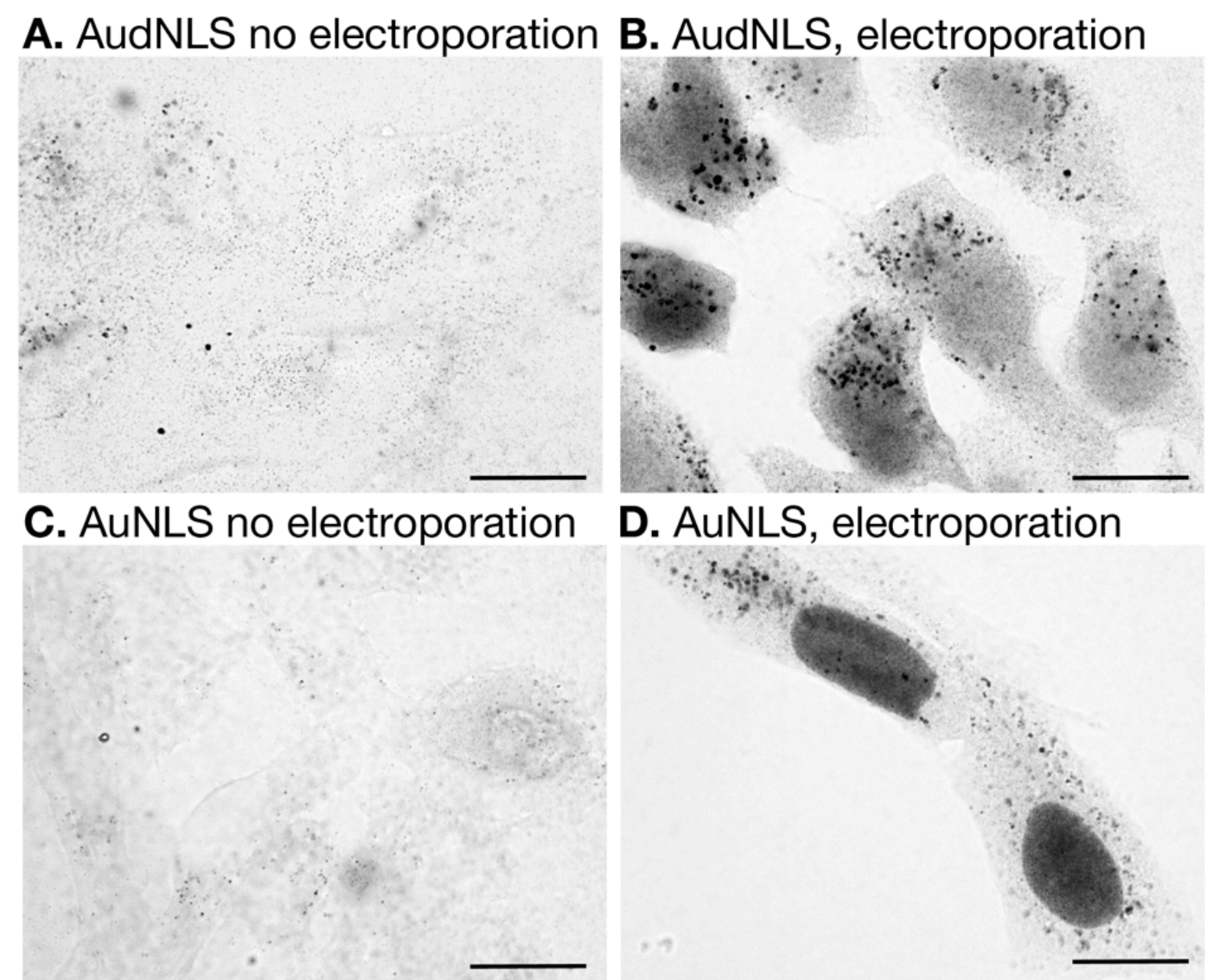

D. AuNLS, electroporation

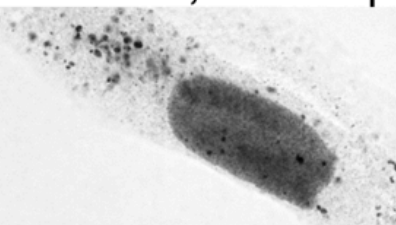

\section{E. AuNES no electroporation}
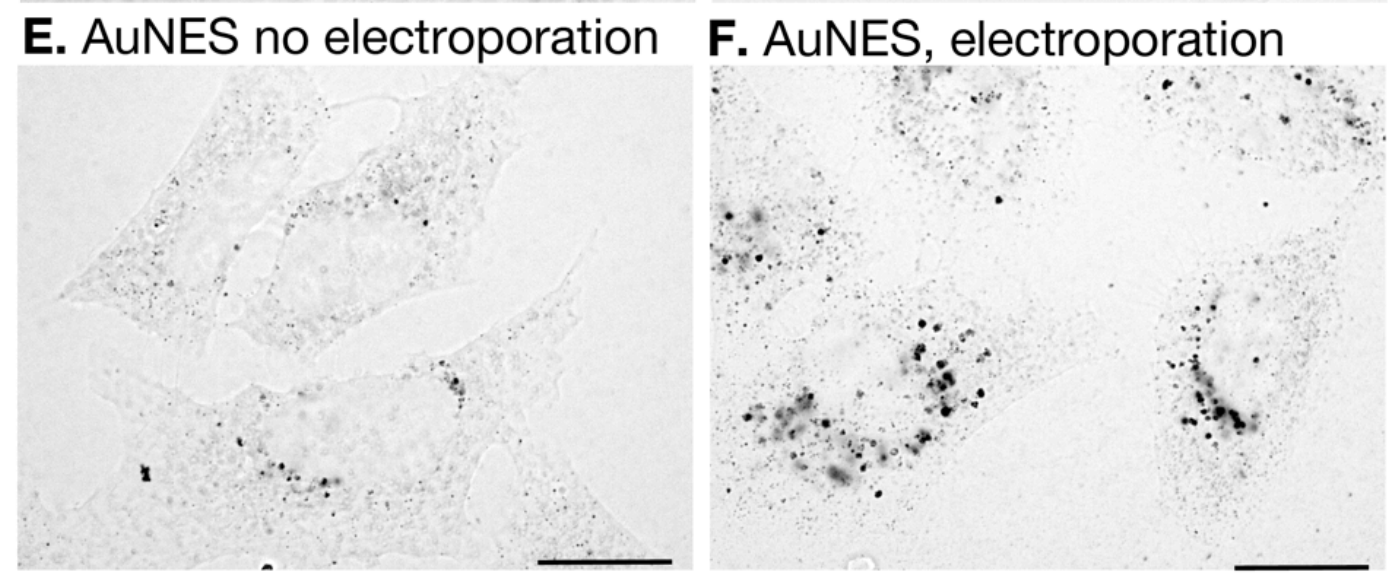

Figure S6. Optical microscopy images of U2OS cells incubated for $24 \mathrm{~h}$ with the indicated peptide-substituted gold nanoclusters (AuNCs). A, C and E. The various peptide-AuNCs were 
To cite : Desplancq, D.; Groysbeck, N.; Chiper, M.; Weiss, E.; Frisch, B.; Strub, J.-M.; Cianferani, S.; Zafeiratos, S.; Moeglin, E.; Holy, X.; et al. Cytosolic Diffusion and Peptide-Assisted Nuclear Shuttling of Peptide-Substituted Circa 102 Gold Atom Nanoclusters in Living Cells. ACS Applied Nano Materials 2018, 1, 4236-4246. Doi :

10.1021/acsanm.8b00988

added to living U2OS cells by dilution in the cell culture medium without an electroporation treatment. B, D and F. The U2OS cells were subjected to electroporation in presence of the indicated AuNCs. Following the $24 \mathrm{~h}$ incubation period at $37^{\circ} \mathrm{C}$, the living cells were fixed with glutaraldehyde $(2.5 \% \mathrm{w} / \mathrm{v})$ and AuNCs were detected by silver staining. Cell viability, estimated by density of the monolayer, was $>80 \%$. Scale bar: $20 \mu \mathrm{m}$. 
To cite : Desplancq, D.; Groysbeck, N.; Chiper, M.; Weiss, E.; Frisch, B.; Strub, J.-M.; Cianferani, S.; Zafeiratos, S.; Moeglin, E.; Holy, X.; et al. Cytosolic Diffusion and Peptide-Assisted Nuclear Shuttling of Peptide-Substituted Circa 102 Gold Atom Nanoclusters in Living Cells. ACS Applied Nano Materials 2018, 1, 4236-4246. Doi :

A. AuCap

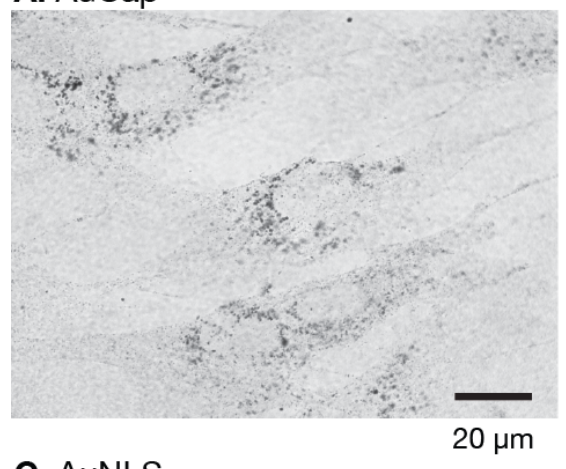

C. AUNLS

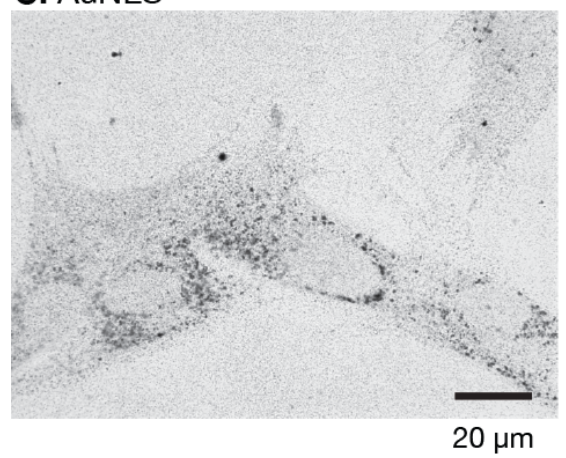

E. AudNLS

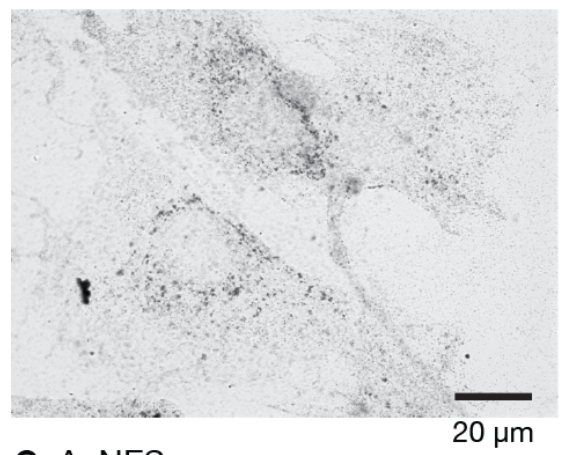

G. AUNES

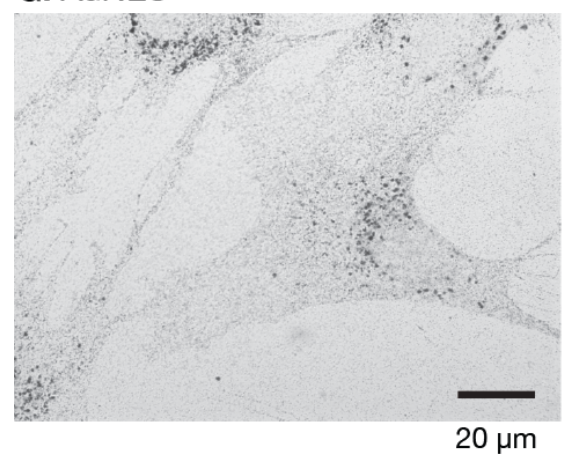

B. AuCap - Electroporation

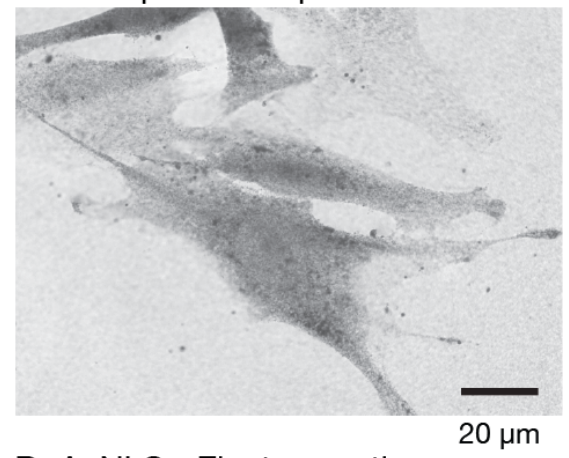

D. AuNLS - Electroporation

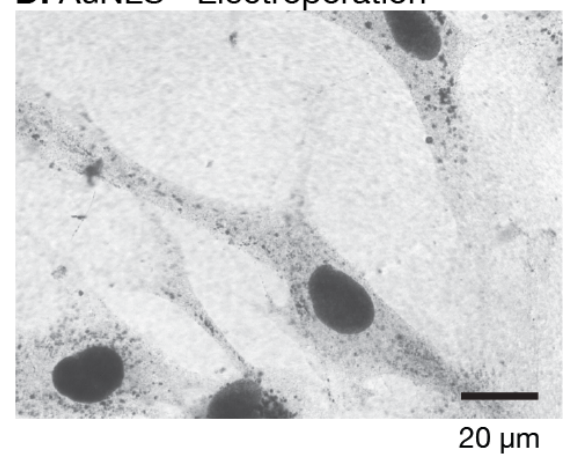

F. AudNLS - Electroporation

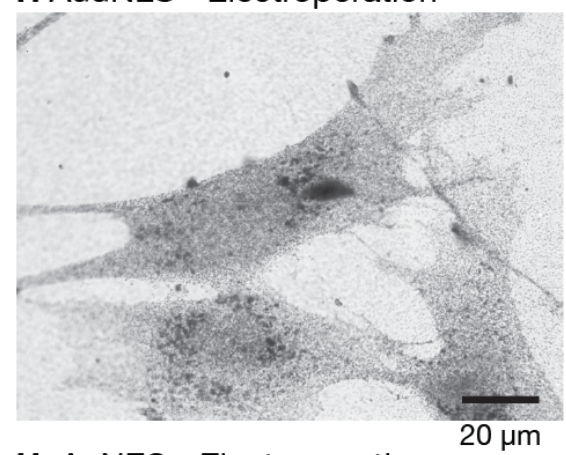

H. AUNES - Electroporation

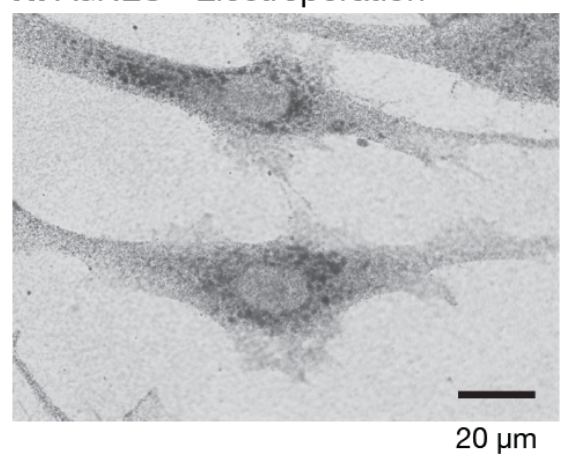

Figure S7. Optical microscopy images of HFF-1 cells incubated for $24 \mathrm{~h}$ with the indicated peptide-substituted gold nanoclusters (AuNCs). A, C, E and $\mathbf{G}$. The various peptide-AuNCs were added to living HFF-1 cells by dilution in the cell culture medium without an electroporation treatment. B, D, F and $\mathbf{H}$. The HFF-1 cells were subjected to electroporation in 
To cite : Desplancq, D.; Groysbeck, N.; Chiper, M.; Weiss, E.; Frisch, B.; Strub, J.-M.; Cianferani, S.; Zafeiratos, S.; Moeglin, E.; Holy, X.; et al. Cytosolic Diffusion and Peptide-Assisted Nuclear Shuttling of Peptide-Substituted Circa 102 Gold Atom Nanoclusters in Living Cells. ACS Applied Nano Materials 2018, 1, 4236-4246. Doi :

10.1021/acsanm.8b00988

presence of the indicated AuNCs. Following the $24 \mathrm{~h}$ incubation period at $37^{\circ} \mathrm{C}$, the living cells were fixed with glutaraldehyde $(2.5 \% \mathrm{w} / \mathrm{v})$ and AuNCs were detected by silver staining. Cell viability, estimated by density of the monolayer, was $>80 \%$. 
To cite : Desplancq, D.; Groysbeck, N.; Chiper, M.; Weiss, E.; Frisch, B.; Strub, J.-M.; Cianferani, S.; Zafeiratos, S.; Moeglin, E.; Holy, X.; et al. Cytosolic Diffusion and Peptide-Assisted Nuclear Shuttling of Peptide-Substituted Circa 102 Gold Atom Nanoclusters in Living Cells. ACS Applied Nano Materials 2018, 1, 4236-4246. Doi :

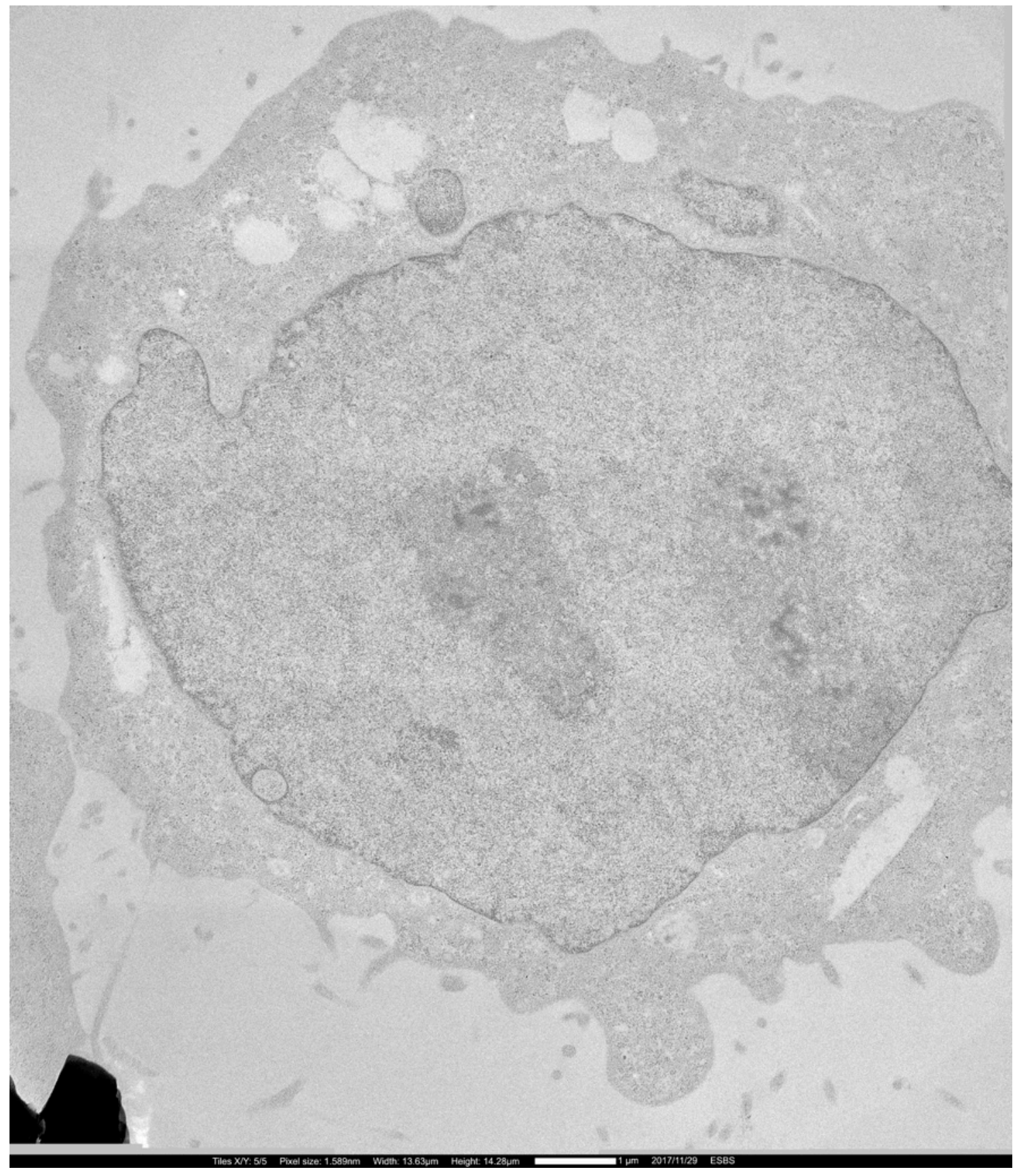

Figure S8. Transmission electron microscopy of untreated HeLa cells. After fixation with 2.5\% glutaraldehyde, the specimen was treated with the Aurion Silver enhancement solution exactly as the AuNCs-containing specimens. After the silver staining, the HeLa cells were processed for resin-embedding and imaged. 
To cite : Desplancq, D.; Groysbeck, N.; Chiper, M.; Weiss, E.; Frisch, B.; Strub, J.-M.; Cianferani, S.; Zafeiratos, S.; Moeglin, E.; Holy, X.; et al. Cytosolic Diffusion and Peptide-Assisted Nuclear Shuttling of Peptide-Substituted Circa 102 Gold Atom Nanoclusters in Living Cells. ACS Applied Nano Materials 2018, 1, 4236-4246. Doi :

10.1021/acsanm.8b00988

A. Synthesis of functionalized Gold nanoparticles

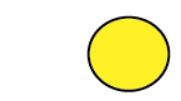

Citrate-stabilized Gold nanoparticle

AuCi

B. TEM image of AuCi

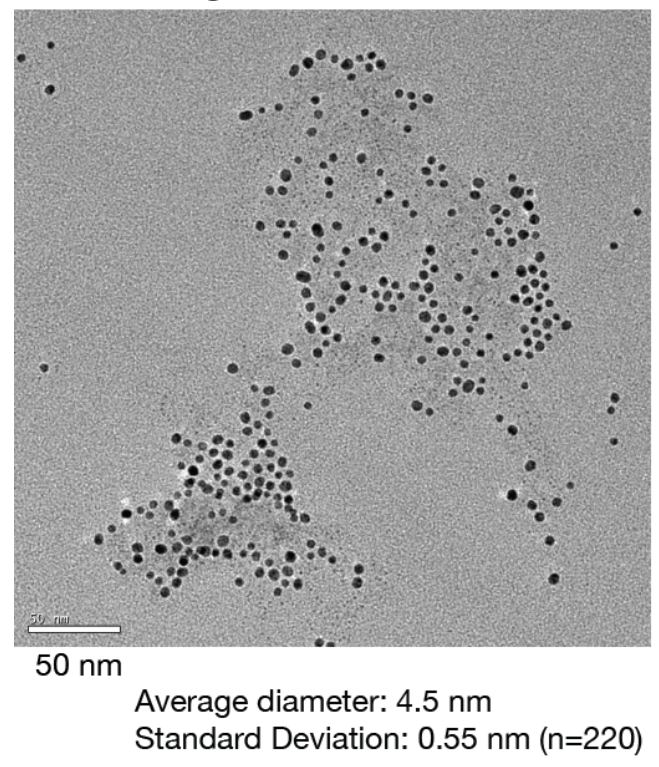

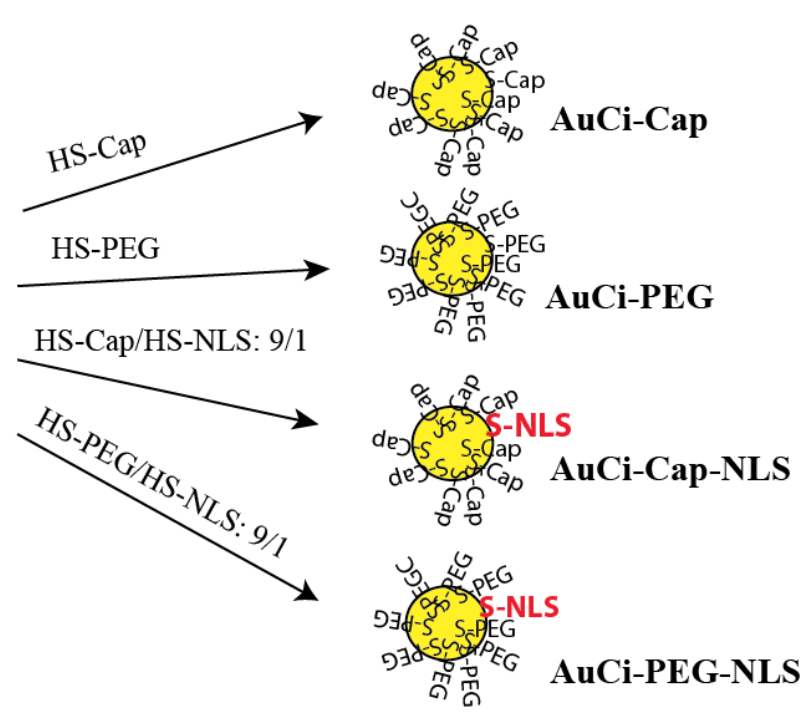

C. PAGE analysis

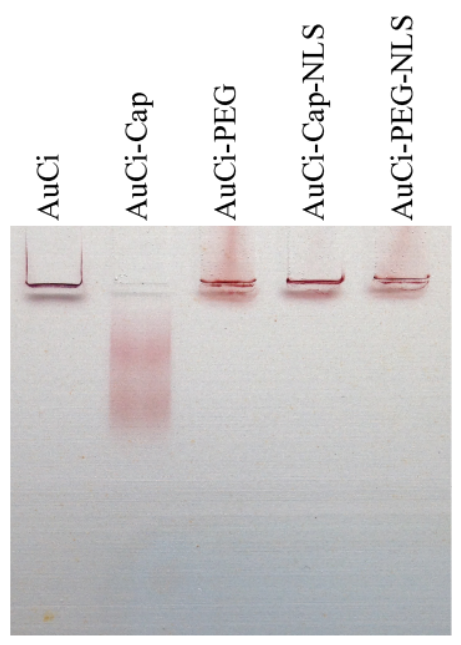

Figure S9. A. Synthesis of peptide-grafted gold nanoparticle from citrate-gold nanoparticle. B. TEM image of the starting gold nanoparticle showing a population of particle with average diameter of $4.5 \mathrm{~nm}$. C. SDS-denaturing 15\% Polyacrylamide gel electrophoresis of the peptidegrafted gold nanoparticles. The gold nanoparticles were red-colored and did not require any staining. 
To cite : Desplancq, D.; Groysbeck, N.; Chiper, M.; Weiss, E.; Frisch, B.; Strub, J.-M.; Cianferani, S.; Zafeiratos, S.; Moeglin, E.; Holy, X.; et al. Cytosolic Diffusion and Peptide-Assisted Nuclear Shuttling of Peptide-Substituted Circa 102 Gold Atom Nanoclusters in Living Cells. ACS Applied Nano Materials 2018, 1, 4236-4246. Doi :

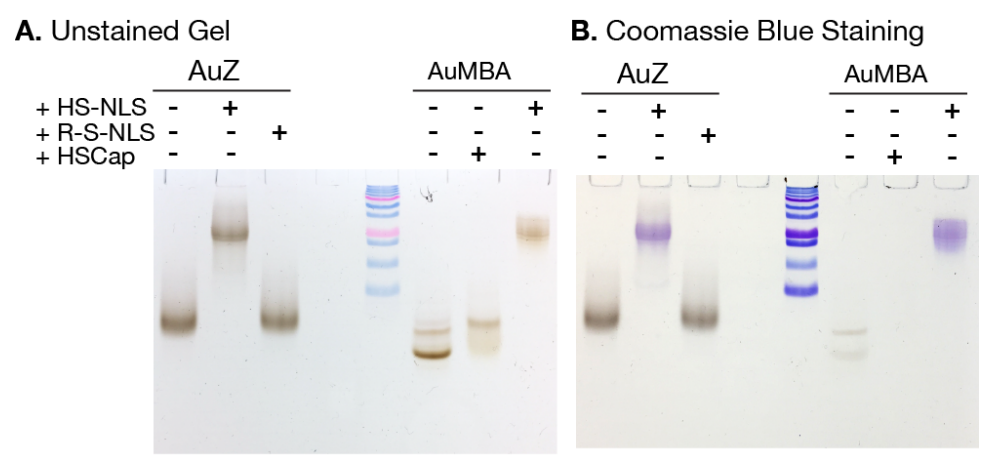

C. MALDI-TOF Mass spectrum of AuMBA

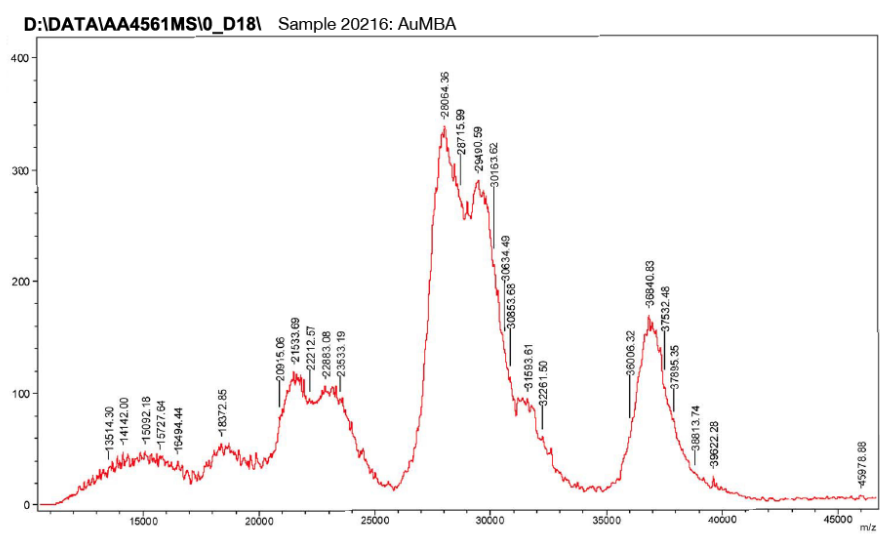

D. Incubation of AuMBA-NLS to membrane-permeabilized cells HeLa + AuMBA-NLS, 24h HFF-1 + AuMBA-NLS, $24 \mathrm{~h}$
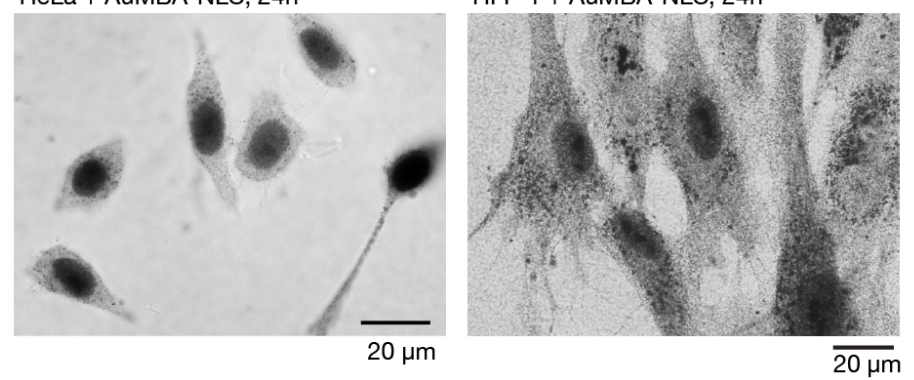

Figure S10. Reactivity and delivery of NLS-grafted gold nanoclusters from AuMBA. A and B. Comparative reactivity of the AuZ to the HS-NLS peptide or to an S-alkyl-NLS peptide (R-SNLS) and analysis of AuMBA and subsequent reaction with HS-Cap or HS-NLS. Images are PAGE images of the same gel before and after Coomassie blue staining. The data indicated that our AuMBA batch contains several nanoclusters. We were unable to obtain a batch containing only one band. The S-Alkyl-NLS was obtained by reacting the HS-NLS to N-ethylmaleimide (1.2 molar equivalent) 30 min before addition to AuZ. Condition 1: $80 \mu \mathrm{M}$ AuZ, $2 \mathrm{mM}$ HS-NLS (or R-SNLS), $0.1 \mathrm{M}$ HEPES, $\mathrm{pH} 7.4$ (10 $\mu \mathrm{L}$ volume). Condition 2. $80 \mu \mathrm{M}$ AuMBA, $4 \mathrm{mM}$ HSCap or $4 \mathrm{mM}$ HSNLS (100 $\mu \mathrm{L}$ volume, 16h reaction). The subsequent particles were purified using a $30 \mathrm{kDa}$ UltraConcentrator device. Aliquots were analyzed and the AuMBANLS was used for the electroporation treatment (see images D). C. MALDI-TOF Mass spectrum of the AuMBA. The results confirmed that our preparation contains several clusters. D. The HeLa or the HFF-1 cells were subjected to electroporation in presence of the AuMBS-NLS. Following the $24 \mathrm{~h}$ incubation period at $37^{\circ} \mathrm{C}$, the living cells were fixed with glutaraldehyde $(2.5 \% \mathrm{w} / \mathrm{v})$ and AuNCs were detected by silver darkening. They accumulated as well in the cell nucleus as 
To cite : Desplancq, D.; Groysbeck, N.; Chiper, M.; Weiss, E.; Frisch, B.; Strub, J.-M.; Cianferani, S.; Zafeiratos, S.; Moeglin, E.; Holy, X.; et al. Cytosolic Diffusion and Peptide-Assisted Nuclear Shuttling of Peptide-Substituted Circa 102 Gold Atom Nanoclusters in Living Cells. ACS Applied Nano Materials 2018, 1, 4236-4246. Doi :

10.1021/acsanm.8b00988

expected from an NLS-driven nuclear import. The AuMBA-NLS appears to be less effectively imported in the HFF-1 nuclei than the AuNLS, suggesting a benefit of the zwitterionic TAB shell. Cell viability, estimated by monolayer density was $>80 \%$.

A. Scheme of the experiment

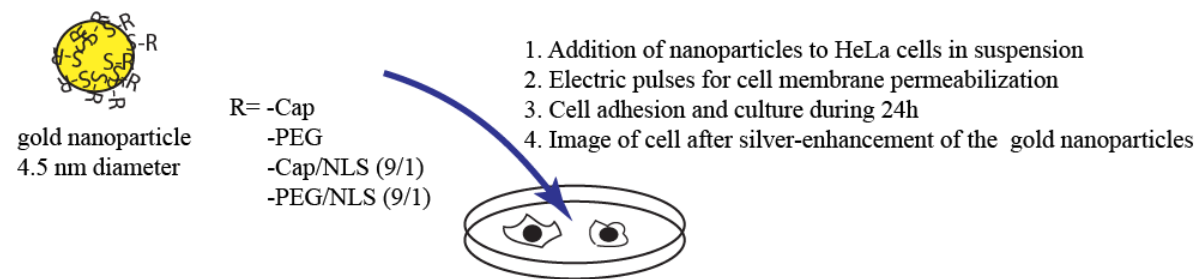

B. Incubation of the nanoparticles with electroporated HeLa cell
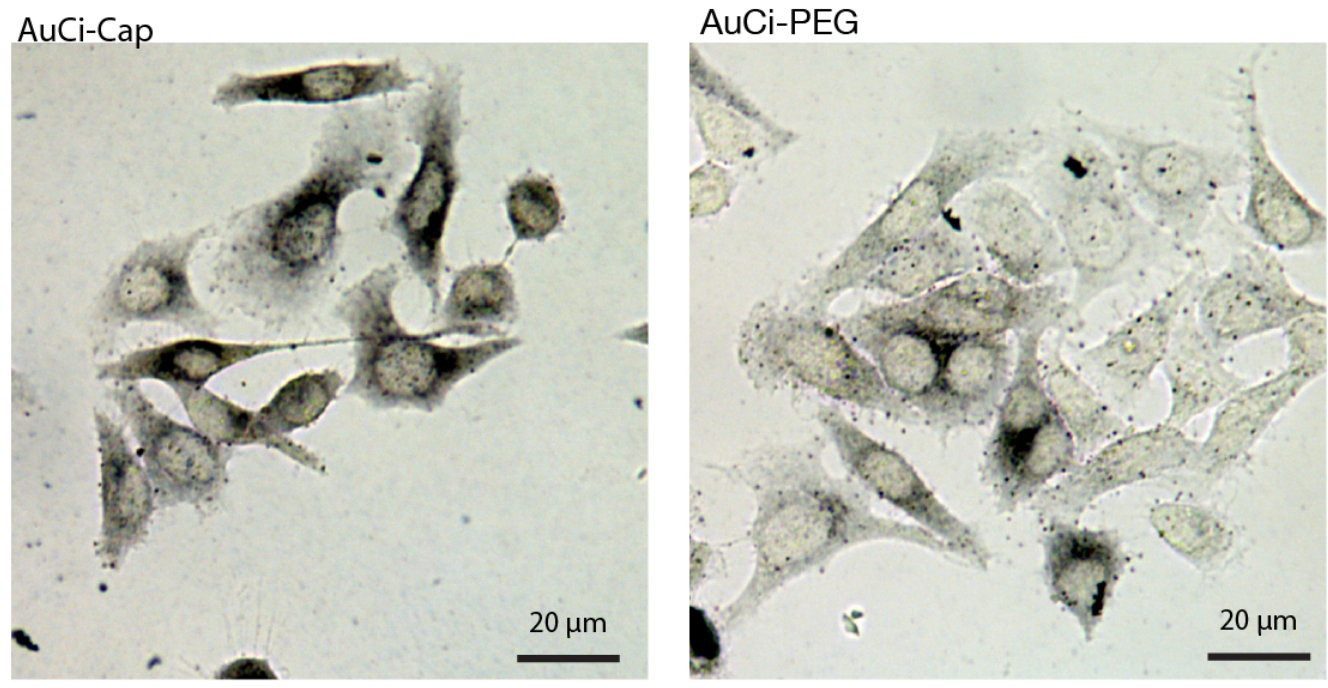

AuCi-Cap-NLS

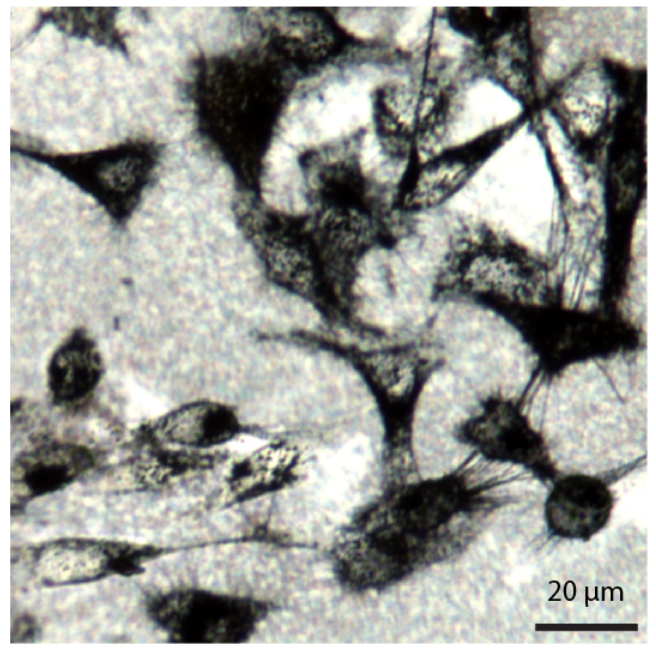

AuCi-Cap-NLS

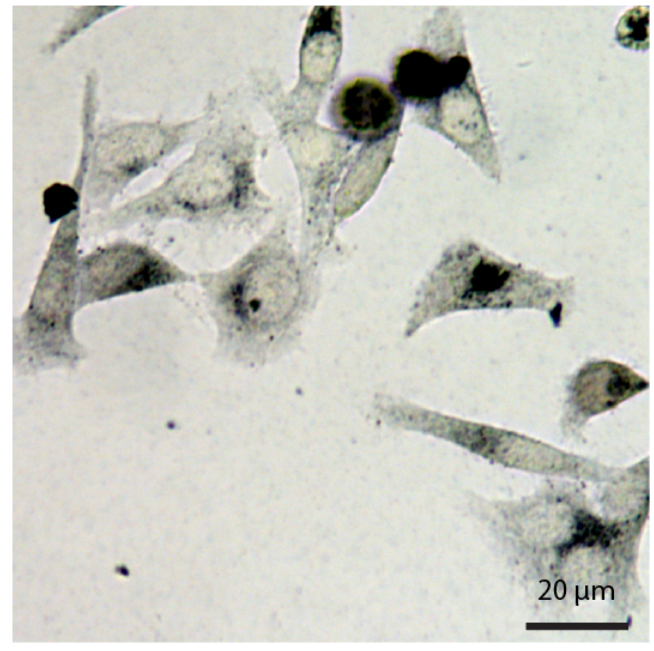

Figure S11. Evaluation of the intracellular fate of peptide-subtituted $4.5 \mathrm{~nm}$ nanoparticles. A. Scheme of the experiment. B. The various gold nanoparticles as indicated were mixed with HeLa cells and the mixtures s were subjected to electroporation. Following the $24 \mathrm{~h}$ incubation period 
To cite : Desplancq, D.; Groysbeck, N.; Chiper, M.; Weiss, E.; Frisch, B.; Strub, J.-M.; Cianferani, S.; Zafeiratos, S.; Moeglin, E.; Holy, X.; et al. Cytosolic Diffusion and Peptide-Assisted Nuclear Shuttling of Peptide-Substituted Circa 102 Gold Atom Nanoclusters in Living Cells. ACS Applied Nano Materials 2018, 1, 4236-4246. Doi :

10.1021/acsanm.8b00988

at $37^{\circ} \mathrm{C}$, the living cells were fixed with glutaraldehyde $(2.5 \% \mathrm{w} / \mathrm{v})$ and the gold nanoparticles were detected by silver darkening. Results showed heterogeneous distribution. These NLSequipped nanoparticles did not accumulate in the cell nuclei even when the nanoparticle's surface was equipped with PEG for minimizing unspecific association to cellular component. We did not determine whether the poor cytosolic delivery was due to poor diffusion inside he cytosol or to poor passage across the transient holes. Cell viability, estimated by monolayer density was $>80 \%$.

A. Fluorescence emission spectra of the AuZ nanocluster
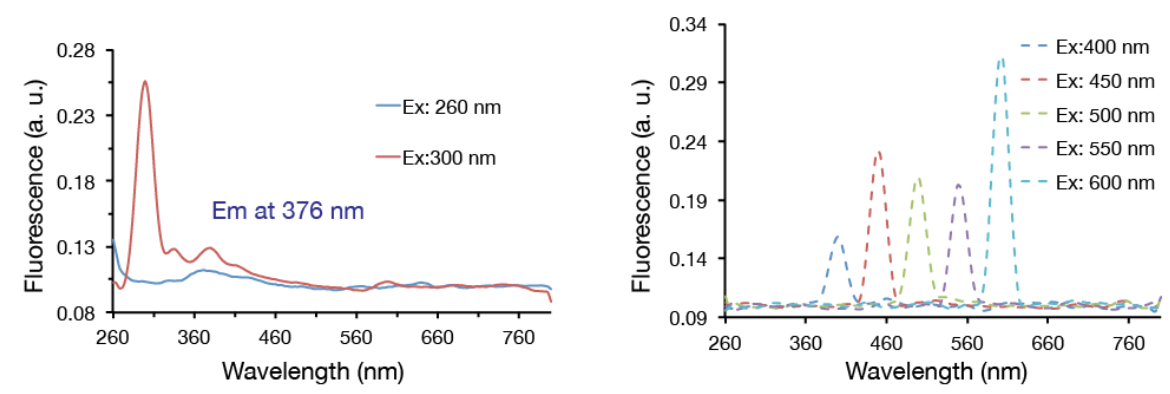

B. Fluorescence emission spectra of the AuGS nanocluster
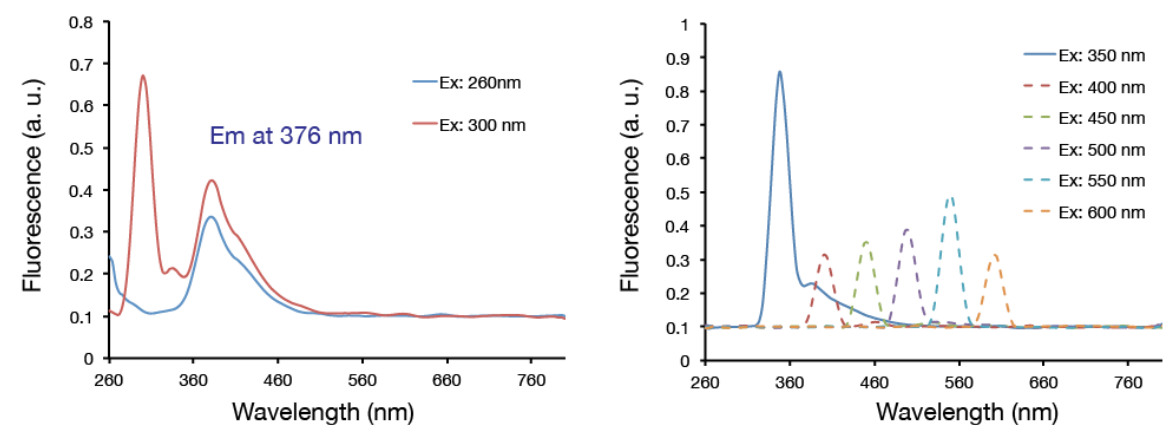

Figure S12. Fluorescence emission spectra of the AuZ (A) and AuGS (B) nanoclusters at various excitation wavelengths as indicated. Results indicated that the AuZ and the AuGS have photoluminescent abilities (Ex: 300, Em: $376 \mathrm{~nm}$ ). The intensity of the photoluminescnet was extremely weak and practically useless for in cellulo imaging or nanocluster tracking. Condition: $0.6 \mu \mathrm{M}$ AuNC in $10 \mathrm{mM} \mathrm{K}_{2} \mathrm{CO}_{3}$. 
To cite : Desplancq, D.; Groysbeck, N.; Chiper, M.; Weiss, E.; Frisch, B.; Strub, J.-M.; Cianferani, S.; Zafeiratos, S.; Moeglin, E.; Holy, X.; et al. Cytosolic Diffusion and Peptide-Assisted Nuclear Shuttling of Peptide-Substituted Circa 102 Gold Atom Nanoclusters in Living Cells. ACS Applied Nano Materials 2018, 1, 4236-4246. Doi :

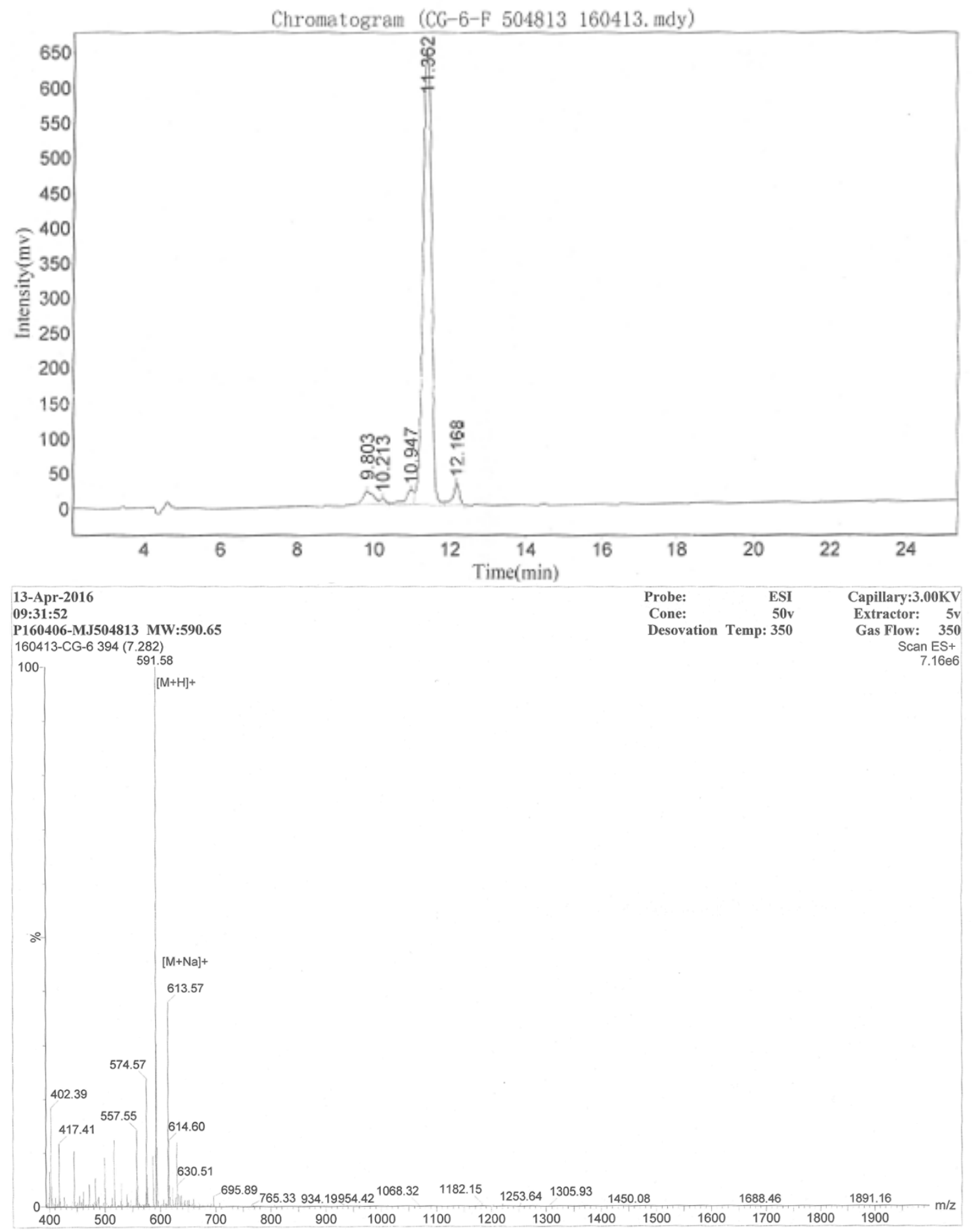

Figure S13. HPLC profile and mass spectrometry analysis of the Cap peptide (CALLNG, $\mathrm{C}_{22} \mathrm{H}_{38} \mathrm{~N}_{8} 0_{9} \mathrm{~S}_{1}$; MW : 1801.06). Column: 4.6mmx250mm Diamonsil $5 \mu \mathrm{C} 18$. Solvent A: 0.1\% TFA in 100\% Acetonitrile, Solvent B : $0.1 \%$ TFA in water. Gradient: 0 to $25 \mathrm{~min}, 7$ to $32 \%$ A. 
To cite : Desplancq, D.; Groysbeck, N.; Chiper, M.; Weiss, E.; Frisch, B.; Strub, J.-M.; Cianferani, S.; Zafeiratos, S.; Moeglin, E.; Holy, X.; et al. Cytosolic Diffusion and Peptide-Assisted Nuclear Shuttling of Peptide-Substituted Circa 102 Gold Atom Nanoclusters in Living Cells. ACS Applied Nano Materials 2018, 1, 4236-4246. Doi :

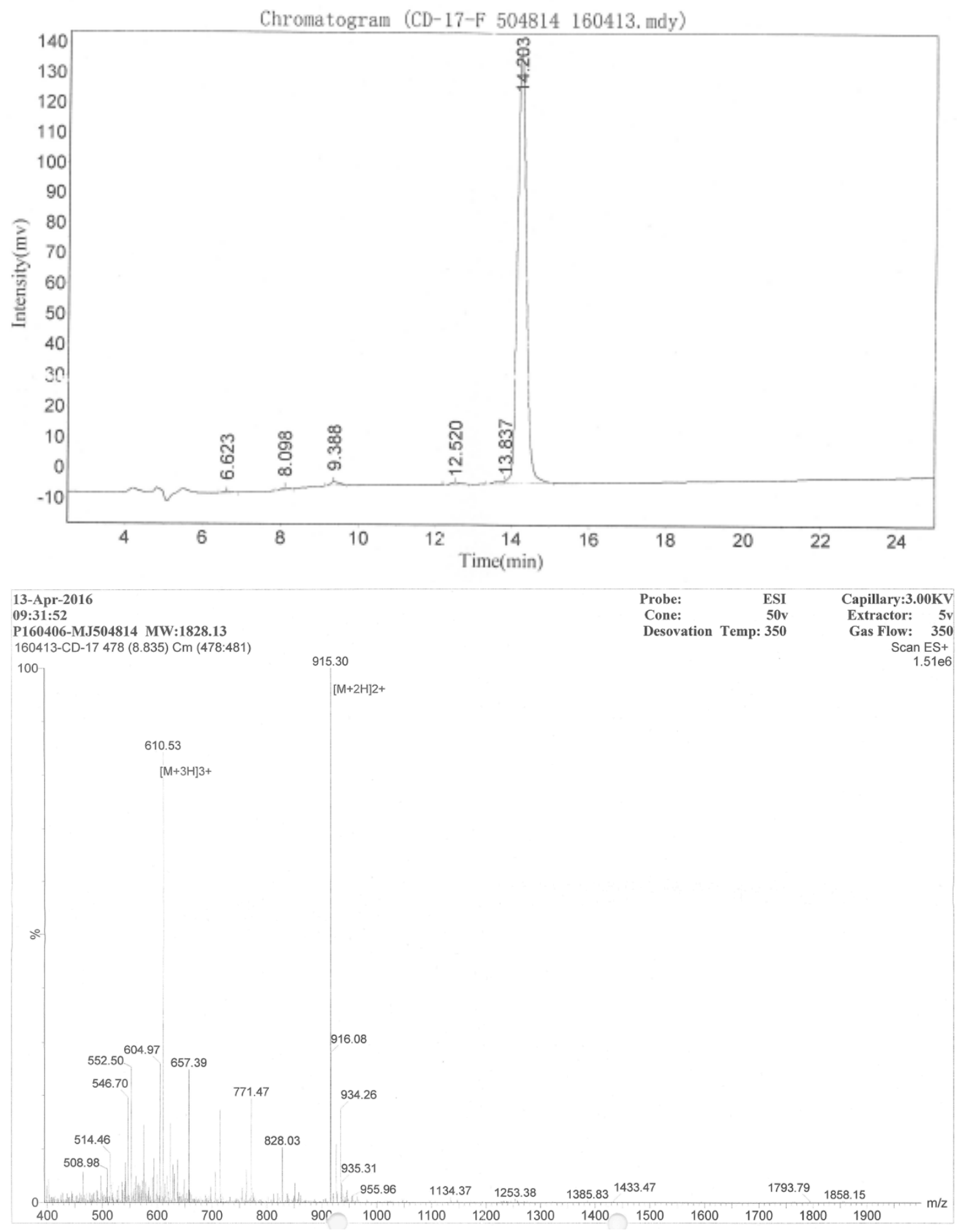

Figure S14. HPLC profile and mass spectrometry analysis of the NLS peptide (CALNNGAGPKKKRKVED, $\mathrm{C}_{76} \mathrm{H}_{134} \mathrm{~N}_{26} \mathrm{O}_{25} \mathrm{~S}_{1} ; \mathrm{MW}$ : 1828.13). Column 4.6mmx250mm 
To cite : Desplancq, D.; Groysbeck, N.; Chiper, M.; Weiss, E.; Frisch, B.; Strub, J.-M.; Cianferani, S.; Zafeiratos, S.; Moeglin, E.; Holy, X.; et al. Cytosolic Diffusion and Peptide-Assisted Nuclear Shuttling of Peptide-Substituted Circa 102 Gold Atom Nanoclusters in Living Cells. ACS Applied Nano Materials 2018, 1, 4236-4246. Doi :

10.1021/acsanm.8b00988

Diamonsil $5 \mu \mathrm{C} 18$. Solvent A: 0.1\% TFA in 100\% Acetonitrile, Solvent B : $0.1 \%$ TFA in water. Gradient: 0 to $25 \mathrm{~min}, 7$ to $32 \% \mathrm{~A}$. 
To cite : Desplancq, D.; Groysbeck, N.; Chiper, M.; Weiss, E.; Frisch, B.; Strub, J.-M.; Cianferani, S.; Zafeiratos, S.; Moeglin, E.; Holy, X.; et al. Cytosolic Diffusion and Peptide-Assisted Nuclear Shuttling of Peptide-Substituted Circa 102 Gold Atom Nanoclusters in Living Cells. ACS Applied Nano Materials 2018, 1, 4236-4246. Doi :

10.1021/acsanm.8b00988

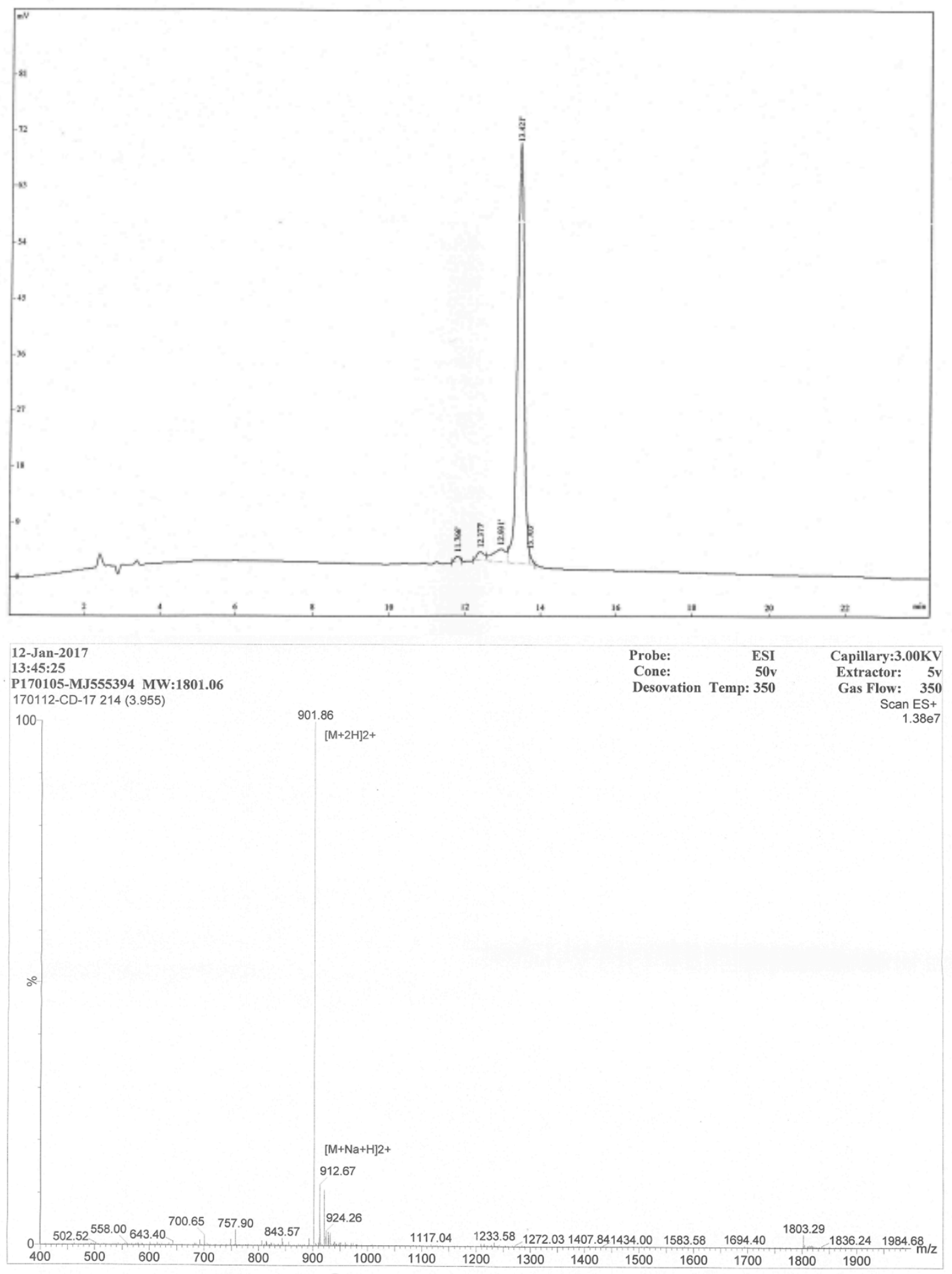

Figure S15. HPLC profile and mass spectrometry analysis of the dNLS peptide (CALNNGAGPKTKRKVED, $\mathrm{C}_{74} \mathrm{H}_{129} \mathrm{~N}_{25} \mathrm{O}_{25} \mathrm{~S}_{1}$; MW : 1801.06). Column 4.6mmx250mm Inertsil ODS-SP. Solvent A: 0.1\% TFA in 100\% Acetonitrile, Solvent B: $0.1 \%$ TFA in water. 
To cite : Desplancq, D.; Groysbeck, N.; Chiper, M.; Weiss, E.; Frisch, B.; Strub, J.-M.; Cianferani, S.; Zafeiratos, S.; Moeglin, E.; Holy, X.; et al. Cytosolic Diffusion and Peptide-Assisted Nuclear Shuttling of Peptide-Substituted Circa 102 Gold Atom Nanoclusters in Living Cells. ACS Applied Nano Materials 2018, 1, 4236-4246. Doi :

10.1021/acsanm.8b00988

Gradient: 0 to $25 \mathrm{~min}, 8$ to $33 \% \mathrm{~A}$. 
To cite : Desplancq, D.; Groysbeck, N.; Chiper, M.; Weiss, E.; Frisch, B.; Strub, J.-M.; Cianferani, S.; Zafeiratos, S.; Moeglin, E.; Holy, X.; et al. Cytosolic Diffusion and Peptide-Assisted Nuclear Shuttling of Peptide-Substituted Circa 102 Gold Atom Nanoclusters in Living Cells. ACS Applied Nano Materials 2018, 1, 4236-4246. Doi :

10.1021/acsanm.8b00988

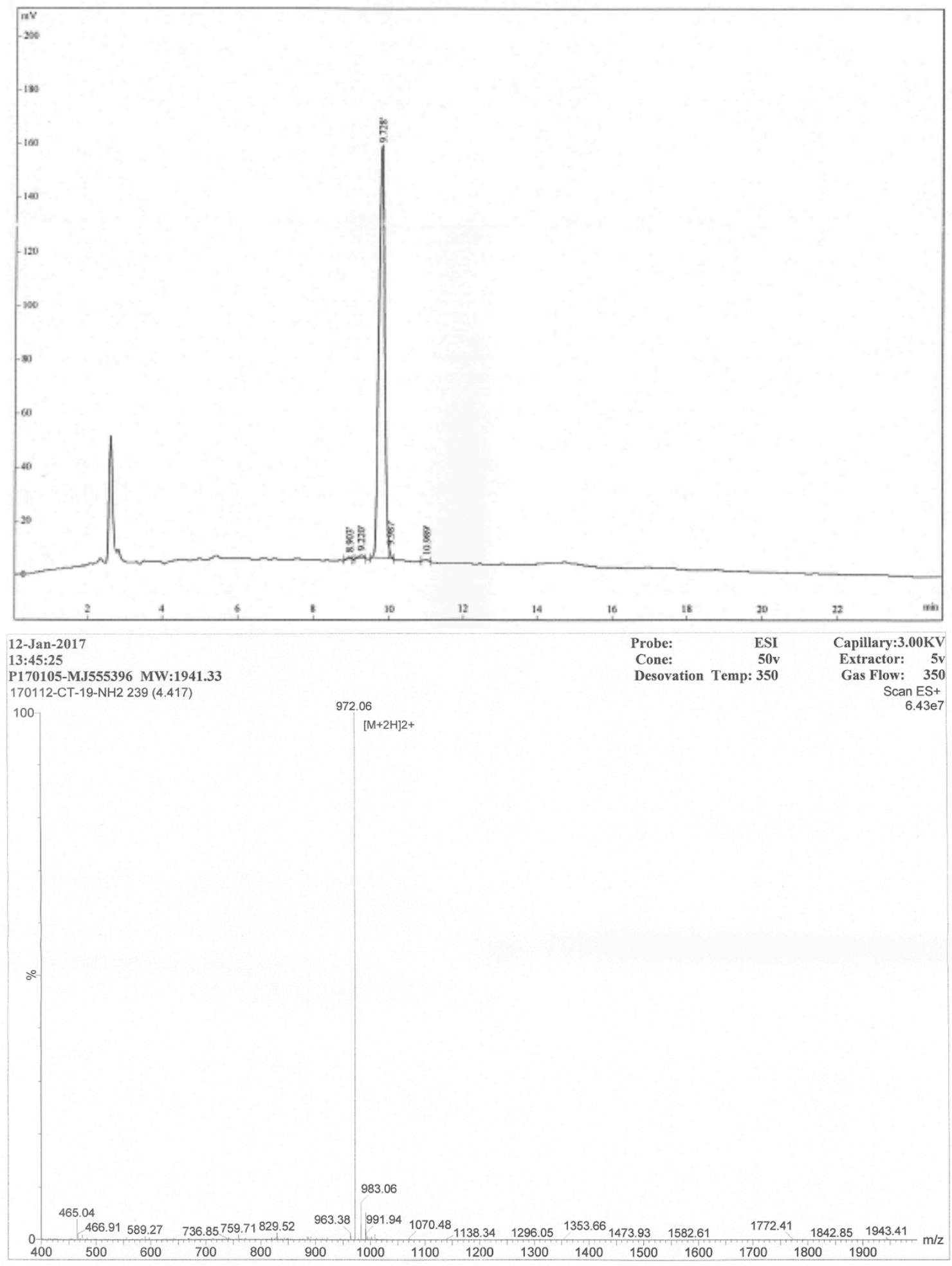

Figure S16. HPLC profile and mass spectrometry analysis of the NES peptide (CALNNGLALKLAGLDINKT -amide, $\quad \mathrm{C}_{84} \mathrm{H}_{149} \mathrm{~N}_{25} \mathrm{O}_{25} \mathrm{~S}_{1} ; \quad \mathrm{MW}: \quad$ 1941.33). Column 
To cite : Desplancq, D.; Groysbeck, N.; Chiper, M.; Weiss, E.; Frisch, B.; Strub, J.-M.; Cianferani, S.; Zafeiratos, S.; Moeglin, E.; Holy, X.; et al. Cytosolic Diffusion and Peptide-Assisted Nuclear Shuttling of Peptide-Substituted Circa 102 Gold Atom Nanoclusters in Living Cells. ACS Applied Nano Materials 2018, 1, 4236-4246. Doi :

10.1021/acsanm.8b00988

4.6mmx 250mm Inertsil ODS-SP. Solvent A: 0.1\% TFA in 100\% Acetonitrile, Solvent B: $0.1 \%$ TFA in water. Gradient: 0 to $25 \mathrm{~min}, 8$ to $33 \% \mathrm{~A}$. 
To cite : Desplancq, D.; Groysbeck, N.; Chiper, M.; Weiss, E.; Frisch, B.; Strub, J.-M.; Cianferani, S.; Zafeiratos, S.; Moeglin, E.; Holy, X.; et al. Cytosolic Diffusion and Peptide-Assisted Nuclear Shuttling of Peptide-Substituted Circa 102 Gold Atom Nanoclusters in Living Cells. ACS Applied Nano Materials 2018, 1, 4236-4246. Doi :

10.1021/acsanm.8b00988

FT-IR spectrum of AuZ

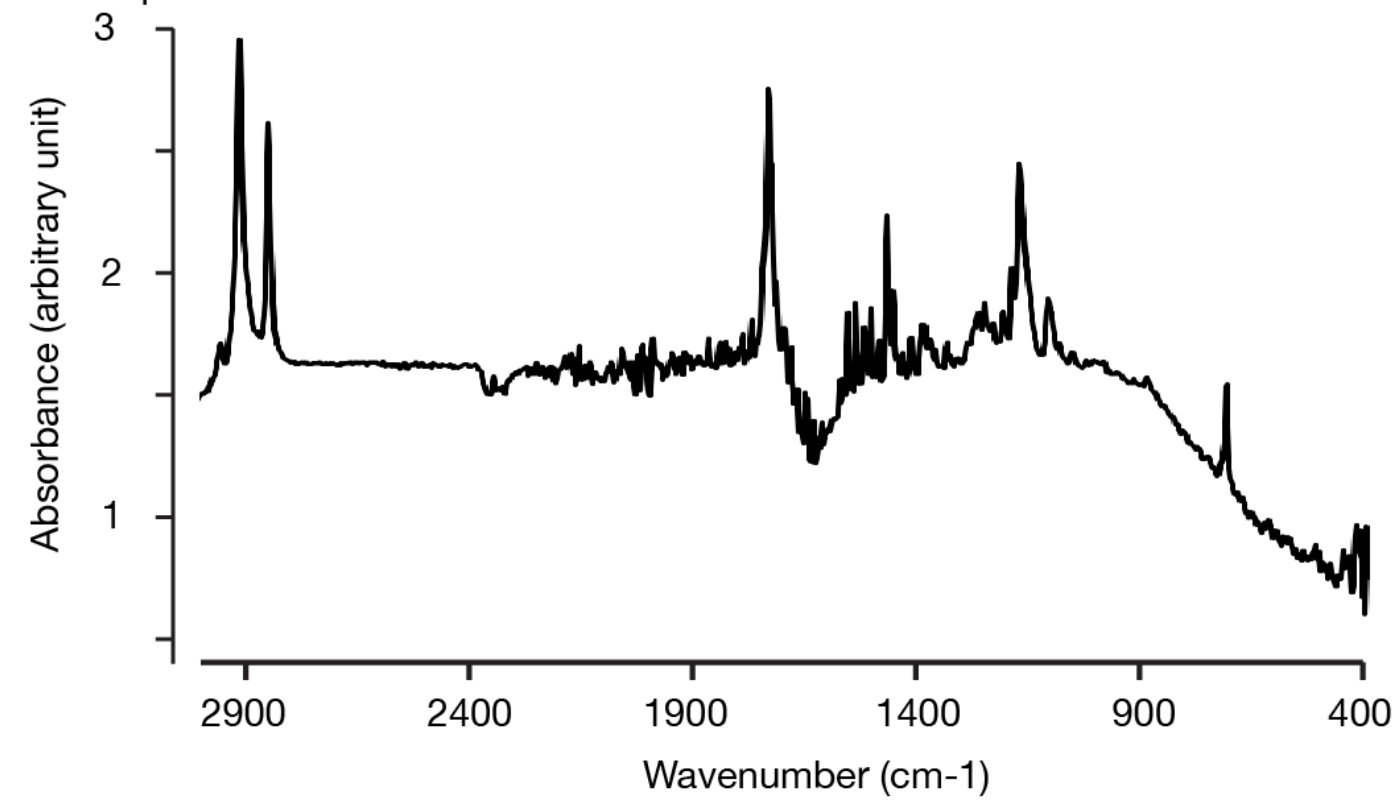

Figure S17. FT IR spectrum of the AuZ nanocluster. The spectrum was taken using a Nicolet 380 FT-IR spectrometer and a diamond ATR by ThermoFisher Scientific. Number of scans: 32. 
To cite : Desplancq, D.; Groysbeck, N.; Chiper, M.; Weiss, E.; Frisch, B.; Strub, J.-M.; Cianferani, S.; Zafeiratos, S.; Moeglin, E.; Holy, X.; et al. Cytosolic Diffusion and Peptide-Assisted Nuclear Shuttling of Peptide-Substituted Circa 102 Gold Atom Nanoclusters in Living Cells. ACS Applied Nano Materials 2018, 1, 4236-4246. Doi :

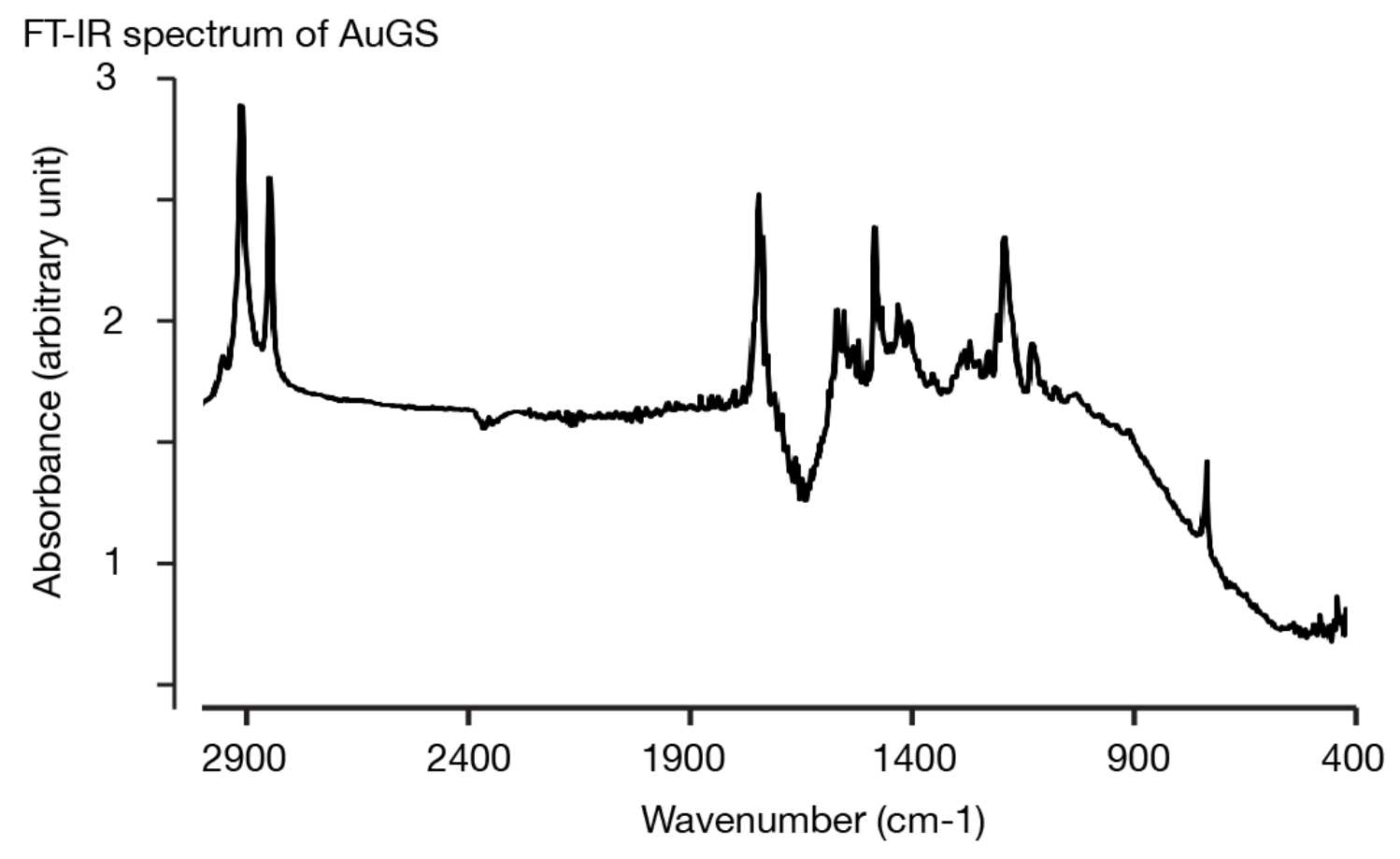

Figure S18. FT IR spectrum of the AuGS nanocluster. The spectrum was taken using a Nicolet 380 FT-IR spectrometer and a diamond ATR by ThermoFisher Scientific. Number of scans: 32 . 
To cite : Desplancq, D.; Groysbeck, N.; Chiper, M.; Weiss, E.; Frisch, B.; Strub, J.-M.; Cianferani, S.; Zafeiratos, S.; Moeglin, E.; Holy, X.; et al. Cytosolic Diffusion and Peptide-Assisted Nuclear Shuttling of Peptide-Substituted Circa 102 Gold Atom Nanoclusters in Living Cells. ACS Applied Nano Materials 2018, 1, 4236-4246. Doi :

10.1021/acsanm.8b00988

FT-IR spectrum of AuCap

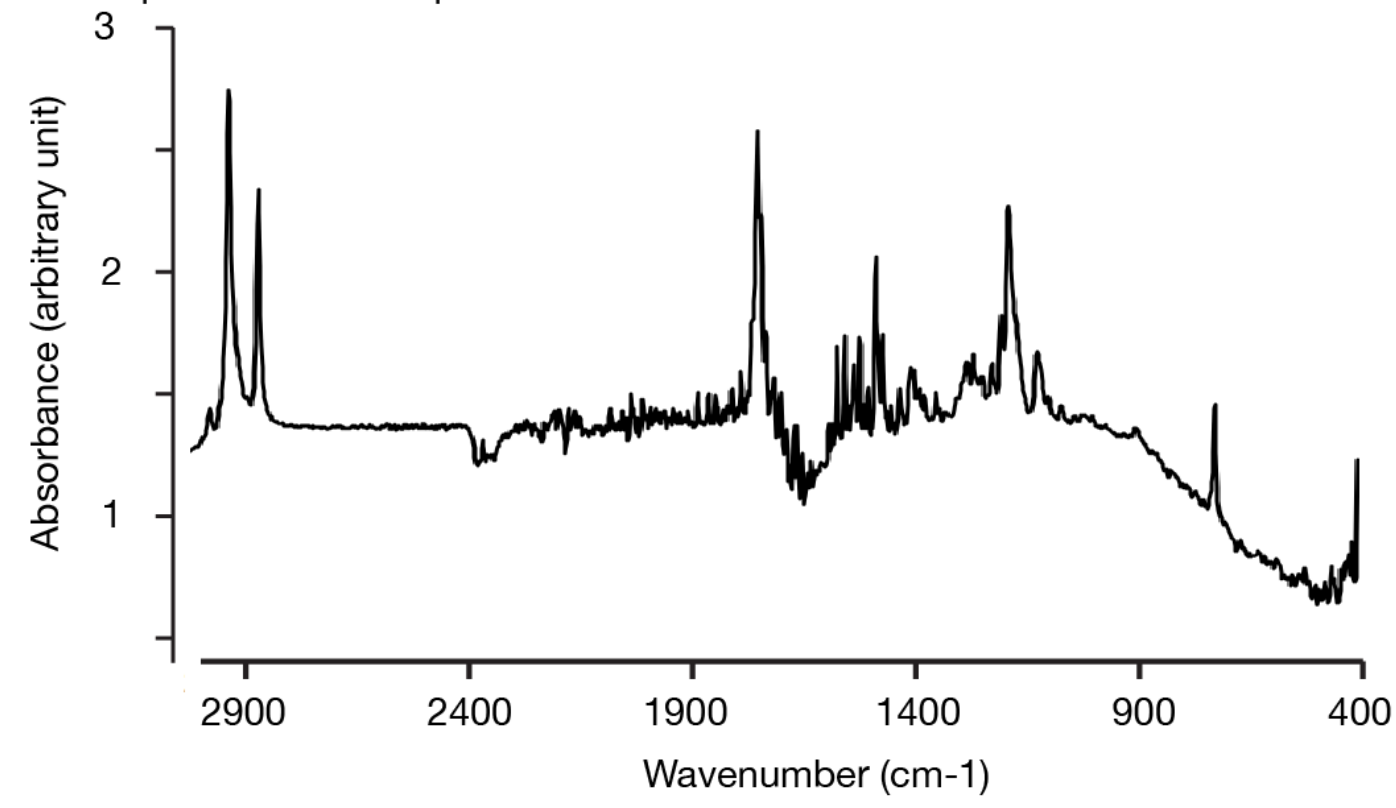

Figure S19. FT IR spectrum of the AuCap nanocluster. The spectrum was taken using a Nicolet 380 FT-IR spectrometer and a diamond ATR by ThermoFisher Scientific. Number of scans: 32. 
To cite : Desplancq, D.; Groysbeck, N.; Chiper, M.; Weiss, E.; Frisch, B.; Strub, J.-M.; Cianferani, S.; Zafeiratos, S.; Moeglin, E.; Holy, X.; et al. Cytosolic Diffusion and Peptide-Assisted Nuclear Shuttling of Peptide-Substituted Circa 102 Gold Atom Nanoclusters in Living Cells. ACS Applied Nano Materials 2018, 1, 4236-4246. Doi :

10.1021/acsanm.8b00988

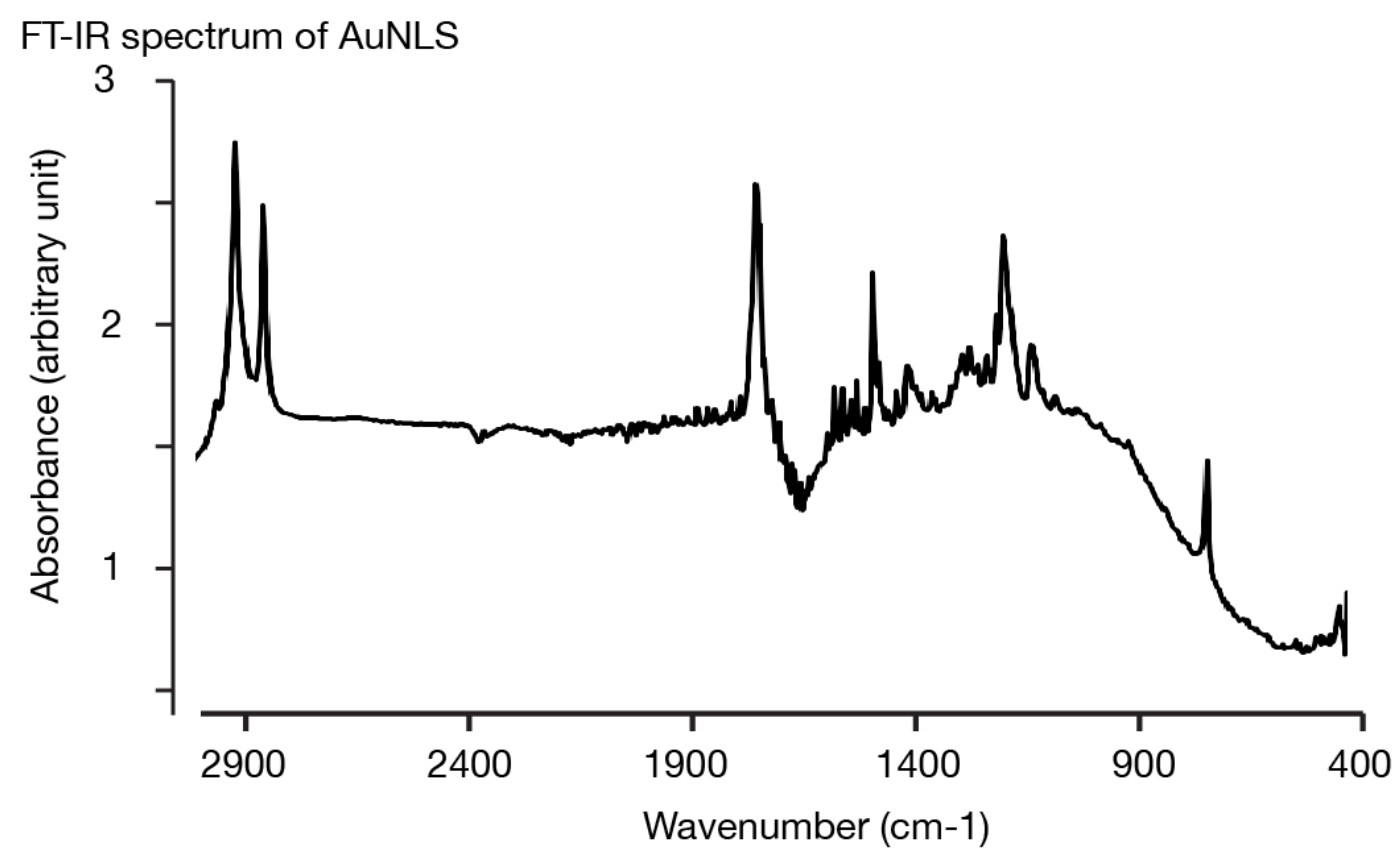

Figure S20. FT IR spectrum of the AuNLS nanocluster. The spectrum was taken using a Nicolet 380 FT-IR spectrometer and a diamond ATR by ThermoFisher Scientific. Number of scans: 32. 
To cite : Desplancq, D.; Groysbeck, N.; Chiper, M.; Weiss, E.; Frisch, B.; Strub, J.-M.; Cianferani, S.; Zafeiratos, S.; Moeglin, E.; Holy, X.; et al. Cytosolic Diffusion and Peptide-Assisted Nuclear Shuttling of Peptide-Substituted Circa 102 Gold Atom Nanoclusters in Living Cells. ACS Applied Nano Materials 2018, 1, 4236-4246. Doi :

10.1021/acsanm.8b00988

FT-IR spectrum of AudNLS

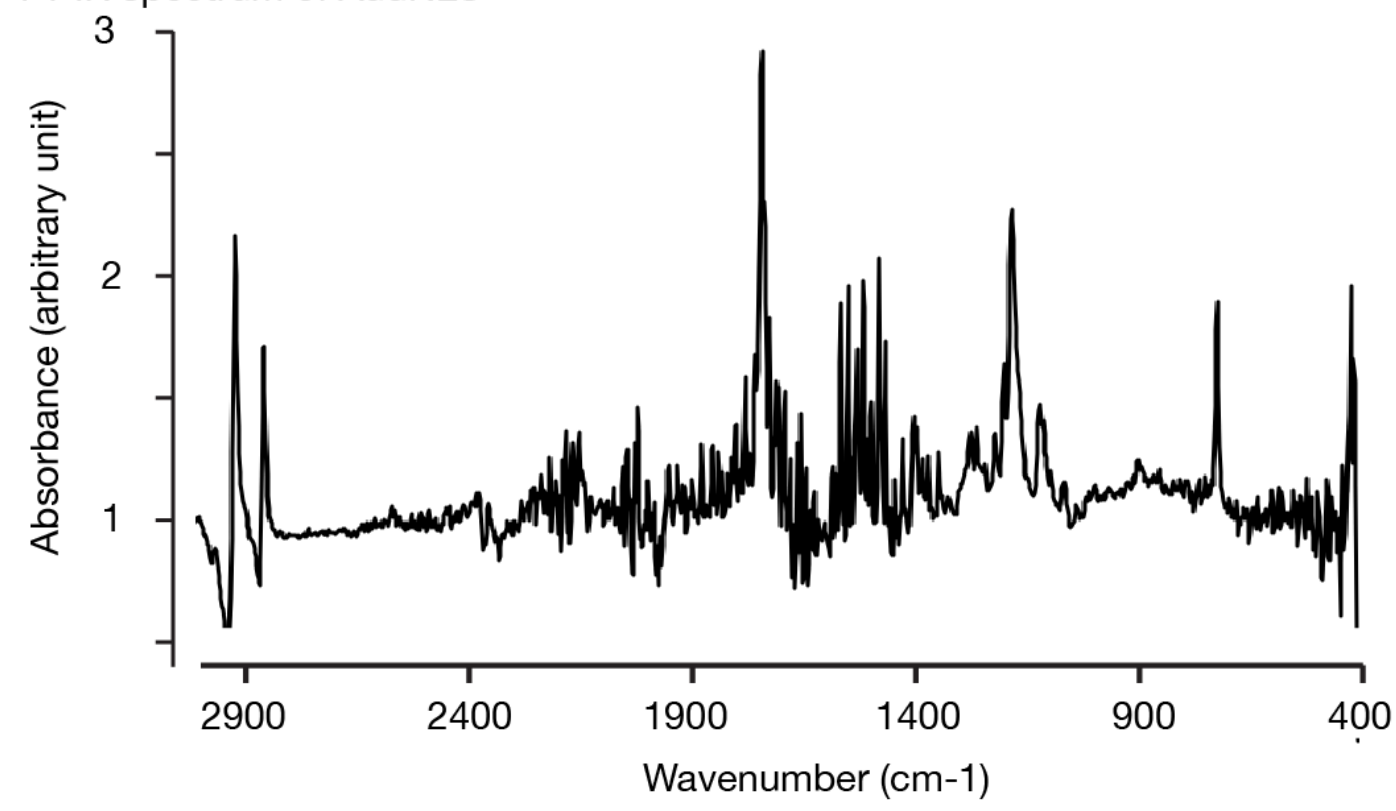

Figure S21. FT IR spectrum of the AudNLS nanocluster. The spectrum was taken using a Nicolet 380 FT-IR spectrometer and a diamond ATR by ThermoFisher Scientific. Number of scans: 32 . 
To cite : Desplancq, D.; Groysbeck, N.; Chiper, M.; Weiss, E.; Frisch, B.; Strub, J.-M.; Cianferani, S.; Zafeiratos, S.; Moeglin, E.; Holy, X.; et al. Cytosolic Diffusion and Peptide-Assisted Nuclear Shuttling of Peptide-Substituted Circa 102 Gold Atom Nanoclusters in Living Cells. ACS Applied Nano Materials 2018, 1, 4236-4246. Doi :

10.1021/acsanm.8b00988

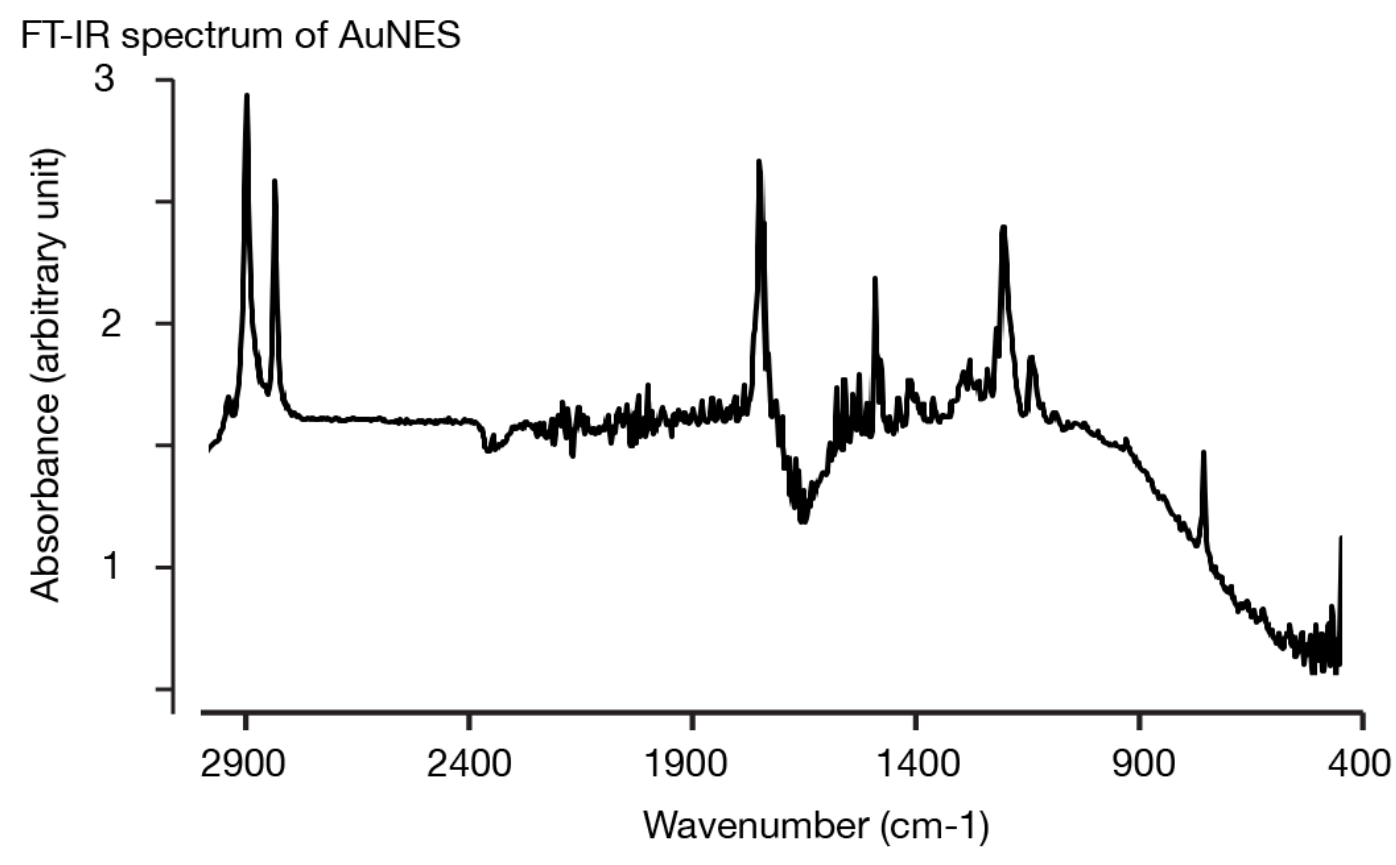

Figure S22. FT IR spectrum of the AuNES nanocluster. The spectrum was taken using a Nicolet 380 FT-IR spectrometer and a diamond ATR by ThermoFisher Scientific. Number of scans: 32 . 


\section{A. Route for labeling AuNLS with Alexa488}

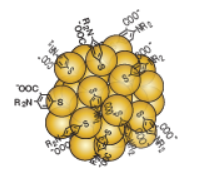

AuZ
1. HS-NLS-Alexa488 (2 eq)

2. HS-NLS (32 eq)

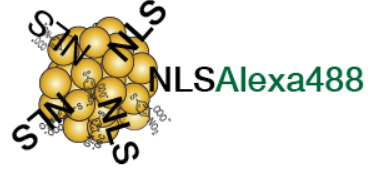

AuNLSAlexa488

B. UV-vis spectrum of Alexa488-labeled AuNLS

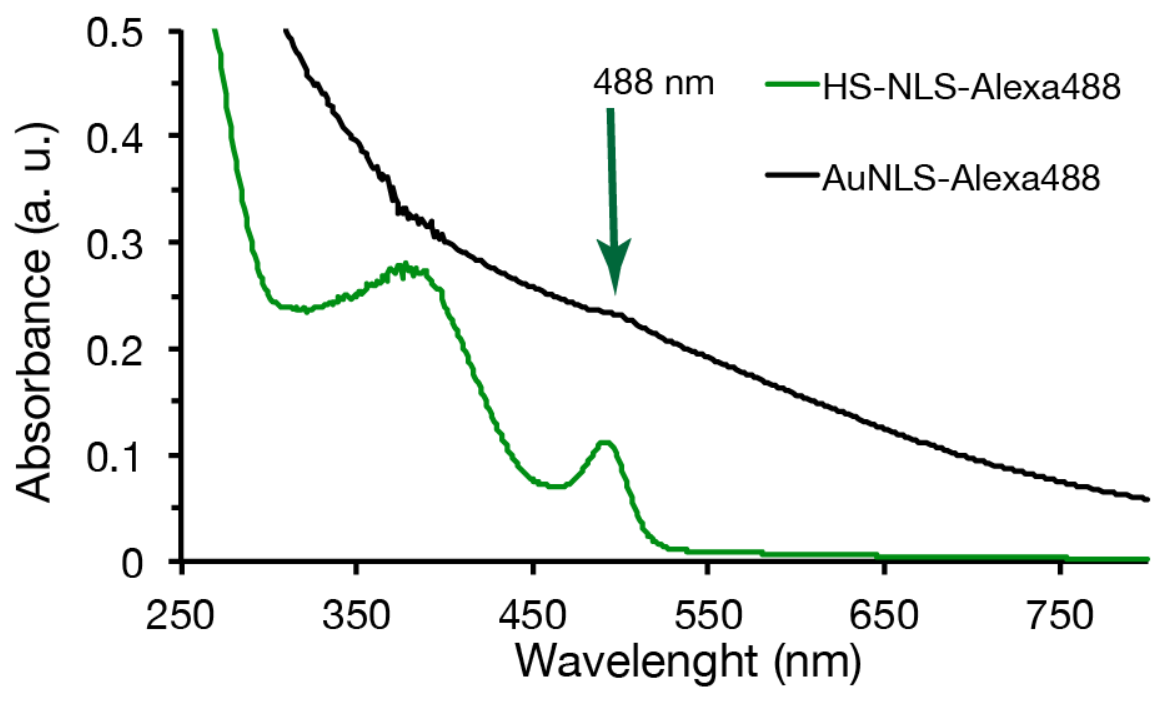

Figure S23. Synthesis of Alexa488-labeled AuNLS. A. Route for preparing Alexa488-labeled AuNLS. AlexaFluo488 NHS ester (ThermoFisher) (16 nmol) was mixed with the HS-NLS (16 $\mathrm{nmol}$ ) in $150 \mathrm{mM} \mathrm{K} \mathrm{CO}_{3}$ and incubated for $24 \mathrm{~h}$ for labeling the peptide on the Lysines. The reaction mixture was then treated with TCEP $(32 \mathrm{nmol})$ and then AuZ $(8 \mathrm{nmol})$. After a $24 \mathrm{~h}$ reaction, unlabeled SH-NLSs $(240 \mathrm{nmol})$ and TCEP $(240 \mathrm{nmol})$ were added and the reaction was incubated for $24 \mathrm{~h}$ before purification using an ultracentrifugation device with a $30 \mathrm{kDa}$ cut-off. B. UV-vis spectrum of the Alexa488-labeled AuNLS (black line). The green line corresponds to the UV/vis spectrum of Alexa488-NHS ester. 
To cite : Desplancq, D.; Groysbeck, N.; Chiper, M.; Weiss, E.; Frisch, B.; Strub, J.-M.; Cianferani, S.; Zafeiratos, S.; Moeglin, E.; Holy, X.; et al. Cytosolic Diffusion and Peptide-Assisted Nuclear Shuttling of Peptide-Substituted Circa 102 Gold Atom Nanoclusters in Living Cells. ACS Applied Nano Materials 2018, 1, 4236-4246. Doi :

A. Scheme of the experiment for characterizing the AuNLSAlexa488

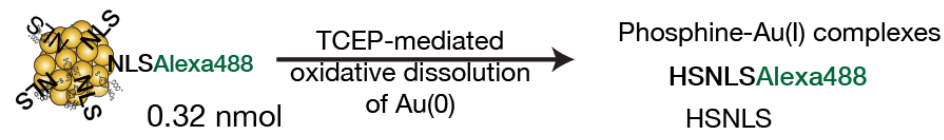

B. PAGE Analysis of AuNLS-alexa488 and TCEP-treated AuNLS-alexa488

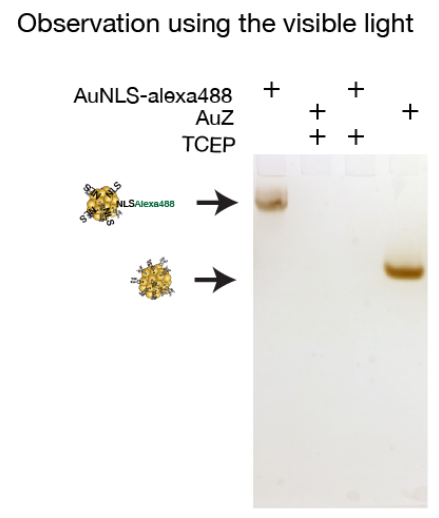

Observation under

UV transillumination

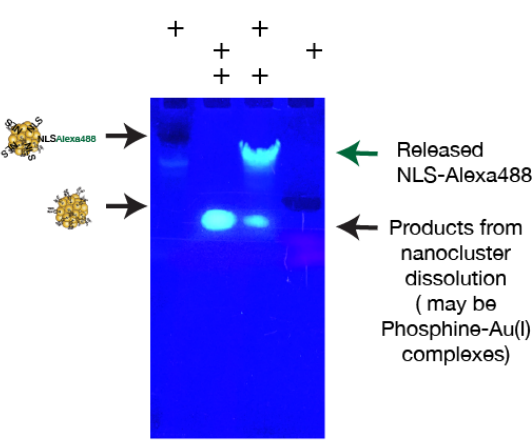

C. Fluorescence emission spectra of AuNLS-Alexa488 before and after treatment with TCEP (Excitation wawelenght : $480 \mathrm{~nm}$ )

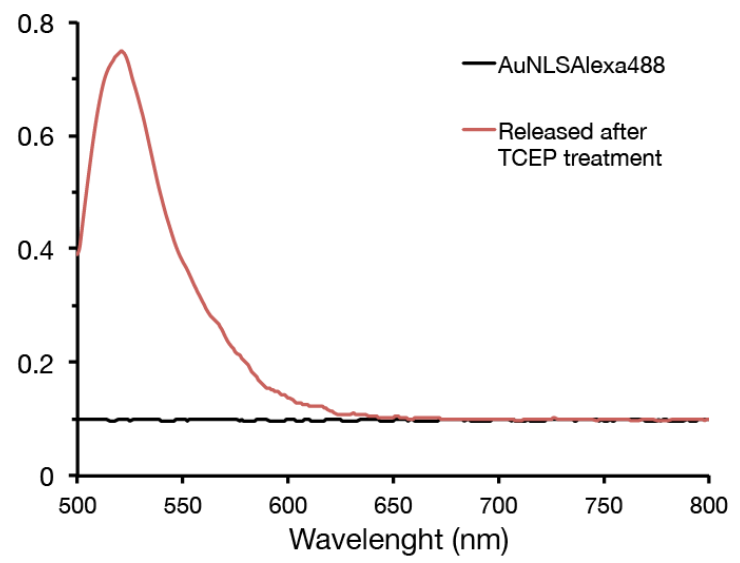

Figure S24. Characterization of Alexa488-labeled AuNLS. A. Scheme of experiment done for characterizing the AuNLSAlexa488. The nanocluster $(0.32 \mathrm{nmol})$ was treated in water with TCEP, pH $7.0(500 \mathrm{nmol})$ in a $6 \mu \mathrm{L}$ volume to perform an oxidative dissolution of the $\mathrm{Au}(0)$ and to release the ligand from the nanocluster. ${ }^{10,11}$ B. PAGE analysis of AuZ, AuNLSAlexa488 and the TCEP-treated corresponding nanoclusters as indicated. After analysis, the gel was visualized under visible light (left image) or under UV (right image). Data showed AuZ and AuNLSAlexa488 to be non-fluorescent (actually they absorb UV light (intense dark band). TCEP-treated samples showed release of a fluorescent species (the likely released species are indicated in the graph), suggesting that AuNC actually quenches fluorescence. C. Fluorescence emission spectra of the AuNLSAlexa488 and of the TCEP-treated AuNLSAlexa488. 
To cite : Desplancq, D.; Groysbeck, N.; Chiper, M.; Weiss, E.; Frisch, B.; Strub, J.-M.; Cianferani, S.; Zafeiratos, S.; Moeglin, E.; Holy, X.; et al. Cytosolic Diffusion and Peptide-Assisted Nuclear Shuttling of Peptide-Substituted Circa 102 Gold Atom Nanoclusters in Living Cells. ACS Applied Nano Materials 2018, 1, 4236-4246. Doi :

10.1021/acsanm.8b00988

Comment: data indicated that the TCEP-treated AuNLSAlexa488 released fluorescent species whereas AuNLSAlexa488 did not emit the Alexa488 fluorescence. These experiment clearly demonstrated that: -1 . AuNLSAlexa488 is grafted with the Alexa488, -2. The AuNC quenches fluorescence of the bound Alexa488 fluorophore, as previously observed. ${ }^{4}$ 
To cite : Desplancq, D.; Groysbeck, N.; Chiper, M.; Weiss, E.; Frisch, B.; Strub, J.-M.; Cianferani, S.; Zafeiratos, S.; Moeglin, E.; Holy, X.; et al. Cytosolic Diffusion and Peptide-Assisted Nuclear Shuttling of Peptide-Substituted Circa 102 Gold Atom Nanoclusters in Living Cells. ACS Applied Nano Materials 2018, 1, 4236-4246. Doi :

A. HFF-1 cells + AuNLS-Alexa488, $24 \mathrm{~h}$.
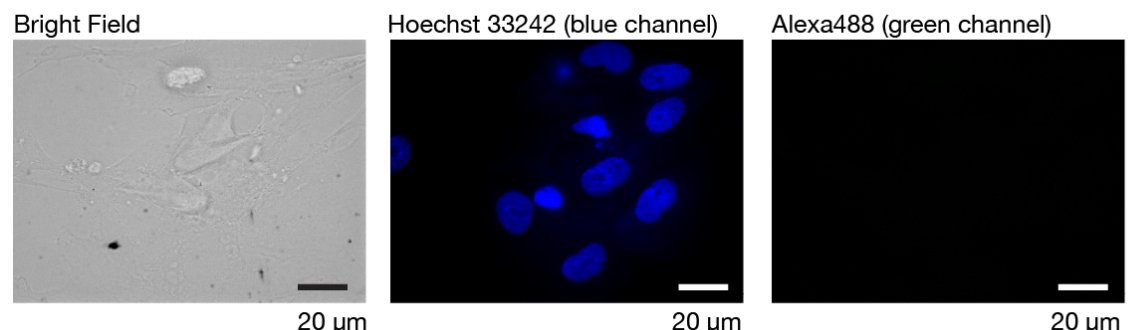

B. HFF-1 cells + AuNLS-Alexa488, 24h. Silver-enhanced specimen Bright Field

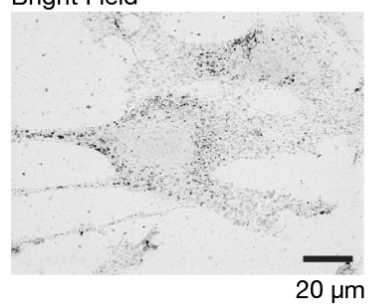

C. HFF-1 cells + AuNLS-Alexa488, Electroporation treatment, $24 \mathrm{~h}$

D. HFF-1 + AuNLS-Alexa488 Electroporation treatment, $24 \mathrm{~h}$. Silver-enhanced specimen

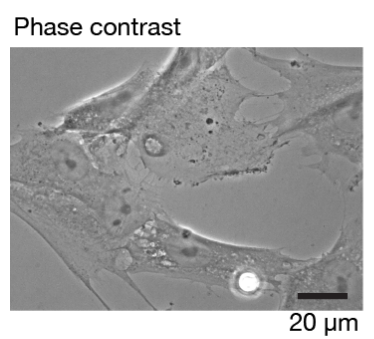

Hoechst 33242 (blue channel)

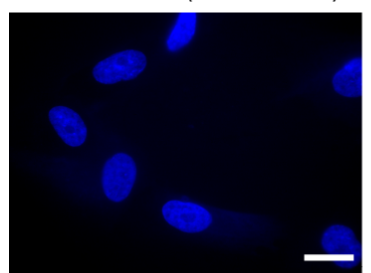

$20 \mu \mathrm{m}$
Bright Field

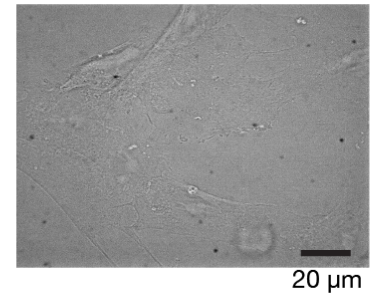

Alexa488 (green channel)

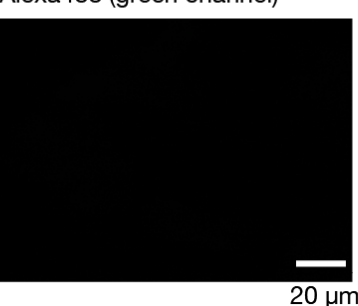

Bright Field

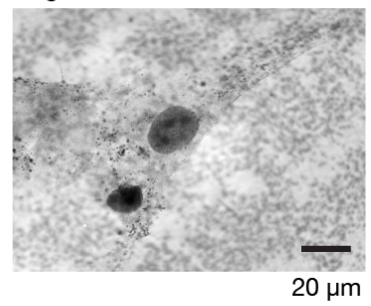

Figure S25. Analysis of fate of Alexa488-labeled AuNLS after addition to HFF-1 cells. A. Images of HFF-1 cells incubated with the AuNLSAlexa488 for $24 \mathrm{~h}$. Hoechst 33242 -stained cells were observed under bright field, blue channel, for detection of Hoechst 33242-stained nuclei, and green channel for detection of the Alexa488. B. Images of HFF-1 cells incubated with the AuNLSAlexa488 for $24 \mathrm{~h}$ followed by silver staining. C. Images of electroporated HFF-1 cells incubated with the AuNLSAlexa488 for 24h. Hoechst 33242-stained cells were observed using phase contrast, under bright field, blue channel (for detection of Hoechst 33242-stained nuclei) and green channel for detection of the Alexa488). D. Images of electroporated HFF-1 cells incubated with the AuNLSAlexa488 and for $24 \mathrm{~h}$ followed by silver staining. Following the $24 \mathrm{~h}$ incubation period at $37^{\circ} \mathrm{C}$, the living cells were fixed with glutaraldehyde $(2.5 \% \mathrm{w} / \mathrm{v})$. Data showed absence of Alexa488 fluorescence, suggesting that the Alexa488 remained bound to the 
To cite : Desplancq, D.; Groysbeck, N.; Chiper, M.; Weiss, E.; Frisch, B.; Strub, J.-M.; Cianferani, S.; Zafeiratos, S.; Moeglin, E.; Holy, X.; et al. Cytosolic Diffusion and Peptide-Assisted Nuclear Shuttling of Peptide-Substituted Circa 102 Gold Atom Nanoclusters in Living Cells. ACS Applied Nano Materials 2018, 1, 4236-4246. Doi :

10.1021/acsanm.8b00988

gold nanocluster (see Figure S26 for experiment showing the AuNC to quench the Alexa488 fluorescence). 


\section{A. without gold nanocluster}
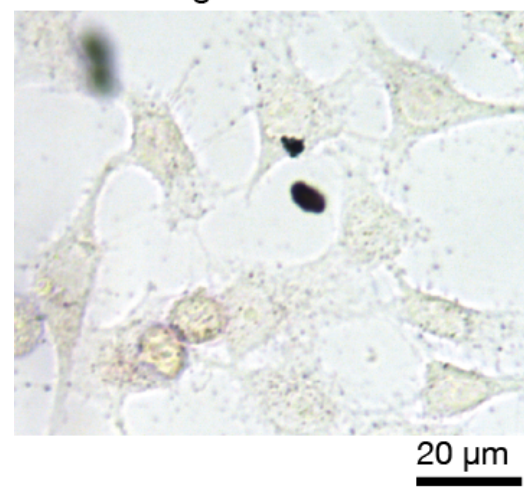

\section{B. AuCap}

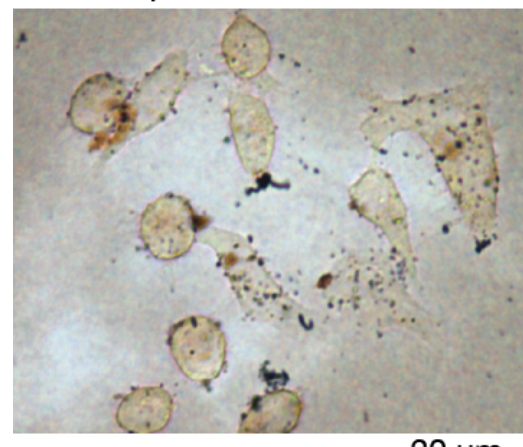

C. AuNLS

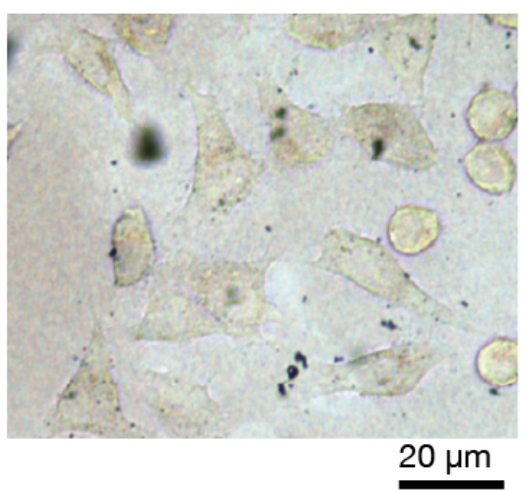

E. AuCap - Electroporation

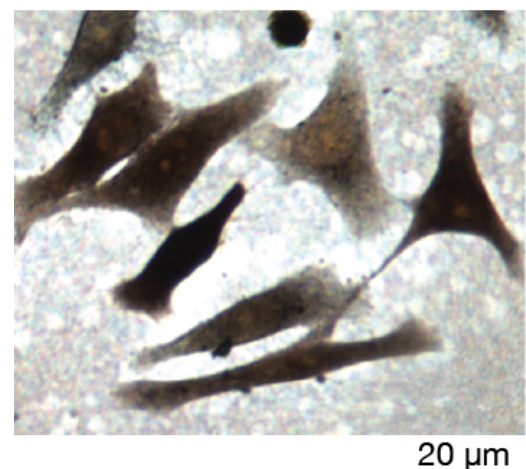

F. AuNLS - Electroporation

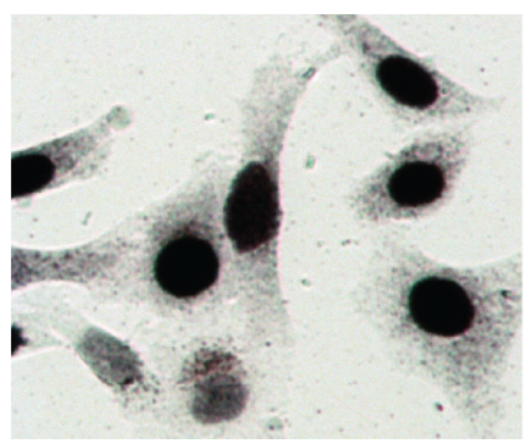

$20 \mu \mathrm{m}$
D. AudNLS

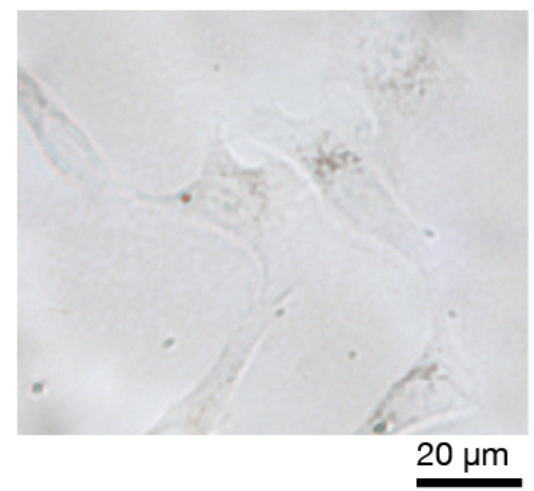

G. AudNLS - Electroporation

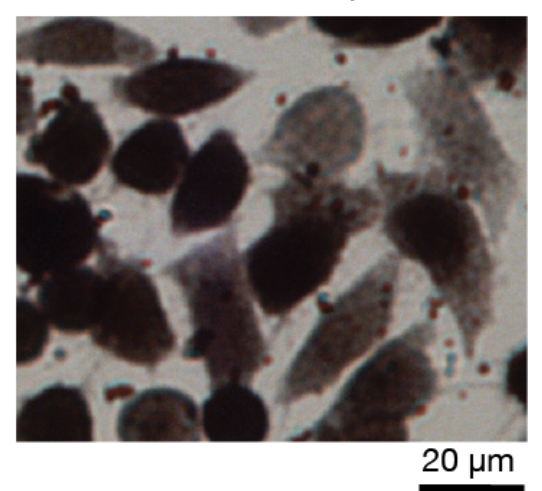

Figure S26. Color images of HeLa cells incubated with AuCap, AuNLS and AudNLS. A. Untreated cells. B, C and D. The various peptide-AuNCs were added to living HeLa cells by dilution in the cell culture medium without an electroporation treatment. E, F and $\mathbf{G}$. The HeLa cells were subjected to electroporation in presence of the indicated AuNCs. Following the 24h incubation period at $37^{\circ} \mathrm{C}$, the living cells were fixed with glutaraldehyde $(2.5 \% \mathrm{w} / \mathrm{v})$ and AuNCs were detected by silver staining. 
To cite : Desplancq, D.; Groysbeck, N.; Chiper, M.; Weiss, E.; Frisch, B.; Strub, J.-M.; Cianferani, S.; Zafeiratos, S.; Moeglin, E.; Holy, X.; et al. Cytosolic Diffusion and Peptide-Assisted Nuclear Shuttling of Peptide-Substituted Circa 102 Gold Atom Nanoclusters in Living Cells. ACS Applied Nano Materials 2018, 1, 4236-4246. Doi :

A. AuNES and leptomycin - Electroporation treatment

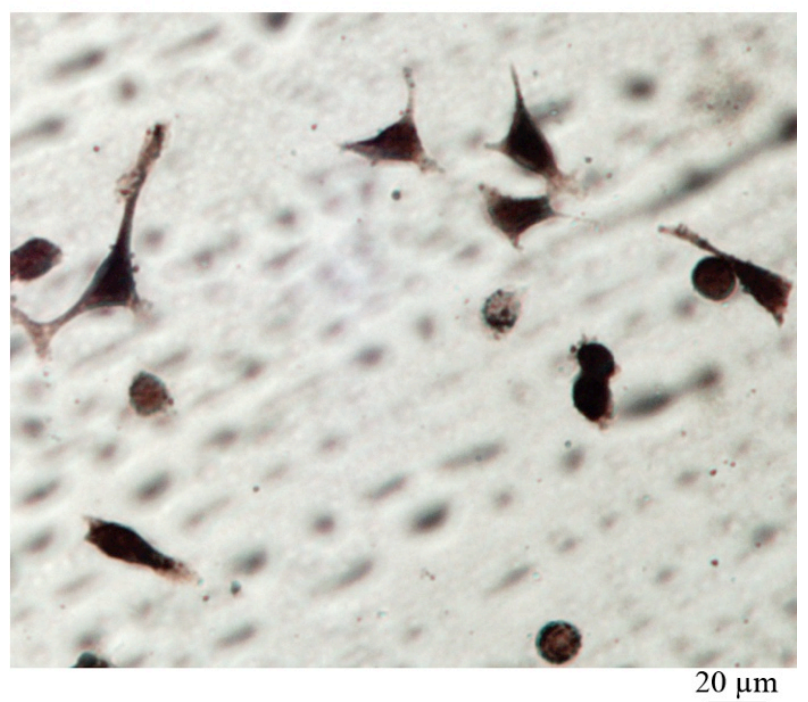

B. AuNES - Electroporation treatment

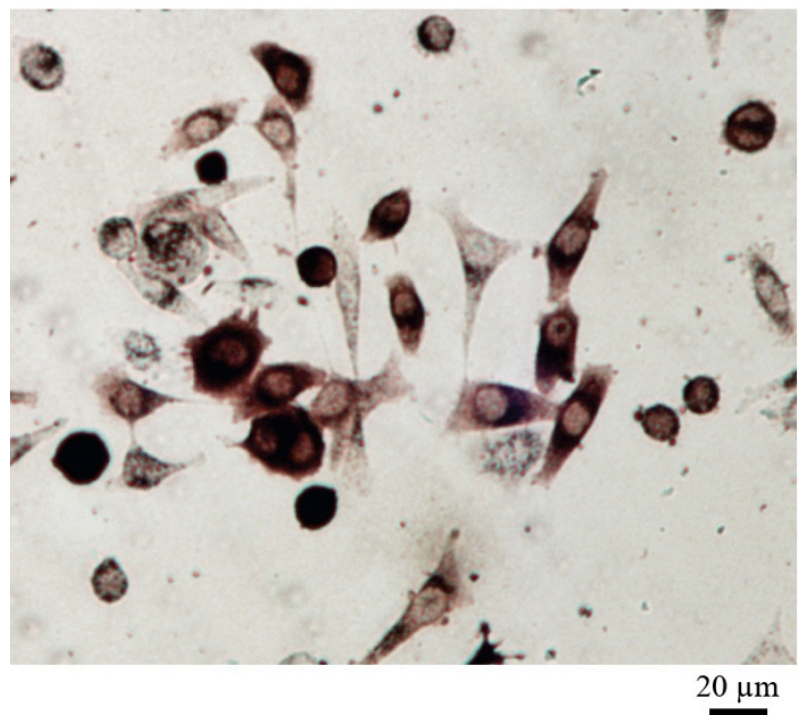

Figure S27. Color images of HeLa cells incubated or 24h with: A. AuNES and leptomycin, or B. AuNES alone. The AuNES was added to living HeLa cells by dilution in the cell culture medium with an electroporation treatment. Following the $24 \mathrm{~h}$ incubation period at $37^{\circ} \mathrm{C}$, the living cells were fixed with glutaraldehyde $(2.5 \% \mathrm{w} / \mathrm{v})$ and the AuNES was detected by silver staining. 


\section{References}

(1) Piella, J.; Bastús, N. G.; Puntes, V. Size-Controlled Synthesis of Sub-10-Nanometer Citrate-Stabilized Gold Nanoparticles and Related Optical Properties. Chem. Mater. 2016, 28 (4), 1066-1075.

(2) Kremer, J. R.; Mastronarde, D. N.; McIntosh, J. R. Computer Visualization of ThreeDimensional Image Data Using IMOD. J. Struct. Biol. 1996, 116 (1), 71-76.

(3) Levi-Kalisman, Y.; Jadzinsky, P. D.; Kalisman, N.; Tsunoyama, H.; Tsukuda, T.; Bushnell, D. A.; Kornberg, R. D. Synthesis and Characterization of $\operatorname{Au}_{102}(P-\mathrm{Mba})_{44}$ Nanoparticles. J. Am. Chem. Soc. 2011, 133 (9), 2976-2982.

(4) Sousa, A. A.; Morgan, J. T.; Brown, P. H.; Adams, A.; Jayasekara, M. P. S.; Zhang, G.; Ackerson, C. J.; Kruhlak, M. J.; Leapman, R. D. Synthesis, Characterization, and Direct Intracellular Imaging of Ultrasmall and Uniform Glutathione-Coated Gold Nanoparticles. Small 2012, 8 (14), 2277-2286.

(5) Lévy, R.; Thanh, N. T. K.; Doty, R. C.; Hussain, I.; Nichols, R. J.; Schiffrin, D. J.; Brust, M.; Fernig, D. G. Rational and Combinatorial Design of Peptide Capping Ligands for Gold Nanoparticles. J. Am. Chem. Soc. 2004, 126 (32), 10076-10084.

(6) Kalderon, D.; Roberts, B. L.; Richardson, W. D.; Smith, A. E. A Short Amino-Acid Sequence Able to Specify Nuclear Location. Cell 1984, 39 (3), 499-509.

(7) Wen, W.; Meinkoth, J. L.; Tsien, R. Y.; Taylor, S. S. Identification of a Signal for Rapid Export of Proteins From the Nucleus. Cell 1995, 82 (3), 463-473.

(8) Castner, D. G.; Hinds, K.; Grainger, D. W. X-Ray Photoelectron Spectroscopy Sulfur 2p Study of Organic Thiol and Disulfide Binding Interactions with Gold Surfaces. Langmuir 1996, 12 (21), 5083-5086.

(9) Yang, J.; Wu, H.; Yang, P.; Hou, C.; Huo, D. Sensors and Actuators B: Chemical. Sensors \& Actuators: B. Chemical 2018, 255 (Part 3), 3179-3186.

(10) Shu, T.; Wang, J.; Su, L.; Zhang, X. Chemical Etching of Bovine Serum AlbuminProtected Au25 Nanoclusters for Label-Free and Separation-Free Ratiometric Fluorescent Detection of Tris(2-Carboxyethyl)Phosphine. Anal. Chem. 2016, 88 (22), 11193-11198.

(11) Britvin, S. N.; Lotnyk, A. Water-Soluble Phosphine Capable of Dissolving Elemental Gold: the Missing Link Between 1,3,5-Triaza-7-Phosphaadamantane (PTA) and Verkade's Ephemeral Ligand. J. Am. Chem. Soc. 2015, 137 (16), 5526-5535. 